\title{
The stress of panic: neuroendocrinological and neuroimmunological studies in Panic Disorder
}

Citation for published version (APA):

van Duinen, M. A. (2005). The stress of panic: neuroendocrinological and neuroimmunological studies in Panic Disorder. [Doctoral Thesis, Maastricht University]. Datawyse / Universitaire Pers Maastricht. https://doi.org/10.26481/dis.20051104md

Document status and date:

Published: 01/01/2005

DOI:

10.26481/dis.20051104md

Document Version:

Publisher's PDF, also known as Version of record

\section{Please check the document version of this publication:}

- A submitted manuscript is the version of the article upon submission and before peer-review. There can be important differences between the submitted version and the official published version of record.

People interested in the research are advised to contact the author for the final version of the publication, or visit the DOI to the publisher's website.

- The final author version and the galley proof are versions of the publication after peer review.

- The final published version features the final layout of the paper including the volume, issue and page numbers.

Link to publication

\footnotetext{
General rights rights.

- You may freely distribute the URL identifying the publication in the public portal. please follow below link for the End User Agreement:

www.umlib.nl/taverne-license

Take down policy

If you believe that this document breaches copyright please contact us at:

repository@maastrichtuniversity.nl

providing details and we will investigate your claim.
}

Copyright and moral rights for the publications made accessible in the public portal are retained by the authors and/or other copyright owners and it is a condition of accessing publications that users recognise and abide by the legal requirements associated with these

- Users may download and print one copy of any publication from the public portal for the purpose of private study or research.

- You may not further distribute the material or use it for any profit-making activity or commercial gain

If the publication is distributed under the terms of Article $25 \mathrm{fa}$ of the Dutch Copyright Act, indicated by the "Taverne" license above, 


\section{Druk: Datawyse}

ISBN: $90-5278-482-5$

\section{C) Marlies Alice van Duinen, Maastricht 2005}

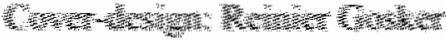

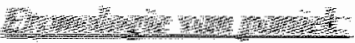

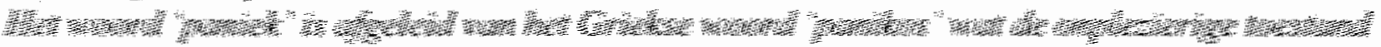

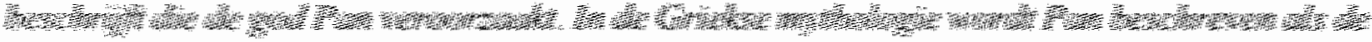

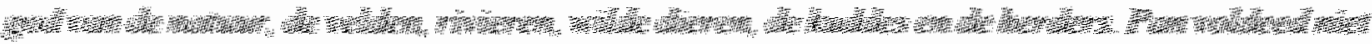

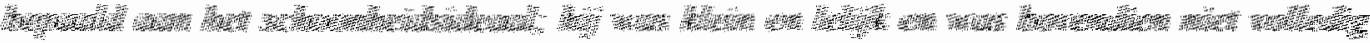

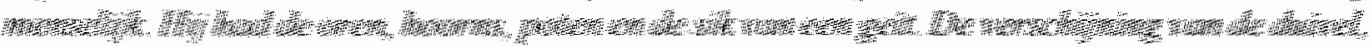

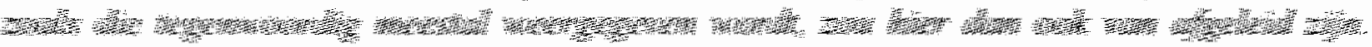

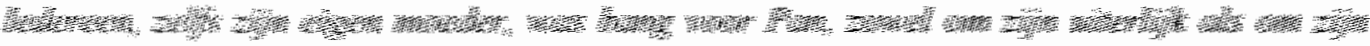

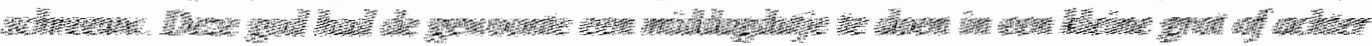

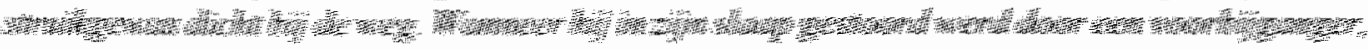

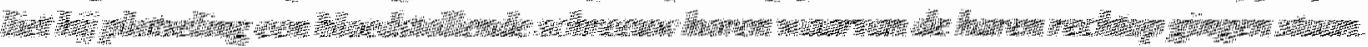

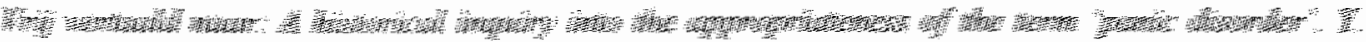

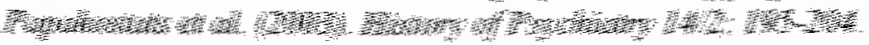




\section{The stress of panic}

Neuroendocrinological and neuroimmunological studies in Panic Disorder

\section{PROEFSCHRIFT}

ter verkrijging van de graad van doctor

aan de Universiteit Maastricht, op gezag van de Rector Magnificus, Prof. mr. G.P.M.F. Mols

volgens het besluit van het College van Decanen,

in het openbaar te verdedigen

op vrijdag 4 november 2005 om 14.00 uur

door

Marlies Alice van Duinen

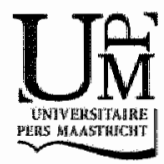


Promotor:

Prof. dr. E.J.L. Griez

\section{Co-promotor:}

Dr. K. R.J. Schruers

\section{Beourdelingscommissie:}

Prof. dr. H.W.M. Steinbusch (voorzitter)

Prof. dr. B.E. Leonard (National University of Ireland, Galway)

Dr. N.A. Nicolson

Prof. dr. D.J. Nutt (University of Bristol, United Kingdom)

Prof. dr. H.M. van Praag

Prof dr. W.J. Riedel 


\section{Table of Contents}

Chapter 1 General introduction

Chapter 2 Hypothalamic-pituitary-adrenal axis function following a 35\%

$\mathrm{CO}_{2}$ inhalation in healthy volunteers

Chapter 3 Salivary cortisol in panic: Are males more vulnerable?

Chapter $4 \quad \mathrm{CO}_{2}$ challenge results in hypothalamic-pituitary-adrenal activation in healthy volunteers

Chapter $5 \quad \mathrm{CO}_{2}$ challenge induced HPA axis activation in panic

Chapter 6 Desynchrony of fear: phobic exposure is not stressful

Chapter 7 Neuroimmunological parameters in Panic Disorder

Chapter 8 Effects of experimental panic on neuroimmunological functioning

Chapter 9 General discussion

Summary

Samenvatting

Dankwoord

Publications 
. 


\section{CHAPTER 1}

General introduction 
Since the publication of the Diagnostic and Statistical Manual of Mental Disorders (DSM-III) in 1980, Panic Disorder (PD) has officially been classified as an anxiety disorder. The collective 'anxiety disorder' implies that in PD anxiety mechanisms are dysfunctional. Anxiety in general is an adaptive response to a threatening situation in which distinction is made between distal threats, referred to as anxiety stricto sensu, and proximal threats, referred to as fear (Blanchard \& Blanchard, 1988; Graeff, 1994; Rosen \& Schulkin, 1998). One might argue that in PD both types of threat are represented. Panic Attacks (PAs) constitute the central pathological core of $\mathrm{PD}$, representing bursts of intense fear or discomfort accompanied by physiological and cognitive symptoms. These attacks occur unexpectedly and show a fast crescendo course, reaching a peak within a matter of moments. It's worth noting that fears experienced during the attack are directly related to disruption of vital functions. Typically, they include fear of suffocating, fear of having a heart attack, and in general, fear of dying.

Following recurrent PAs in the first phase of the disorder, patients develop persistent concem about having subsequent PAs, or worry about the implications of the attack or its consequences. This latter pathognomonic feature is referred to as anticipatory anxiety.

In terms of distal and proximate threats, PAs are proximate threats, being perceived as immediate, inescapable, and life-threatening events, while anticipatory anxiety refers to a remote, long-term distal threat. Accordingly, PD would be an instance of both acute fear on the one hand, and anxiety on the other.

Hans Selye originally defined stress as any threat to homeostasis to which the organism reacts with a large number of non-specific adaptive responses in order to survive (Selye, 1936). If, as formulated above, panic is an acute episode of disturbed autonomic functions, perceived by the subject as life-threatening and attended by a fear of dying, panic arguably may be expected to represent an extreme stress response. This equation assumes the involvement of the same underlying mechanisms in panic, fear and stress. In the original definition of stress, one distinctive aspect of the non-specific response to noxious stimuli was increased adrenocorticotropic hormone (ACTH) secretion, an hypothalamic-pituitary-adrenal (HPA-) axis hormone (Selye, 1936). Non-pathological fear is indeed characterised by activation of two major stress-responsive systems: the sympathetic autonomous nervous system and also the HPA-axis (Tsigos \& Chrousos, 2002). Activation of the sympathetic nervous system during panic has been demonstrated (Wilkinson et al., 1998) and little doubt exists about the involvement of the noradrenergic system in PD (D. Nutt \& Lawson, 1992). However, the role of the HPA-axis in panic has not been clarified, despite the extensive work that has been performed in this field. The primary focus of the current thesis is directed at this very subject.

\section{Measurement of stress}

The HPA-axis consists of three secretional levels. Corticotropin releasing hormone (CRH) is secreted by the hypothalamus and stimulates the pituitary to secrete ACTH which in turn stimulates the adrenal cortex to release cortisol (figure 1). Hormones at all these three secretional levels can be measured to provide an index of the activity of the HPA-axis.

Cortisol, the end product of the axis, has received most attention as such. The glucocorticoid cortisol can relatively easily be measured in urine, serum and saliva. Measurements in urine are mostly employed in 24 hour collection designs, providing information on total cortisol secretion. The drawback of this method is that only overall increased or decreased HPA-axis activity can be detected, whereas acute shifts in secretional patterns are masked. 
If we, as stated above, equate panic, fear and stress, we would expect cortisol to be released following the event of a PA. However, when a PA is experienced only once or twice per day it is conceivable that 24-hr cumulative cortisol levels are not affected. Serum and saliva cortisol on the other hand, can provide a good index of HPA-axis activation as a direct result of a supposedly acute stressful event such as a PA.

Several studies have been dedicated to the investigation of HPA-axis functioning in $\mathrm{PD}$, but findings were inconsistent as will be discussed hereafter. Levels of HPA-axis hormones in basal conditions, following panic both in daily life and in the laboratory, and following neurochemical challenges have been studied. A concise overview on HPA-axils functioning in PD is presented below.

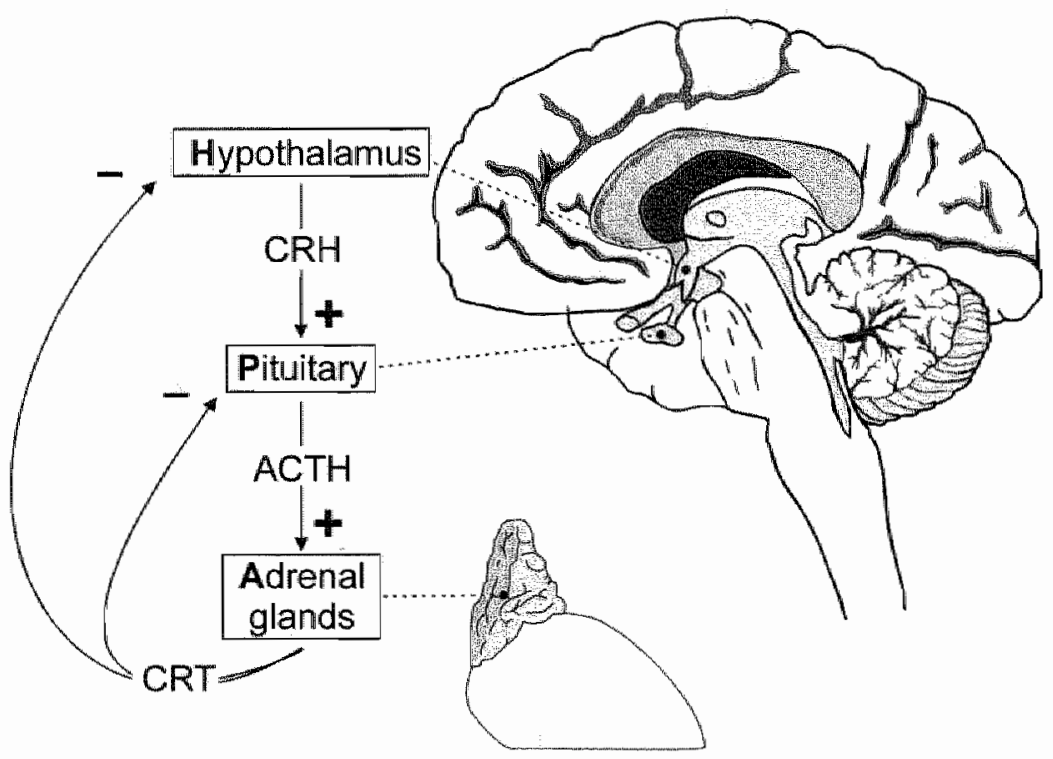

Figure 1. Hypothalamic-pituitary-adrenal axis. $\mathrm{CRH}=$ corticotropin releasing hormone, $\mathrm{ACTH}=$ adrenocorticotropic hormone, $\mathrm{CRT}=$ cortisol

\section{Basal HPA-axis functioning in Panic Disorder}

Inconsistent results have been reported in studies on HPA-axis functioning in PD, with some reporting increased basal plasma cortisol levels (Goldstein, Halbreich, Asnis, Endicott, \& Alvir, 1987; Nesse, Cameron, Curtis, MoCann, \& Huber-Smith, 1984; Roy-Byme et al., 1986) and others reporting cortisol levels not significantly different from levels in healthy control subjects (Brambilla et al., 1992; Gurguis, Mefford, \& Uhde, 1991; Woods, Channey, Goodman, \& Heninger, 1988). Differences in severity of illness and time of the day in the different study 
populations might partly account for these inconsistencies. Elevated basal plasma cortisol levels are particularly relevant in more severely affected individuals and increased cortisol levels are mostly reported during evening or nocturnal hours (Abelson \& Curtis, 1996; Bandelow, Wedekind, Sandvoss et al., 2000; Wedekind, Bandelow, Broocks, Hajak, \& Ruther, $2000)$.

Several negative feedback systems work to keep the activity of the axis within normal ranges. Dysfunction of the HPA-axis affects these systems resulting in altered sensitivity. The responsiveness of the HPA-axis can be tested with the combined dexamethasone-corticotropinreleasing hormone (DEX-CRH) test. Following stimulation of the negative feedback system by administration of the synthetic glucocorticoid dexamethasone, the neuroendocrine response to CRH stimulation provides information on the reactivity of the axis. In PD patients, the DEXCRH test showed increased cortisol and adrenocorticoid hormone (ACTH) levels as compared to healthy controls, indicative of altered glucocorticoid feedback regulation during the acute illness episode (Schreiber, Lauer, Krumrey, Holsboer, \& Krieg, 1996). Overall, results seem to show only subtly altered HPA axis functioning in $P D$. In view of the paroxysmal nature of $P D$, relatively normal basal functioning of the stress-responsive HPA-axis might not be surprising. The presumed overactivity of the HPA-axis related to PAs is not continuous, which provides the system the opportunity to restore and then complete desensitisation due to chronic stimulation fails to occur.

\section{Real-life panic attacks}

$\mathrm{PAs}$, the central pathological core of PD, represent bursts of intense anxiety or discomfort accompanied by physiological and cognitive symptoms. There is little doubt that PAs evoke high levels of subjective distress. Some have even suggested that PAs can be traumatic (McNally \& Lukach, 1992). Accordingly, strong activation of the HPA-axis following the occurrence of a PA might seem obvious. However, studies on HPA-axis function in real-life panic are scarce, which is no surprise since the unpredictable occurrence is a characteristic feature of the attack. To date, three studies have been performed on PAs in daily life (Bandelow, Wedekind, Pauls et al., 2000; Cameron, Lee, Curtis, \& McCann, 1987; Woods, Charney, McPherson, Gradman, \& Heninger, 1987). All three did report increased cortisol levels following naturally occurring panic. This would be congruent with the assumption that the PA is indeed a spontaneous spell of paroxysmal fear, attended by a stress-related surge in cortisol. However, questions arise regarding the methodology of these studies. In the study of Woods et al. (1987) the 'spontaneousness' of the attacks can be questioned as the attacks were situationally triggered by taking patients into phobic situations. It is worth remembering that PAs are by definition unexpected spells of acute fear. Taking patients to phobic situations probably leads them to worry about the occurrence of a PA. One may speculate that possible effects of anticipatory anxiety on cortisol secretion interfered with the results. Moreover, in this study, cortisol levels in PD patients were affected to a similar degree as in the control subjects, with patient values being higher during the period of actual exposure. In the study of Cameron et al. (1987) only four subjects experienced nine PAs together during a 36 hr stay at the research centre. This is a relatively small sample and no statistically significant increases in serum cortisol values were found during or following a PA as compared with (pre-fixed) baseline values. Bandelow et al. (2000) more recently performed a rather elegant study on cortisol values in spontaneous panic. They found a subtle but statistically significant increase in salivary 
cortisol. Salivary cortisol offers the advantage that it can easily be sampled in a naturalistic situation by the subjects themselves. This makes it feasible to study true 'real-life' PAs without the necessity of interference of the investigators. However, such naturalistic studies have their drawbacks as well. Heterogeneity of circumstances might mask certain effects. For example, the HPA-axis shows a strong circadian rhythm with high activity in the moming hours, which declines in the afternoon. Altered reactivity in morning hours compared to evening hours has been suggested (van Eekelen, Kerkhof, \& van Amsterdam, 2003). PAs that occur in the morning might show a different neuroendocrine profile than evening or nocturnal PAs. Furthermore, comparison with healthy control subjects can only include basal cortisol values.

\section{Laboratory-induced panic}

Following the finding of Pitts and McClure that PAs could be triggered by lactate infusion (Pitts \& McClure, 1967), a scala of laboratory models have been developed to study panic. These include sodium lactate infusion (Liebowitz et al., 1984), $\alpha_{2}$-adrenergic antagonists (Charney, Heninger, \& Breier, 1984), administration of adenosine receptor blockers (Klein, Zohar, Geraci, Murphy, \& Uhde, 1991), serotonergic agonists (Kahn, Asnis, Wetzler, \& van Praag, 1988), carbon dioxide inhalation (Papp et al., 1989), benzodiazepine antagonists (D. J. Nutt, Glue, Lawson, \& Wilson, 1990), and administration of neuropeptides such as cholecystokinin-4 (CCK-4)(van Megen, Westenberg, Den Boer, \& Kahn, 1996). However, most of these models have been criticised for their lack of panic specificity. In general, the biochemical manipulations induce merely a state of anxiety rather than panic. Interestingly however, lactate, carbon dioxide, and possibly CCK do induce characteristic panic symptoms (E. Griez \& Schruers, 1998). Standard infusion with sodium lactate (about $0.5 \mathrm{M}$ at $10 \mathrm{~mL} / \mathrm{kg}$ over about 20 minutes) provokes panic attacks which include both affective and somatic symptoms of panic and which resemble patients" naturally occurring attacks (Liebowitz et al., 1984). It has consistently been shown that PD patients are more vulnerable to lactate-induced panic than normal controls (Cowley \& Arana, 1990; Den Boer, Westenberg, Klompmakers, \& van Lint, 1989; Liebowitz et al., 1984). However, its specificity may be limited since patients with generalised anxiety disorder (Cowley, Dager, McClellan, Roy-Byrne, \& Dunner, 1988), premenstrual dysphoric disorder (Sandberg, Endicott, Harrison, Nee, \& Gorman, 1993), and fibromyalgia (Tanum \& Malt, 1995) were suggested to be hypersensitive to lactate as well.

While CCK is a peptide originally discovered in the gastrointestinal tract, it is also found in high density in the mammalian brain (Noble \& Roques, 1999). Panic induced by CCK-4 and its synthetic analogue pentagastrin include both somatic and affective symptoms and are appraised by patients to mimic real-life attacks. Response to CCK agonists differentiates PD patients from healthy controls (Bradwejn, Koszycki, \& Shriqui, 1991; van Megen et al., 1996). However, also patients with obsessive compulsive disorder (de Leeuw, Den Boer, Slaap, \& Westenberg, 1996), social phobia (McCann et al., 1997), generalised anxiety disorder (Brawman-Mintzer et al., 1997), and post-traumatic stress disorder (Kellner et al., 2000) do react with an augmented response compared to healthy controls, which considerably clouds the diagnostic specificity of the model.

Among all the above models, carbon dioxide $\left(\mathrm{CO}_{2}\right)$ inhalation seems to be the most interesting as panicogenic challenge, with the highest specificity as far as PD subjects are concerned. The increased vulnerability of $\mathrm{PD}$ patients to $\mathrm{CO}_{2}$ inhalation has been convincingly demonstrated (E. J. Griez, Lousberg, van den Hout, \& van der Molen, 1987; Papp et al., 1989; G. Perna, 
Barbini, Cocchi, Bertani, \& Gasperini, 1995; Woods et al., 1988). Control subjects are significantly less affected. Vulnerability to $\mathrm{CO}_{2}$ in other psychiatric disorders is usually comparable to the vulnerability of controls. Patients with generalised anxiety disorder $(\mathrm{K}$. Verburg, Griez, Meijer, \& Pols, 1995), obsessive compulsive disorder (G. Perna, Bertani, Arancio, Ronchi, \& Bellodi, 1995) and major depression (G. Perna, Barbini et al., 1995) displayed a response similar as healthy controls. In social phobics an increased response has been reported (Caldirola, Perna, Arancio, Bertani, \& Bellodi, 1997), but this was not confirmed by others (Schruers et al., unpublished data). The only instance in which a truly augmented response to $35 \% \mathrm{CO}_{2}$ was found is in situational phobia. However, this may be rather suggestive of a common constitutional predisposition for PD and situational phobias (C. Verburg, Griez, \& Meijer, 1994).

Typically, considering HPA-axis activation following lactate, $\mathrm{CCK}$ and $\mathrm{CO}_{2}$, in most instances no clear cut increase in cortisol levels has been found so far, despite marked increases in subjective fear. Studies with lactate infusion quite consistently found that panic is not accompanied by marked increases in cortisol levels (Liebowitz et al., 1985; Targum, 1992). Results from studies with cholecystokinin infusion in PD are mixed. Van Megen et al. (1996) showed that CCK infusion was not accompanied by an increase in plasma cortisol, but most studies did find HPA-axis activation (Abelson, Nesse, \& Vinik, 1994; McCann et al., 1997; Wiedemann, Jahn, Yassouridis, \& Kellner, 2001). Importantly, no differences were found between PD patients and controls. Studies using $\mathrm{CO}_{2}$ inhalation also leave room for speculation. In panic disorder patients, HPA response was only measured following the inhalation of relatively low $\mathrm{CO}_{2}$ concentration challenges (Sasaki et al., 1996; Sinha et al., 1999; Woods et al., 1988). This paradigm requires patients to inhale a gas mixture with a $\mathrm{CO}_{2}$ concentration up to $7.5 \%$ for 10 to 20 minutes, or to the point of panic. Measuring cortisol levels, no evidence was found for HPA-axis activation using 5 or $7 \% \mathrm{CO}_{2}$. However, a slight increase in cortisol values was found following $7.5 \% \mathrm{CO}_{2}$ induced panic (Woods et al., 1988). This suggests that HPA-axis response to $\mathrm{CO}_{2}$ inhalation might be dose-dependent. Strangely enough, so far, HPAaxis activation has not specifically been studied in panic disorder patients using the single breath $35 \% \mathrm{CO}_{2}$ inhalation. Our group has extensive experience with this model. Referring to the above discussion, $\mathrm{CO}_{2}$ inhalation can be considered as the most specific panicogenic challenge and therefore offers the best possibility to study panic in the laboratory. Hence HPAaxis function in $35 \% \mathrm{CO}_{2}$ induced panic will be addressed in the current thesis.

\section{Neuroimmunology of panic}

Connections between the HPA-axis and the immune system are well known (figure 2). This explains why the present thesis not only focuses on the HPA-axis but on the immune system as well. The possible role of the immunological system in PD is addressed in the last chapters of this thesis.

Classically, the immune system is regarded as an autonomous system that protects the organism against potentially harmful foreign substances. However, over the last 20 years this view has been challenged to the extent that the immune system is now regarded as a stress-responsive system, capable of responding to different stressors. In a strict sense, the immune system is still regarded as a defence system, an adaptive system whose main function is to maintain homeostasis (Ader, Cohen, \& Felten, 1995; Elenkov, Wilder, Chrousos, \& Vizi, 2000), but its capacities have proven to be more extensive. 


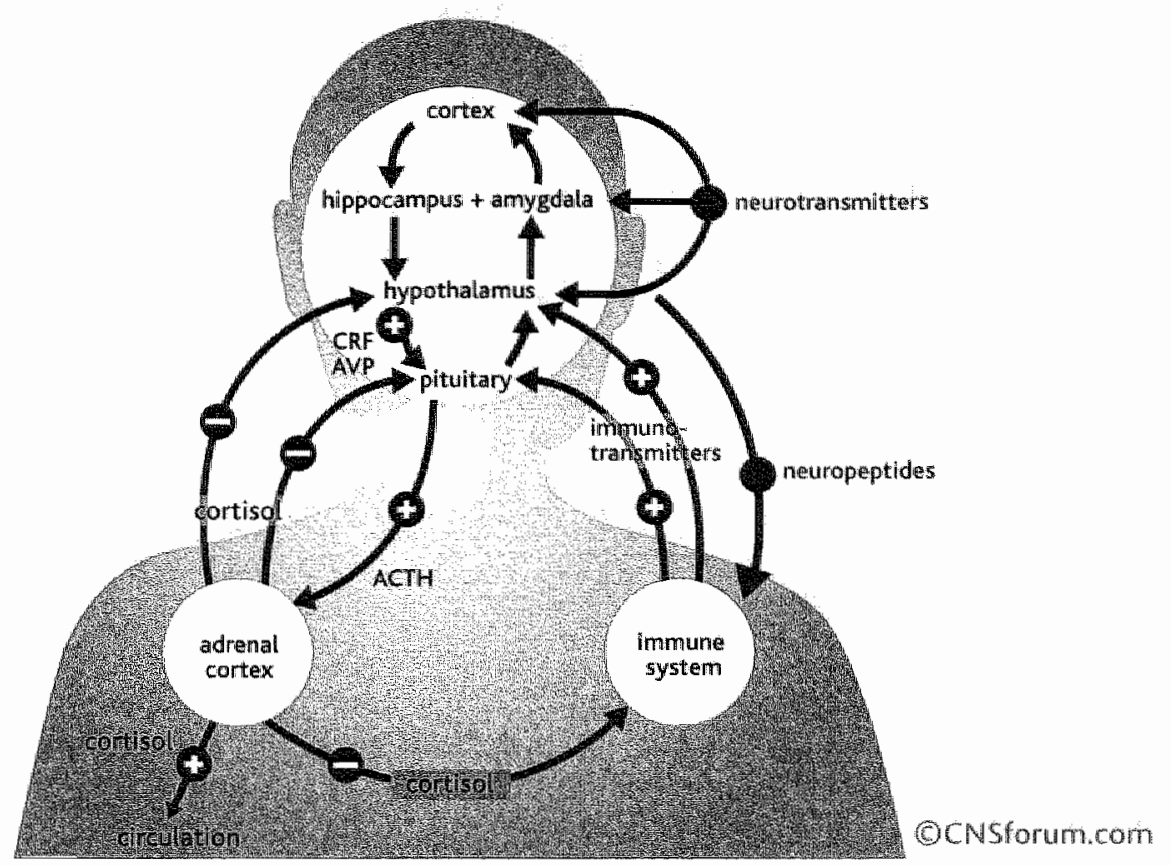

Figure 2. Interaction between the HPA-axis and the immune system

Also, the so-called autonomy of the immune system has been challenged. Evidence of reciprocal communication between the brain, neuroendocrine, and immune systems has been found, suggestive of a tridimensional circuit of reciprocal interference (Brambilla et al., 1992). In fact, in major depression (MD) it has been shown that levels of pro-inflammatory cytokines are increased and are capable of stimulating the HPA-axis (Maes, Bosmans, Meltzer, Scharpe, \& Suy, 1993; Maier \& Watkins, 1998). Hyperactivity of the HPA-axis has been implicated as a causal factor in MD (Holsboer, 2000). When taking into account the stimulating effect of proinflammatory cytokines on the HPA-axis, this hyperactivity might be the direct result of ongoing inflammatory processes.

$\mathrm{PD}$ and MD are related disorders clustered in the spectrum of affective disorders, showing high levels of comorbidity, and involving the same central neurotransmitter systems (Asnis, Wetzler, Sanderson, Kahn, \& van Praag, 1992; Stein, Tancer, \& Uhde, 1990). Therefore, apart from the question whether HPA-axis function is affected in PD, shifts in immune functioning and the relationship between these two stress-responsive systems might be equally important. In fact, in PD indications of altered immune function have been found. Andreoli et al. (1992) found increased numbers of T cells and lymphocytic proliferation in depressed patients with comorbid $\mathrm{PD}$ in response to in vitro mitogen stimulation as compared to depressed subjects without $\mathrm{PD}$. These data express the dynamic capacity of specific immune cells to react to stimuli and imply that $\mathrm{PD}$ amplifies the immune effects related to MD. Moreover, pro-inflammatory cytokines can 
induce anxiety. For example, interferon-alpha (IFN- $\alpha$ ) administration in human is associated with increased anxiety and anxiolytical drugs prevent these effects (Trask, Esper, Riba, \& Redman, 2000). Some studies have been performed that studied immune functioning in $P D$, but interpretation of the outcomes is hampered by methodological differences and limited power related to small sample sizes.

Since different stressors are shown to exert immediate effects on different inmune variables (Owen \& Steptoe, 2003; F. M. Perna, Schneiderman, \& LaPerriere, 1997; Steptoe, Willemsen, Oweri, Flower, \& Mohamed-Ali, 2001), it can be assumed that the immune system is also affected by the acute stressful event of a PA. However, studies measuring immune responses following a PA are lacking.

\section{The stress of panic}

Considering the symptomis of panic, the equation between panic and fear seems obvious. Panic would be an instance of an extreme fear reaction, emerging spontaneously. However, when considering neuroendocrinology, the similarity between fear and panic seems to disappear. Provocation tests that show the highest specificity for PD are generally not accompanied by HPA-axis activation. However, a possible a dosis-effect relationship exists between $\mathrm{CO}_{2}$ inhalation and HPA-axis activation. $\mathrm{HPA}$-axis response in $\mathrm{PD}$ following $35 \% \mathrm{CO}_{2}$ inhalation has not yet been addressed. Studies on real-life panic are scarce. One reliable study did show increased HPA-axis activation related to panic, which underlines the necessity of further exploration.

With regard to the stress-responsive immune system, analogues with depression and stress in general suggest that immune functioning in PD might be affected as well. However, studies so far have not provided clear insights in this matter. The $35 \% \mathrm{CO}_{2}$ challenge offers the possibility to study the effects of panic on variables that are indicative of immune responsivity.

The subject of the current thesis is the neuroendocrinology and neuroimmunology of panic. The $35 \% \mathrm{CO}_{2}$ inhalation challenge is used to systematically study the involvement of these stressresponsive systems in paric.

In chapter two the HPA-axis response to $35 \% \mathrm{CO}_{2}$ inhalation in healthy volunteers is studied using salivary cortisol. Athough the $35 \% \mathrm{CO}_{2}$ inhalation is known to be specific for PD patients and affects healthy volunteers somewhat physically, but only marginally psychologically ( $\mathrm{E}$. Griez, de Loof, Pols, Zandbergen, \& Lousberg, 1990; G. Perna et al., 1994), surprisingly, contrasting results were found by Argyropoulos et al. (2002). The challenge was applied to healthy volunteers and a significant increase in fear with a concomitant increase in cortisol levels was found. The results of our study show only a minor increase in anxiety levels, and no cortisol increase. Possible explanations for the discrepancy between the two studies and the implications of the results are discussed.

In chapter three the same protocol is applied to compare the cortisol response of PD patients and healthy control subjects following $35 \% \mathrm{CO}_{2}$ inhalation. Since a majority of the patients experienced an experimental $\mathrm{PA}$, conclusions are allowed on the relationship between panic and fear. As stated before, HPA-axis activation is a characteristic feature of fear and if panic would be an extreme form of fear, robust increases in cortisol values following panic can be expected. However, the results of this study do not demonstrate that panic is equal to fear. 
Chapter four provides a second study on the neuroendocrinological response to $35 \% \mathrm{CO}_{2}$ inhalation in healthy volunteers. Questions that arose from the first study are addressed in this methodologically improved subsequent investigation. Measurements on HPA-axis activation are extended with ACTH determinations, and cortisol measurements were not only performed in saliva but also in serum. Although the adjustments result in a somewhat different outcome, they don't contradict our former results, but rather refine them.

Dissociation between ACTH and cortisol in PD has been suggested (Strohle, Holsboer, \& Rupprecht, 2000). Following CCK induced panic, ACTH levels were increased whereas cortisol levels remained unaffected. In other words, measurement of cortisol following panic might not be conclusive with regard to the question whether panic is qualitatively different from fear. Accordingly, in chapter five, both the ACTH and cortisol response were assessed following $35 \% \mathrm{CO}_{2}$ induced panic. Since PD patients and healthy controls showed the same neuroendocrinological response, our main conclusion from chapter three is confirmed.

The first chapters showed that panic is not accompanied by increased HPA-axis activation, and as such panic is not a spontaneously occurring fight flight response. This might seem counterintuitive, but an explanation might be related to the uniqueness of panic, which lies in the fact that it involves an internal stressor. Panic is better described as a form of acute distress induced by internal disturbances. It would be expected then, that in other anxiety disorders, where fear is elicited by external stressors such as specific phobia's, confrontation with the feared stimulus is accompanied by HPA axis activation. This hypothesis was put to the test in chapter six. Spider phobic subjects and control subjects were exposed to spiders in a standardised paradigm. Salivary cortisol was used as an index of HPA-axis activity.

In chapter seven, the focus shifts to another stress responsive system. In this chapter literature on immunological variables in PD is reviewed. It is concluded that no firm evidence is found for immune changes in PD. However, this only concerns results from studies that included basal levels of immune variables. In chapter eight, in addition to the assessment of immune variables in the resting condition, aspects of immune functioning are assessed after the event of experimental panic. In other words, the direct effect of panic on the functional capacity of the immune system was investigated.

Finally, the results from the different experiments are integrated and critically reviewed in the concluding chapter, in which is also alluded to future research. 


\section{References}

Abelson, J. L. \& Curtis, G. C. (1996). Hypothalamic-pituitary-adrenal axis activity in panic disorder. 24-hour secretion of corticotropin and cortisol. Arch Gen Pychiatry, 53(4), 323-331.

Abelson, J. L., Nesse, R. M. \& Vinik, A. I. (1994). Pentagastrin infusions in patients with panic disorder. II. Neuroendocrinology. Biol Psychiatry. 36(2), 84-96.

Ader, R., Cohen, N., \& Felten; D. (1995). Psychoneuroimmunology: interactions between the nervous system and the immune system. Lancet, 345(8942), 99-103.

Andreoli, A., Keller, S. E., Rabaeus, M., Zaugg, L., Garrone, G., \& Taban, C. (1992). Immunity, major depression, and painic disorder comorbidity. Biol Psychiatry, 3/(9), 896-908.

Argyropoulos, S. V., Bailey, J. E., Hood, S. D., Kendrick, A. H., Rich, A. S., Luszlo, G., el al. (2002). Inhalation of $35 \% \mathrm{CO}(2)$ results in activation of the HPA axis in healthy volunteers. Psychonenroendocrinology. $27(6), 715-729$.

Asnis, G. M., Wetzler, S., Sanderson, W. C., Kahn, R. S., \& van Praag, H. M. (1992). Functional interrelationship of serotonin and norepinephrine: cortisol response to MCPP and DMI in patients with panic disorder, patients with depression, and normal control subjects. Psychiatry Res, 43(1), 65-76.

Bandelow, B., Wedekind, D., Pauls, J., Broocks, A., Hajak, G., \& Ruther, E. (2000). Salivary cortisol in panic attacks. Am J Psychiatry, 157(3), 454-456.

Bandelow, B., Wedekind, D., Sandvoss, V., Broocks, A., Hajak, G., Pauls, J., et al. (2000). Diumal variation of cortisol in panic disorder. Psychiatry Res, 95(3), 245-250.

Blanchard, D. C., \& Blanchard, R. J. (1988). Ethoexperimental approaches to the biology of emotion. Anmu Rev Psychol, 39, 43-68.

Bradwejn, J., Koszycki, D., \& Shriqui, C. (1991). Enhanced sensitivity to cholecystokinin tetrapeptide in panic disorder. Clinical and behavioral findings. Arch Gen Psychiaty, 48(7), 603-610.

Brambilla, F., Bellodi, L., Perna, G., Battaglia, M., Scitto, G., Diaferia, G., et al. (1992). Psychoimmunoendocrine aspects of panic disorder. Neuropsychobiology, 26(1-2), 12-22.

Brawman-Mintzer, O., Lydiard, R. B., Bradwejn, J., Villarreal, G., Knapp, R., Emmanuel, N., et al. (1997). Effects of the cholecystokinin agonist pentagastrin in patients with generalized anxiety disorder. Am I Psychiaty, 154(5), 700-702.

Caldirola, D., Perna, G., Arancio, C., Bertani, A., \& Bellodi, L. (1997). The $35 \%$ CO2 challenge test in patients with social phobid. Psychiatry Res, $7 I(1), 41-48$.

Cameron, O. G., Lee, M. A., Curtis, G. C., \& McCann, D. S. (1987). Endocrine and physiological changes during "spontaneous" panic attacks. Psychoneuroendocrinology, 12(5), 321-331.

Charney, D. S., Heninger, G. R., \& Breier, A. (1984). Noradrenergic function in panic anxiety. Effects of yohimbine in healthy subjects and patients with agoraphobia and panic disorder. Arch Gen Psychiatry, $41(8), 751-763$.

Cowley, D. S., \& Arana, G. W. (1990). The diagnostic utillty of lactate sensitivity in panic disorder. Arch Gen Psychiaty. 47(3), $277-284$.

Cowley, D. S., Dager, S. R. MoClellan, J., Roy-Byme, P. P., \& Durner, D. L. (1988). Response to lactate infusion in generalized anxiety disorder. Biol Psychiatry, 24(4), 409-414.

de Leeuw. A. S., Den Boer, J. A., Slaap, B. R., \& Westenberg, H. G. (1996). Pentagastrin has panic-inducing properties in obsessive compulsive disorder. Psychopharmacology (Berl), 126(4), 339-344.

Den Boer, J. A., Westenberg, H. O., Klompmakers, A. A.s \& van Lint, L. E. (1989). Behavioral biochemical and neuroendocrine concomitants of lactate-induced panic anxiety. Biol Psychiatry, 26(6), 612-622.

Nienkov, I. J., Wilder, R. L., Clurousos, G. P., \& Vizi, E. S. (2000). The sympathetic nerve--an integrative interface between two supersystems: the brain and the immune system. Pharmacol Rev, 52(4), 595-638.

Goldstein, S., Halbreich, U., Asnis, G., Endicott, J., \& Alvir, J. (1987). The hypothallamic-pituitary-adrenal system in panic disorder. Am J Psychiatry, 144(10), 1320-1323.

Graeff, F. G. (1994). Neuroanatomy and neurotransmitter regulation of defensive behaviors and related emotions in mammals. Braz J Med Biol Res, 27(4), 811-829.

Griez, E., de Loof, C., Pols, H., Zandbergen, J., \& Lousberg, H. (1990). Specific sensitivity of patients with panic attacks to carbon dioxide inhalation. Psychiatry Res, 3/(2), 193-199.

Griez, E., Schruers, K. (1998). Experimental pathophysiology of panic. J Psychosom Res, 45(6), 493-503. 
Griez, E. J., Lousberg, H., van den Hout, M. A., \& van der Molen, G. M. (1987). CO2 vulnerability in panic disorder. Psychiatry Res, 20(2), 87-95.

Gurguis, G. N., Mefford, I. N., \& Uhde, T. W. (1991). Hypothalamic-pituitary -adrenocontical activity in panic disorder: relationship to plasma catecholamine metabolites. Biol Psychiony, 30(5), 502-506.

Holsboer, F. (2000). The corticosteroid receptor hypothesus of depression. Neuropsychophannacology, 23(5), 477-501.

Kahn, R. S., Asnis, G. M., Wetzler, S., \& van Praag, H. M. (1988). Neuroendocrine evidence for serotonin receptor hypersensitivity in panic disorder. Psychopharmacology. 96(3),360-364.

Kellner, M., Wiedemann, K., Yassouridis, A., Levengood, R, Guo, L. S., Holsboer, F, et al. (2000). Behavioral and endocrine response to cholecystokinin tetrapeptide in patients with posttraumatic stress disorder. Biol Psychiary, 47(2), 107-111.

Klein, E., Zohar, I., Geraci, M. F., Murphy, D. L., \& Uhde, T. W. (1991). Anxiogenic effects of m-CPP in patients with panic disorder: comparison to caffeine's anxiogenic effects. Biol Pxychiatry, $30(10), 973$ 984.

Liebowitz, M. R., Fyer, A. J., Gorman, J. M., Dillon, D., Appleby, I. L., Levy, G., et al. (1984). Lactate provocation of panic attacks. I. Clinical and behavioral findings. Arch Gen Psychiatry, 4I(8), 764-770.

Liebowitz, M. R., Gorman, J. M., Fyer, A. J., Levitt, M., Dillon, D., Levy, G. et al. (1985). Lactate provocation of panic attacks. II. Biochemical and physiological findings. Arch Gen Psychiatry, 42(7), 709-719.

Maes, M., Bosmans, E., Meltzer, H. Y., Scharpe, S., \& Suy, E. (1993). Interleukin-1 beta: a putative mediator of HPA axis hyperactivity in major depression? Am J Psychiatry, 150(8), 1189-1193.

Maier, S. F., \& Watkins, L. R. (1998). Cytokines for psychologists: implications of bidirectional immune-tobrain communication for understanding behavior, mood, and cognition. Psychol Rev, 105(1), 83-107.

McCann, U. D., Morgan, C. M., Geraci, M., Slate, S. O., Murphy, D. L., \& Post, R. M. (1997). Eflects of the 5-HT3 antagonist, ondansetron, on the behavioral and physiological effects of pentagastrin in patients with panic disorder and social phobia. Neuropsychopharnacology, $17(6), 360-369$.

McNally, R. J., \& Lukach, B. M. (1992). Are panic attacks traumatic stressors? Ams J Psychiatry, 149(6), 824826.

Nesse, R. M., Cameron, O. G., Curtis, G. C., McCann, D. S., \& Huber-Smith, M. I. (1984). Adrenergic function in patients with panic anxiety. Arch Gen Psychiatry, 4l(8), 771-776.

Noble, F., \& Roques, B. P. (1999). CCK-B receptor: chemistry, molecular biology, biochentistry and pharmacology. Prog Neurobiol, 58(4), 349-379.

Nutt, D., \& Lawson, C. (1992). Panic attacks. A neurochemical overview of models and mechanisms. $B r J$ Psychiatry, $160,165-178$.

Nutt, D. J., Glue, P., Lawson, C., \& Wilson, S. (1990). Flumazenill provocation of panic attacks. Evidence for altered benzodiazepine receptor sensitivity in panic disorder. Arch Gen Psychiatry, 47(10), 917-925.

Owen, N., \& Steptoe, A. (2003). Natural killer cell and proinflammatory cytokine responses lo menteil stress: associations with heart rate and heart rate variability. Biol Psychol, 63(2), 101-115.

Papp, L. A., Goetz, R., Cole, R., Klein, D. F., Jordan, F., Liebowitz, M. R., et al, (1989). Hypersensitivity to carbon dioxide in panic disorder. Am J Psychiaty, 146(6), 779-781.

Perna, F. M, Schneiderman, N. \& LaPerriere, A. (1997). Psychological stress, exercise and immunity. Int J Sports Med, 18 Suppl 1, S78-83.

Perna, G., Barbini, B., Cocehi, S., Bertani, A. \& Gasperini, M. (1995). 35\% CO2 challenge in panic and mood disorders. J Affect Disord, 33(3), 189-194.

Perna, G., Battaglia, M., Garberi, A., Arancio, C., Bertani, A., \& Bellodi, L. (1994). Carbon dioxide/oxygen challenge test in panic disorder. Psychiatry Res, 52(2), 159-171.

Perna, G. Bertani, A., Arancio, $C_{\text {, }}$ Ronchi, $P_{\text {, }}$ \& Bellodi ${ }^{2}$. (1995). Laboratory response of patients with panic and absessive-compulsive disorders to 35\% CO2 challenges. Am J Psychiary. 152 (1), 85-89.

Pitts, F. N., Jr., \& McClure, J. N., Jr. (1967). Lactate metabolism in anxiety neurosis. N Engl J Med, 277(25), 1329-1336.

Rosen, J. B., \& Schulkin, J. (1998). From normal fear to pathological anxiety. Psychol Rev, 105(2), 325-350.

Roy-Byme, P. P., Uhde, T. W., Post, R. M., Gallucei, W., Chrousos, G. P., \& Gold, P. W. (1986). The corticotropin-releasing hormone stimulation test in patients with panic disorder. Am I Psychiatry, $143(7), 896-899$. 
Sandberg, D., Endicott, J., Harrison, W., Nee, J., \& Gorman, J. (1993). Sodium lactate infusion in late luteal phase dysphoric disorder. Psychiatry Res, 46(1), 79-88.

Sasaki, I., Akiyoshi, I., Sakurai, R., Tsutsumi, T., Ono, H., Yamada, K., et al. (1996). Carbon dioxide induced panic attack in panic disorder in Japan. Prog Neuropsychopharmacol Biol Psychiary, 20(7), 145-1157.

Schreiber, W, Lauer, C. J., Krumrey, K., Holsboer, F., \& Krieg, J. C. (1996). Dysregulation of the hypothalamic-pitulary-adrenocortical system in panic disorder. Newopsychophamacology, 15(1), 7 15.

Selye, H. (1936). A syndrome produced by diwerse noxious agents. Nature, $32,138$.

Sinha, S. S., Coplan, J. D., Pine, D. S., Martinez, J. A., Klein, D. F., \& Gorman, J. M. (1999). Panic induced by carbion dioxide inhalation and lack of hypothalamic-pituitary-adrenal axis activation. Psychiary Res, $86(2), 93-98$.

Stein, M. B., Tancer, M. E. \& Uhde, T. W. (1990). Major depression in patients with panic disorder: factors associated with course and recurrence. $J$ Affect Disord, 19(4), 287-296.

Steptoe, A., Willemsen, G., Owen, N., Flower, L., \& Mohamed-Ali, V. (2001). Acute mental stress elicits delayed increases in circulating inflammatory cytokine levels. Clin Sci (Lond), 101(2), 185-192.

Strohle, A. Holsboer, F., \& Rupprecht, R. (2000). Increased ACTH concentrations associated with cholecystokinin tetrapeptide-induced panic attacks in patients with panic disorder. Neuropsychophawmacology, 22(3), 251-256.

Tanum, L. \& Malt, U. F. (1995). Sodium lactate infusion in fibromyalgia patients. Biol Psychiatry, 38(8), 559561 .

Targum, S. D. (1992). Cortisol response during different anxiogenic challenges in panic disorder patients. Psychoneuroendocrinology, $17(5), 453-458$.

Trask, P. C., Esper, P., Riba, M., \& Reciman, B. (2000). Psychiatric side effects of interferon therapy: prevalence, proposed mechanisms, and future directions. J Clin Oncol, 18(11), 2316-2326.

Tsigos, C. \& Chrousos, G. P. (2002). Hypothalamic-pituitary-adrenill axis, neuroendocrine factors and stress. I Psychosom Res, 53(4), 865-871.

van Eekelen, A. P., Kerkhof, G. A., \& van Amsterdam, J. G. (2003). Circadian variation in cortisol reactivity to an acute stressor. Chronobiol Int, 20(5), 863-878.

van Megen, H. J., Westenberg, H. G., Den Boer, J. A., \& Kahn, R. S. (1996). The panic-inducing properties of the cholecystokinin tetrapeptide CCK4 in patients with panic disorder. Eur Neuropsychopharmacol, $6(3), 187-194$.

Verburg, C., Griez, E, \& Meijer, J. (1994). A 35\% carbon dioxide challenge in simple phobias. Acta Psychiatr Scand, $90(6), 420-423$.

Verburg, K., Griez, E., Meijer, J., \& Pols, H. (1995). Discrimination between panic disorder and generalized anxiety disorder by $35 \%$ carbon dioxide challenge. Am J Psychiatry, 152(7), 1081-1083.

Wedekind, D., Bandelow, B., Broocks, A., Hajak, G., \& Ruther, E. (2000). Salivary, total plasma and plasma free cortisol in panic disorder. N Newral Transm, 107(7), 831-837.

Wiedemann, K., Jahn, H., Yassouridis, A., \& Kellner, M. (2001), Anxiolyticlike effects of atrial natriuretic peptide on cholecystokinin tetrapeptide-induced panic attacks: preliminary findings. Arch Gen Psychioury, 58(4), 371-377.

Wilkinson, D. J., Thompson, J. M., Lambert, G. W., Jennings, G. L., Schwarz, R. G., Jefferys, D., et al. (1998). Sympathetic activity in patients with panic disorder at rest, under laboratory mental stress, and during panic attacks. Arch Gen Psychiatry, 55(6), 511-520.

Woods, S. W., Channey, D. S., Goodman, W. K., \& Heninger, G. R. (1988). Carbon dioxide-induced anxiety. Behavioral, physiologic, and biochemical effects of carbon dioxide in patients with panic disorders and healthy subjects. Arch Gen Psychiatry, 45(1), 43-52.

Woods, S. W., Charney, D. S., McPherson, C. A., Gradman, A. H., \& Heninger, G. R. (1987). Situational panuc attacks. Behavioral, physiologic, and biochemical characterization. Arch Gen Psychiarry, 44(4), 365375. 


\title{
CHAPTER 2
}

\section{Hypothalamic-pituitary-adrenal axis function following a $35 \% \mathrm{CO}_{2}$ inhalation in healthy volunteers}

\begin{abstract}
The hypothalamic-pituitary-adrenal axis (HPA-axis) is a central component of the brain's neuroendocrine response to stress. The extent of increase in cortisol secretion, provides an index of the HPA-axis activity, and in this way, objectively reflects perceived stress. In healthy subjects, the $35 \% \mathrm{CO}_{2}$ inhalation does hardly induce stress, as expressed in anxiety. However, inconsistent results have been found in studies investigating the contisol response following $\mathrm{CO}_{2}$ inhalation. Clarity has to be reached about the normal reaction to this challenge, especially because this model is still a very valuable method to study central aspects of panic.

The present study aimed to test the hypothesis that a single breath of $35 \% \mathrm{CO}_{2}$ would not: induce cortisol release in healthy volunteers.

In the current study, 20 healthy subjects underwent both a $35 \% \mathrm{CO}_{2}$ and a placebo inhalation in a randomised, single blind fashion. Cortisol levels were determined in saliva samples, taken at regular intervals. No differences were found between the $\mathrm{CO}_{2}$ and the placebo condition. In both conditions a significant time effect was found, which can be subscribed to normal variation in the circadian rhythm. Furthermore, only modest subjective anxiety scores were found in the $\mathrm{CO}_{2}$ condition.

These results provide biological evidence for the hypothesis that healthy subjects are not affected by the $35 \% \mathrm{CO}_{2}$ challenge in a clinically significant way . Characteristic, PD patients react much stronger to the inhalation. Thus, in addition to psychological parameters, healthy subjects also constitute an ideal comparison group with regard to endocrinological parameters.
\end{abstract}




\section{Introduction}

The hypothalamic-pituitary-adrenal axis (HPA-axis) is a central component of the brain"s neuroendocrine response to stress. The end product of the HPA-axis, cortisol, arouses the body in order to cope with a challenging situation by increasing the rate and the strength of heart contractions, sensitising the blood vessels to the actions of norepinephrine, and affecting many metabolic functions, mainly to provide energy which might be necessary to react to the stressor (Sternberg and Gold, 2000). Cortisol is secreted in a pulsatile fashion throughout the day, with a peak in the morning and declining towards the evening. Several negative feedback systems are keeping the cortisol secretion within a normal range. However, stress is able to override these feedback systems, resulting in an enhanced frequency and amplitude of the cortisol pulses (Kirschbaum and Hellhammer, 1989).

The $35 \% \mathrm{CO}_{2}$ challenge induces neurovegetative activity and additionally, in vulnerable subjects, anxiety (Griez et al., 1990; Perna et al., 1994). It is still unclear if this particular stress induction causes the adrenals to secrete cortisol. Conflicting results have been reported, which might be due to differences in study designs, as well as the use of different $\mathrm{CO}_{2}$ concentrations. Sinha et al. (1999) did not find an increase in cortisol values following a $5 \%$ and a $7 \% \mathrm{CO}_{2}$ inhalation in healthy subjects, whereas Woods et al. (1988) found a slight increase following $7,5 \% \mathrm{CO}_{2}$ inhalation, but not after $5 \% \mathrm{CO}_{2}$. Argyropoulos et al. (2002) used the $35 \% \mathrm{CO}_{2}$ inhalation and found a significant cortisol increase. The first two studies used a study design in which both male and female subjects inhaled the gas mixture for respectively 15 and 20 minutes; these inhalations were performed in the morning. Argyropoulos et al. (2002) performed the challenge in the early afternoon, and used only male subjects. This clearly shows that $\mathrm{CO}_{2}$ inhalation does not necessarily induce cortisol release. Both the percentage of inhaled $\mathrm{CO}_{2}$ and the time of the day may influence the cortisol response. Differences in study designs hamper comparison and, therefore, make it difficult to draw any definite conclusions. Furthermore, several aspects are of importance with regard to the magnitude of the cortisol response, such as the novelty, predictabillity, and the controllability of the stressor (Kirschbaum and Hellhammer, 1989).

As stated earlier, $\mathrm{CO}_{2}$ induces anxiety in vulnerable subjects. Panic Disorder (PD) patients show a marked increase in both physical symptoms and anxiety following a $35 \% \mathrm{CO}_{2}$ inhalation, whereas in healthy volunteers these increases are clearly less pronounced. Furthermore, the symptoms induced by the $\mathrm{CO}_{2}$ inhalation are perceived as very stressful by PD patients. Since in healthy volunteers these symptoms generally are not experienced to be stressful, but can be considered as a minor disturbance of homeostasis which can adequately be restored, we should not expect to find an activation of the HPA-axis, characterised by an increase in cortisol release. HPA-axis function has been studied in other panicogenic challenges as well. For example, lactate induced panic attacks (PAs) are not consistently attended by a large increase in plama cortisol concentration (Liebowitz et al., 1985; Targum, 1992). Furthermore, cholecystokinin infusion was not accompanied by a increase in plasma cortisol levels as well (van Megen et al,, 1996).

The present study was designed to investigate whether healthy volunteers show a cortisol response following a $35 \% \mathrm{CO}_{2}$ inhalation compared to air inhalation. We hypothesized that such an increase would not be found, as healthy volunteers are hardly affected by the $35 \% \mathrm{CO}_{2}$ challenge. 


\section{Methods}

\section{Subjects}

Twenty volunteers ( 10 men, 10 women) with a mean ( $\pm \mathrm{SD}$ ) age of $33 \pm 13$ years participated in the study. None of the participants had a current or prior history of affective disorder and all were physically healthy. Subjects were not allowed to smoke on the test day and during the 24 hours following the inhalation, since smoking has been shown to influence cortisol levels (Kirschbaum and Hellhammer, 1989). The study was approved by the local medical ethics committee and all the participants gave written informed consent before participation.

\section{Procedure}

The subjects arrived at the laboratory at least half an hour before the baseline sampling. In the early afternoon, baseline saliva samples for the cortisol determinations were obtained, using cotton dental rolls on which subjects had to chew for about 1 minute. After collection, cortisol samples were stored at $-20^{\circ} \mathrm{C}$ until analysis. Direct radioimmunoassay, using ${ }^{125} \mathrm{I}$-cortisol and antiserum against the 3-CMO-BSA conjugate, was used to determine cortisol levels (Ansseau et al., 1984). The mean intra assay variance was $4.3 \%$.

The study was performed according to a randomised, single blind design. Half an hour after the baseline sampling, the inhalation procedure was performed.

The $35 \% \mathrm{CO}_{2}$ inhalation procedure has been described in detail elsewhere (Verburg et al., 2001). Briefly, subjects were informed that they would inhale a harmless gas mixture, consisting of $35 \% \mathrm{CO}_{2}$ and $65 \% \mathrm{O}_{2}$, that might induce certain symptoms depending on the individual vulnerability. Symptoms of a PA were described, but the words 'panic attack' were not mentioned literally, to avoid any negative connotation related to expectation. The subjects inhaled the gas mixture through a self-administration mask. At least $80 \%$ of the previously measured vital capacity had to be inhaled to consider the inhalation valid. At the end of the inhalation, the subjects had to hold their breath for 4 seconds to enhance alveolar gas exchange. Before and after the inhalation, the physiological and psychological symptoms were assessed using a Visual Analogue Scale of Anxiety (VAAS), and the Panic Symptom List (PSL), which have been used before to asses experimental anxiety (Schruers et al., 2000). An increase in at least 4 physical symptoms of the PSL together with an increase of at least $25 \mathrm{~mm}$ at the VAAS was scored as a PA (Verburg et al., 2001). Saliva was sampled at 20,40 and 60 minutes after the challenge. An additional sample was taken 24 hours after the $\mathrm{CO}_{2}$ inhalation. On a separate day, the subjects received the same procedure involving a placebo mixture containing $80 \% \mathrm{~N}_{2}$ and $20 \% \mathrm{O}_{2}$. To prevent influences by carry-over effects, the two test days were always separated at least one week (mean: $8.45 \pm 3.69$ days).

\section{Statistical analyses}

Cortisol values were Ln transformed in order to approach normality in the data. The cortisol data were statistically evaluated by using General Linear Models (GLM) for repeated measures (SPSS 10 for Windows) with time (4 levels) and condition (placebo or $\mathrm{CO}_{2}$ ) as within subjects factors. Greenhouse-Geisser correction was always used. It has been suggested that gender differences might be of relevance with regard to HPA-axis activation (Gallucci et al., 1993; Kirschbaum et al., 1999; Roelfsema et al., 1993). Therefore, a second analysis concerned possible gender differences in the response to the $35 \% \mathrm{CO}_{2}$ challenge. Gender was added as 
between subjects factor in a GLM for repeated measures. Within group differences were analysed using t-tests for paired samples. Also, the amount of cigarettes smoked per day and the number of PAs were calculated for each group and were analysed using the Mann-Whitney $U$ test for non-parametric data sets and a chi-square test respectively. Increases in VAAS scores within the group were analysed using the Wilcoxon signed rank test. Finally, age was compared using a student's t-test.

\section{Results}

\section{$35 \% \mathrm{CO}_{2}$ condition versus placebo}

The $\mathrm{CO}_{2}$ inhalation induced a significant increase on the VAAS $(z=-3.58 ; p<0.001)$. The median VAAS score increased from $0.0 \mathrm{~mm}$ pre-challenge to $14.5 \mathrm{~mm}$ post-challenge, whereas in the placebo condition no difference was found (pre: $0.0 \mathrm{~mm}$, post: $0.0 \mathrm{~mm} ; z=-1.15 ; p=$ $0.25)$. The delta scores revealed a significant difference between the placebo and the $\mathrm{CO}_{2}$ condition $(z=-3.12 ; p=0.002)$. Only one subject reported a $\mathrm{PA}$ in the $\mathrm{CO}_{2}$ condition and none in the placebo condition.

The study failed to find a time X condition effect in salivary cortisol after the $\mathrm{CO}_{2}$ challenge ( $F$ $=0.08 ; p=0.9)$. Furthermore, no significant condition effect $(F=0.8 ; p=0.4)$ was found either. However, a significant time effect was present $(F=27.3 ; p<0.001)$. Comparing the cortisol values 20 minutes after the $\mathrm{CO}_{2}$ inhalation to the baseline values using a paired samples $\mathrm{t}$-test, already showed a significant decrease in cortisol values $(t=2.68 ; p=0.02)$. No baseline differences were found between the $35 \% \mathrm{CO}_{2}$ and the placebo condition. Furthermore, the 24hour cortisol measurement did not differ significantly from the baseline values in the $\mathrm{CO}_{2}$ condition $(t=-0.04 ; p=0.97)$, nor in the placebo condition $(t=1.10 ; p=0.28)$. Lower cortisol values 24 hours after the inhalation in a natural, non-laboratory setting, might point to possible increases in cortisol secretion before the inhalation due to anticipatory anxiety. The results are presented in figure $\mathbb{I}$.

\section{Female versus malle subjects}

When comparing the cortisol values of the male and the female subjects, no significant gender effect was found in the $\mathrm{CO}_{2}$ condition $(F=0.04 ; p=0.9)$ using the GLM for repeated measurements. Further, no significant condition $\mathrm{X}$ gender effect $(F=0.003 ; p=1.0)$ and no time $\mathrm{X}$ condition $\mathrm{X}$ gender effect $(F=0.09 ; p=0.9)$ were found. However, a significant time $X$ gender effect existed $(F=5.6 ; p=0.01)$, indicating a different response pattern in female subjects compared to male subjects, present equally strong in both conditions. Table 1 shows the cortisol values of the male and female subjects separately, as well as the total group values. The 24-hour cortisol level of one female subject was $881,18 \mathrm{ng} / \mathrm{dl}$. This outlier was not processed in the mean value and SD presented in this table.

There were no differences between the sexes concerning age $(t=-5.48 ; p=0.59)$ and smoking habits $(z=-1.69 ; p=0.091)$. In total, 5 subjects smoked cigarettes with a mean of 6 cigarettes a day and the maximum being 10 cigarettes a day. 


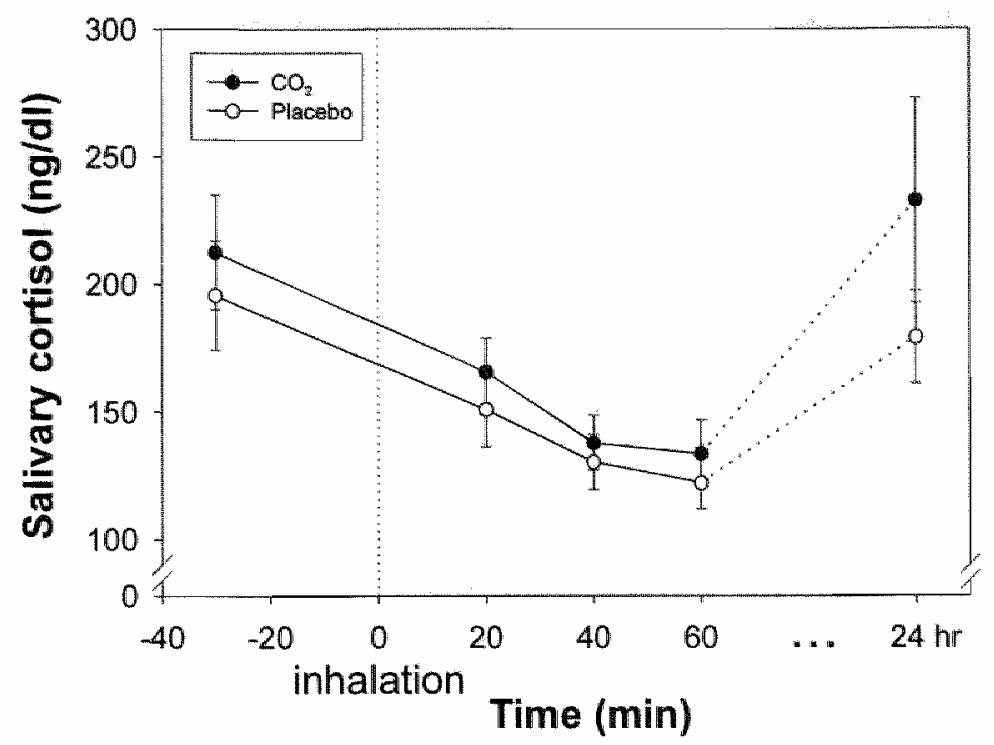

Figure 1. Effects of $35 \% \mathrm{CO}_{2}$ and placebo inhalation on salivary cortisol in healthy volunteers.

Table 1.

Salivary cortisol values (ng/d) in healthy volunteers following a $35 \% \mathrm{CO}_{2}$ and a placebo inhalation

\begin{tabular}{|c|c|c|c|}
\hline & Males $(n=10)$ & Females $(n=10)$ & Whole group \\
\hline pre $\mathrm{CO}_{2}$ & $236.9 \pm 106.9$ & $185.5 \pm 86.1(n=9)$ & $212.5 \pm 98.5$ \\
\hline 20 min. post $\mathrm{CO}_{2}$ & $171.7 \pm 68.9$ & $\mathbb{1} 58.7 \pm 45.3(n=9)$ & $165.5 \pm 57.7$ \\
\hline $40 \mathrm{~min}$. post $\mathrm{CO}_{2}$ & $133.1 \pm 53.0$ & $142.8 \pm 41.8(n=9)$ & $137.7 \pm 47.0$ \\
\hline 60 min. post $\mathrm{CO}_{2}$ & $127.7 \pm 67.7$ & $139.9 \pm 45.8(n=9)$ & $133.5 \pm 57.1$ \\
\hline 24 hr. post $\mathrm{CO}_{2}$ & $221.8 \pm 92.1$ & $165.0 \pm 46.3(n=8)$ & $196.6 \pm 78.8$ \\
\hline pre placebo & $223.7 \pm 122.7$ & $167.6 \pm 52.2$ & $195.6 \pm 96.2$ \\
\hline 20 min. post placebo & $159.2 \pm 84.5$ & $141.6 \pm 31.1(\mathrm{n}=9)$ & $150.9 \pm 63.9$ \\
\hline 40 min. post placebo & $129.7 \pm 56.0$ & $130.8 \pm 42.1$ & $130.2 \pm 48.2$ \\
\hline $60 \mathrm{~min}$. post placebo & $117.6 \pm 43.6$ & $126.4 \pm 49.1$ & $122.0 \pm 45.4$ \\
\hline 24 hr. post placebo & $192.2 \pm 99.1$ & $165.8 \pm 59.7$ & $179.0 \pm 80.8$ \\
\hline
\end{tabular}




\section{Discussion}

The current study shows that there is no significant $\mathrm{HPA}$-axis activation following a $35 \% \mathrm{CO}_{2}$ inhalation in healthy volunteers, as indicated by lack of an increase in salivary cortisol. This provides biological evidence for the hypothesis that healthy volunteers are not vulnerable to the effects of $\mathrm{CO}_{2}$ inhalation. Over the years, several studies from different groups have consistently found that the $\mathrm{CO}_{2}$ inhalation does not affect healthy subjects with regard to subjective anxiety, or only in a modest way (Klaassen et al., 1998; Miller et al., 2000; Perna et al., 1994; Schruers et al., 2000). Moreover, Battaglia and Perna (1995) performed a Receiver Operating Characteristics (ROC) analysis on $35 \% \mathrm{CO}_{2}$ inhalation data, to compute the discriminating power of the challenge in differentiating between true positive and true negative responders. They concluded that $\mathrm{CO}_{2}$-induced subjective anxiety has a high power to differentiate between PD patients and control subjects. Furthermore, using some additional statistics, Battaglia and workers (1995) found the cut-off point at which the discriminatory ability is highest to be a VAAS increase of 20 units. In the current study, the VAAS scores of the subjects were indeed below this specificity threshold. The comparable decrease in cortisol values found both in the placebo and the active condition can be ascribed to the normal circadian thythm and clearly shows that our subjects generally were not stressed during the experiment.

Similar results to ours were obtained in a study of Sinha et al. (1999) in which 5 and $7 \% \mathrm{CO}_{2}$ inhalations for 20 minutes were performed, using a respiratory canopy to inhale the gas mixture. The results of the study of Woods et al. (1988) point to $\mathrm{CO}_{2}$ induced dose-related increases in cortisol: $5 \% \mathrm{CO}_{2}$ did not induce a significant cortisol increase, whereas $7,5 \% \mathrm{CO}_{2}$ did. Remarkably, a significant rise in subjective anxiety was also found in this last condition, and cortisol values are known to be correlated with states of anxiety (Hubert and de Jong-Meyer, 1989).

Argyropoulos et al. (2002) stated that lower $\mathrm{CO}_{2}$ concentrations might be to weak to induce robust $\mathrm{HPA}$-axis activation. In fact, administering one $35 \% \mathrm{CO}_{2}$ inhalation in healthy volunteers resulted in significant increases in plasma cortisol in their study. Although some data from the literature may point to a HPA-axis activation following inhalation of higher $\mathrm{CO}_{2}$ concentrations the possibility of a publication bias should be mentioned here, since it is a common phenomenon that "negative" results are less likely to be published (Gilbody et al., 2000). Nevertheless, the present study fails to find HPA-axis activation following $35 \% \mathrm{CO}_{2}$ inhalation, and therefore, our results are at odds with those of Argyropoulos et al. (2002). The two studies show a number of methodological differences some of which may shed light on the contrasting outcomes.

\section{Gender differences}

In the study of Argyropoulos et al. (2002), only male subjects were included, whereas the current study comprised both mate and female subjects, which is more representative for the general population. When comparing the cortisol response to the $35 \% \mathrm{CO}_{2}$ inhalation of the male subjects and the female subjects, no differences were found, which suggests no gender differences to this stress-stimulus with regard to the cortisol secretion. Admittedly, when comparing sex differences within our group, the remaining groups are small, so no definitive conclusions can be drawn. Argyropoulos et al. (2002) used only fourteen males and did find a cortisol increase. Based on these numbers we could expect to find at least some trends in our data. As we didn't find an increase, it doesn't seem likely that the discrepant results can be ascribed to the differences in gender distribution between the two studies. 


\section{Collecrion methods}

Argyropoulos et al. (2002) used blood sampling. We assessed cortisol in saliva. In the past years there has been a lot of debate about whether cortisol levels in saliva provide a reliable reflection of serum or plasma cortisol levels. Kirschbaum and Hellhammer (1989) have reviewed more than a dozen studies in different populations, and described a high agreement between the two measures. However, salivary cortisol levels show higher correlation coefficients with plasma free cortisol levels, which is the active and therefore most relevant fraction (Kirschbaum and Hellhammer, 1989). Saliva sampling results in increased variability compared to serum sampling of cortisol specimens (Reynolds et al., 1998). Indeed, we found considerable standard deviations in our sample, but that does not influence the fact that most of the subjects showed a clear decrease in cortisol values during the experiment. Even with smaller SD's, it wouldn't have been likely to discover significant increases in cortisol secretion. In other words, despite the large SD's the direction of the change in cortisol values is clearly downwards.

\section{Methodological design}

In the present study, the placebo condition and the $\mathrm{CO}_{2}$ inhalation were conducted on separate days and randomised, whereas Argyropoulos et al. (2002) always conducted the $35 \% \mathrm{CO}_{2}$ condition 40 minutes after the placebo condition. In general, randomised order designs are preferable because they can control for possible order effects. Furthermore, performing both inhallations on one test day might bare the risk of fatigue influencing the cortisol levels in the second half of the experiment. In a study of Bohnen et al. (1990), healthy subjects showed increases in cortisol values following mental stress. Possibly, this influences the findings in the Argyropoulos et al. (2002) study. The fixed order design used makes it impossible to distinguish such a possible influence from the effect of the $\mathrm{CO}_{2}$ inhalation, which was always performed secondly.

\section{Subjective anxiety}

Finally, using a $35 \% \mathrm{CO}_{2}$ challenge in normal subjects, Argyropoulos et al. (2002) induced an increase of about 40 units from baseline on a visual analogue scale for fear. This is twice the increase found in the present study. As stated before, normally, healthy volunteers are hardly affected by the $\mathrm{CO}_{2}$ inhalation paradigm. The VAAS increase in normals reported by Argyropoulos et al. (2002) amounts to $35 \% \mathrm{CO}_{2}$ triggered anxiety in PD patients (Battaglia and Perna, 1995). This aberrant finding, therefore, could point to a factor, which stressed their subjects, priming the HPA-axis, and resulting in enhanced cortisol responses following a second stressor, different from the previous one (Johnson et al., 2002).

Both the fixed order design and the surprising high level of fear induced by $\mathrm{CO}_{2}$ in healthy subjects may help explaining why Argyropoulos et al. (2002) found different results on the HPA parameters after a $35 \% \mathrm{CO}_{2}$ challenge. We speculate that the fixed order may have contributed to the high fear reported by their subjects. However, only an adequate replication with methodological improvements will solve this issue.

\section{Future research}

The $35 \% \mathrm{CO}_{2}$ model is especially relevant to panic disorder. An important issue that can be addressed better in a study including PD patients is whether panic is to be seen as an extreme form of fear, or a qualitatively distinct entity. When no cortisol response is found after $35 \% \mathrm{CO}_{2}$ 
inhalation in PD patients, this might point to a dissociation between panic attacks and the HPAaxis. Future research will have to clarify whether the stronger behavioural reaction is linked to a stronger cortisol response in this population.

\section{Conclusion}

This study provides biological evidence for the hypothesis that the $35 \% \mathrm{CO}_{2}$ challenge does not affect healthy volunteers in a clinically significant way. Thus, the present study shows that, in addition to psychological parameters, healthy subjects also constitute an ideal comparison group for studies in PD patients with regard to endocrinological parameters. 


\section{References}

Ansseau, M., Sulon, J, Doumont, A., Cerfontaine, J.L., Legros, J. J., Sodoyez, J.C., Demey-Ponsart, E, 1984. Use of saliva cortisol in the dexamethasone suppression test, Psychiatry Res. 13, 203-21\%.

Argyropoulos, S.V., Bailey, J.E., Hood, S.D., Kendrick, A.H., Rich, A.S, Laszlo, G., Nash, J. R., Lightman, S.L., Nutt, D.J., 2002. Inhalation of $35 \% \mathrm{CO}_{2}$ results in activation of the HPA axis in healthy volunteers, Psychoneuroendocrinology 27, 715-729.

Battaglia, M., Perna, G., 1995. The 35\% CO2 challenge in panic disorder: optimization by receiver operating characteristic (ROC) analysis, J. Psychiatr. Res. 29,111-119.

Bohnen, N., Houx, P., Nicolson, N., Jolles, J., 1990. Cortisol reactivity and cognitive performance in a continuous mental task paradigm, Biol. Psychol. 31, 107-116.

Gallucci, W.T., Baum, A., Laue, L., Rabin, D.S., Chrousos, G.P., Gold, P.W., Kling, M.A., 1993. Sex differences in sensitivity of the hypothalamic-pituitary-adrenal axis, Health Pychol, 12, 420-425.

Gilbody, S.M., Song, F., Eastwood, A.J., Sutton, A., 2000. The causes, consequences and detection of publication bias in psychiatry, Acta Psychiatr. Scand. 102, $241-249$.

Griez, E., de Loof, C., Pols, H., Zandbergen, J., Lousberg, H., 1990. Specific sensitivity of patients with panic attacks to carbon dioxide inhalation, Psychiatry Res. 31, 193-199.

Hubert, W., de Jong-Meyer, R., 1989. Emotional stress and saliva cortisol response, J. Clin. Chem. Clin. Biochem. 27, 235-237.

Johnson, I.D., O'Connor, K.A., Deak, T., Spencer, R.L. Watkins, L.R., Maier, S.F., 2002. Prior stressor exposure primes the HPA axis, Psychoneuroendocrinology 27, 353-365.

Kirschbaum, C., Hellhammer, D.H., 1989. Salivary cortisol in psychobiological research: An overview, Neuropsychobiology 22, 150-169.

Kirschbaum, C., Kudielka, B.M., Gaab, J., Schommer, N.C., Hellhammer, D.H., 1999. Impact of gender, menstrual cycle phase, and oral contraceptives on the activity of the hypothalamus-pituitary-adrenal axis, Psychosom. Med. 61, 154-162.

Klaassen, T., Klumperbeek, J., Deutz, N.E, van Praag, H.M, Griez, E., 1998. Effects of tryptophan depletion on anxiety and on panic provoked by carbon dioxide challenge, Psychiatry Res. 77, 167-174.

Liebowitz, M.R., Gorman, J.M., Fizyer, A.J., Levitt, M., Dillon, D., Levy, G., Appleby, I.L., Anderson, S., Palij, M.. Davies, S.O., Klein, D.F., 1985. Lactate provocation of panic attacks. II. Biochemical and physiological findings, Arch. Gen. Psychiatry 42, 709-719.

Miller, H.E., Deakin, J.F., Anderson, I.M., 2000. Effect of acute tryptophan depletion on $\mathrm{CO}_{2}$-induced anxiaty in patients with panic disorder and normal volunteers, Br. J. Psychiatry 176, 182-188.

Perna, G., Battaglia, M., Garberi, A., Arancio, C., Bertani, A., Bellodi, L., 1994. Carbon dioxide/oxygen challenge test in panic disorder, Psychiatry Res. 52, 159-171.

Reynolds, R.M., Bendall, H.E., Whorwood, C.B., Wood, P.J., Walker, B.R., Phillips, D.I., 1998. Reproducibility of the low dose dexamethasone suppression test: comparison between direct plasma and salivary cortisol assays, Clin. Endocrimol. (Oxf) 49, 307-310.

Roelfsema, F., van den Berg, G., Frolich, M., Veldhuis, J.D., van Eijk, A., Buuman, M.M., Etman, B.H., 1993. Sex-dependent alteration in cortisol response to endogenous adrenocorticotropin, J. Clin. Endocrinol. Metab. 77, 234-240.

Schruers, K., Pols, H., Overbeek, T., Griez, E, 2000.10 microg CCK-4 premedication and $35 \% \mathrm{CO}_{2}$ challenge in healthy volunteers, Prog. Neuropsychopharmacol. Biol. Psychiatry 24, 409-418.

Sinha, S.S., Coplan, J.D., Pine, D.S., Martinez, J.A., Klein, D.F., Gorman, J.M., 1999. Panic induced by carbon dioxide inhalation and lack of hypothalamic- pituitary-adrenal axis activation, Psychiatry Res. 86, 93-98.

Sternberg, E., Gold, P., 2000. The mind-body interaction in disease, Scient Amer 8-15.

Targum, S.D., 1992. Cortisol response during different anxiogenic challenges in panic disorder patients, Psychoneuroendocrinology 17,453-458.

van Megen, H.J., Westenberg, H.G., Den Boer, J.A., Kahn, R.S., 1996. The panic-inducing properties of the cholecystokinin tetrapeptide CCK 4 in patients with panic disorder, Eur Neuropsychopharmacol 6, 187194. 
Verburg, K., Perna, G., Griez, E.J.L., 2001 . A case study of the $35 \% \mathrm{CO}_{2}$ challenge. In: Griez, E.J.L., Faravelli, C., Nutt, D., Zohar, I. (Eds.). Anxiety disorders. An introduction to clinical management and research. John Wiley \& Sons, Itd.y Chichester, pp. 341-357.

Woods, S.W., Charney, D.S., Goodman, W.K., Heninger, G.R., 1988. Carbon dioxide-induced anxiety. Behavioral, physiologic, and biochemical effects of carbon dioxide in patients with panic disorders and healthy subjects, Arch. Gen. Psychiatry 45, 43-52. 


\section{CHAPTER 3}

\section{Salivary cortisol in panic: Are males more vulnerable?}

\section{ABSTRACT}

The underlying mechanisms of panic attacks (PAs) are still unclear. Theories focusing on these mechanisms differ in their description of the relationship between panic and fear. The main controversy concerns whether a PA resembles the classical flight response, or whether it is qualitatively different from fear. According to the first theory, a PA would result in hypothalamic-pituitary-adrenal axis (HPA-axis) activation, whereas according to the second, it would not. So far, inconclusive results have been reported in studies measuring HPAwaxis activity after laboratory evoked PAs. The present study was designed to assess cortisol levels following a $35 \% \mathrm{CO}_{2}$ challenge in Panic Disorder (PD) patients compared to healthy volunteers as a measurement of HPA-axis activity.

Twenty-three PD patients and 20 healthy volunteers participated in the study. Cortisol was determined in saliva at regular intervals before and after the challenge. Furthermore, attention was paid to possible gender effects.

Although the $35 \% \mathrm{CO}_{2}$ inhalation induced a significant increase in anxiety, no cortisol increase was found. Moreover, there was no difference between patient and control cortisol values following the $35 \% \mathrm{CO}_{2}$ challenge, whereas the delta anxiety scores were far more pronounced in the patient group. Interestingly, male PD patients showed higher cortisol values.

This study may be in accordance with the view that PAs are not accompanied by an important HPA-axis activation. There are some indications for aberrant cortisol secretion in male PD patients. Further research needs to confirm whether male and female PD patients differ in their underlying mechanisms related to HPA-axis activity. 


\section{Introduction}

Panic attacks (PAs), the core feature of panic disorder (PD), are hard to investigate in their real life appearance, as unpredictability is one of their most important features. The $35 \% \mathrm{CO}_{2}$ challenge offers a good opportunity to study PAs in standardized laboratory surroundings. The symptoms elicited by the inhalation procedure closely resemble those of a PA, including their fast crescendo course. Moreover, in PD patients a marked increase in anxious feelings is generated, as opposed to control subjects. This test may therefore represent a very specific stressor which affects in particular patients with $\mathrm{PD}$ [1].

There are two major theories concerning the underlying mechanisms of PAs. Some authors have hypothesized that uncued PAs are comparable to the classical flight response [2-4]. If this primitive flight reaction is indeed related to panic, one would expect that the hypothalamicpituitary-adrenal axis (HPA-axis) is activated and that cortisol release emerges following PA [5]. Contrary to the previous theories, Klein has postulated that panic is qualitatively different from fear. Klein stresses that cortisol secretion is not induced during spontaneous panic, which underlines the difference between panic and fear [6]. Determining cortisol following panic can thus to some extent provide clarity about the origin of PAs.

So far, measuring HPA-axis activity after a $\mathrm{CO}_{2}$-induced PA in PD patients has yielded inconclusive results. An early study suggested increased cortisol concentrations in the subgroup of $\mathrm{PD}$ patients who actually panicked following $\mathrm{CO}_{2}$ inhalation compared to healthy controls [7]. However in the same study, taking all PD patients together, no differences were found. Sinha $e t a l$. [8] did not find increased cortisol response in panicking patients compared to healthy volunteers. In the study of Sasaki et al. [9], again, no statistical differences between both panicking and non-panicking patients and healthy controls were found. Overall, studies show no difference in cortisol response between PD patients, who most often panic, and healthy volunteers, who as a rule do not panic.

The aim of the present study was to assess cortisol concentration following laboratory evoked panic attacks in PD patients compared to healthy volunteers as a measurement of HPA-axis activity.

\section{Methods}

\section{Subjects}

Twenty-three PD patients (13 women, 10 men; mean age $39.7 \pm 13.2$ ), with or without agoraphobia according to the DSM-IV criteria, participated in this study. None of the patients had a concurrent axis I or axis II disorder and all had been free of psychotropic medication for at least three weeks before entering the study. None of the patients used fluoxetine prior to the study. All patients were out-patients of the Academic Anxiety Center, Vijverdal Psychiatric Hospital, Maastricht, The Netherlands. The comparison group consisted of 20 healthy subjects (10 women, $10 \mathrm{men}$ ), with a mean age of 33.3 years \pm 12.8 . All participants were in good physical health.

Since nicotine has been shown to activate the HPA-axis at physiologically relevant doses, subjects were not allowed to smoke on the test day [10]. The study was approved by the local medical ethics committee and written informed consent was obtained from all participants. 


\section{Methods}

The participants arrived at the laboratory in the early afternoon. After a habituation period of 30 minutes, baseline saliva samples for the cortisol determinations were obtained. Saliva was collected by letting the subjects chew on cotton dental rolls for about 1 minute, whereupon the samples were stored at $-20^{\circ} \mathrm{C}$ until analysis. Direct radioimmunoassay, using ${ }^{125} \mathrm{I}$-cortisol and antiserum against the 3-CMO-BSA conjugate, was used to determine cortisol levels [11]. The mean intra assay coefficient of variance was $4.3 \%$.

The $35 \% \mathrm{CO}_{2}$ inhalation procedure, which has been described in detail elsewhere [12], was performed half an hour after the baseline sampling. Briefly, subjects were informed that they would inhale a harmless gas mixture, consisting of $35 \% \mathrm{CO}_{2}$ and $65 \% \mathrm{O}_{2}$, that might induce certain symptoms depending on the individual vulnerability. Symptoms of a panic attack were described, but the words 'panic attack' were not mentioned literally, to avoid any negative bias related to expectation. The gas mixture was inhaled through a self-administration mask. A respirometer connected to the self-administration mask measured the gas volume delivered. To consider the inhalation valid, at least $80 \%$ of the previously measured vital capacity had to be inhaled. At the end of the inhalation, the subjects held their breath for 4 seconds to enhance alveolar gas exchange. Before and after the inhalation, the physiological and psychological symptoms were assessed using a Visual Analogue Scale of Anxiety (VAAS), and the Panic Symptom List (PSL), which have been used before to assess experimental anxiety [13]. An increase in at least 4 physical symptoms of the PSL together with an increase of at least 25 units at the VAAS were used as criteria for an experimental PA [12]. Besides the baseline sample, saliva was sampled at 20,40 and 60 minutes after the inhalation. An additional sample was taken 24 hours after the $\mathrm{CO}_{2}$ inhalation.

\section{Statistical analyses}

Cortisol values were $\mathrm{Ln}$ transformed in order to approach normality of the data. The cortisol data were statistically evaluated by using General Linear Models (GLM) for repeated measurements (SPSS 10 for Windows) with time as the within subjects factor (4 levels: t0, t20, $t 40, t 60$ ), and group (patient or healthy control) as the between subjects factor. Gender and 'panic attack' were examined as a between subjects factor, to compare male and females and the cortisol response of the panickers versus non-panickers. Greenhouse-Geisser correction for sphericity was used in all analyses.

The PSL data, the delta VAAS scores, and the amount of cigarettes smoked per day were analysed using the Mann-Whitney U test for non-parametric data sets. Increases in VAAS and PSL scores within the group were analysed using the Wilcoxon signed rank test. The number of PAs was calculated for both genders and the Pearson chi-square test was used for analysis of this data. Finally, age and baseline cortisol values were compared using a student's t-test.

\section{Results}

\section{Patients and healthy subjects}

The $\mathrm{CO}_{2}$ inhalation induced a significant increase in subjective anxiety as measured on the VAAS in both groups (patients: $Z=-3.82 ; p<0.001$, controls: $Z=-3.58 ; p<0.001$ ), with the patient delta scores being significantly higher $(Z=-3.06 ; p=0.002)$. The median scores in the 
patient group increased from 10.0 units pre-challenge, to 61.0 units post-challenge. In the control group there was an increase from 0.0 to 14.5 units. The same pattern was seen in the PSL data (increase patients: $Z=-4.20 ; p<0.001$, increase controls: $Z=-3.74 ; p<0.001$ ). Again, the patients showed significantly increased values compared to the control group $(Z=$ $-3.54 ; p<0.001$ ). The patients' median scores increased from 3 to 15 , the controls from 0 to 4 . Furthermore, the patients scored significantly more PAs $(Z=-3.79 ; p<0.001)$; in the patient group $14 \mathrm{PAs}$ were reported whereas in the control group only one.

No significant interaction effect was found for group * time $\left(F_{1,39}=1.5 ; p=0.2\right)$, meaning that there was no significant difference in the course of the reaction to the inhalation with respect to cortisol secretion between the two groups. However, a significant effect was found for time $\left(\mathbb{F}_{1,39}=6.5 ; \mathrm{p}=0.006\right)$; both groups showed decreasing cortisol values during the test day. Moreover, no overall group difference was found between the cortisol values of patients and controls after the $35 \% \mathrm{CO}_{2}$ challenge $\left(F_{1,39}=1.3 ; \mathrm{p}=0.3\right)$.

Neither baseline cortisol values $\left(t_{33,2}=0.045 ; p=0.96\right)$ nor the 24 hour measurements $\left(t_{39}=\right.$ $0.22 ; \mathrm{p}=0.82$ ) differed significantly between PD patients and controls. Furthermore, there were no significant differences between the groups concerning age or smoking habits.

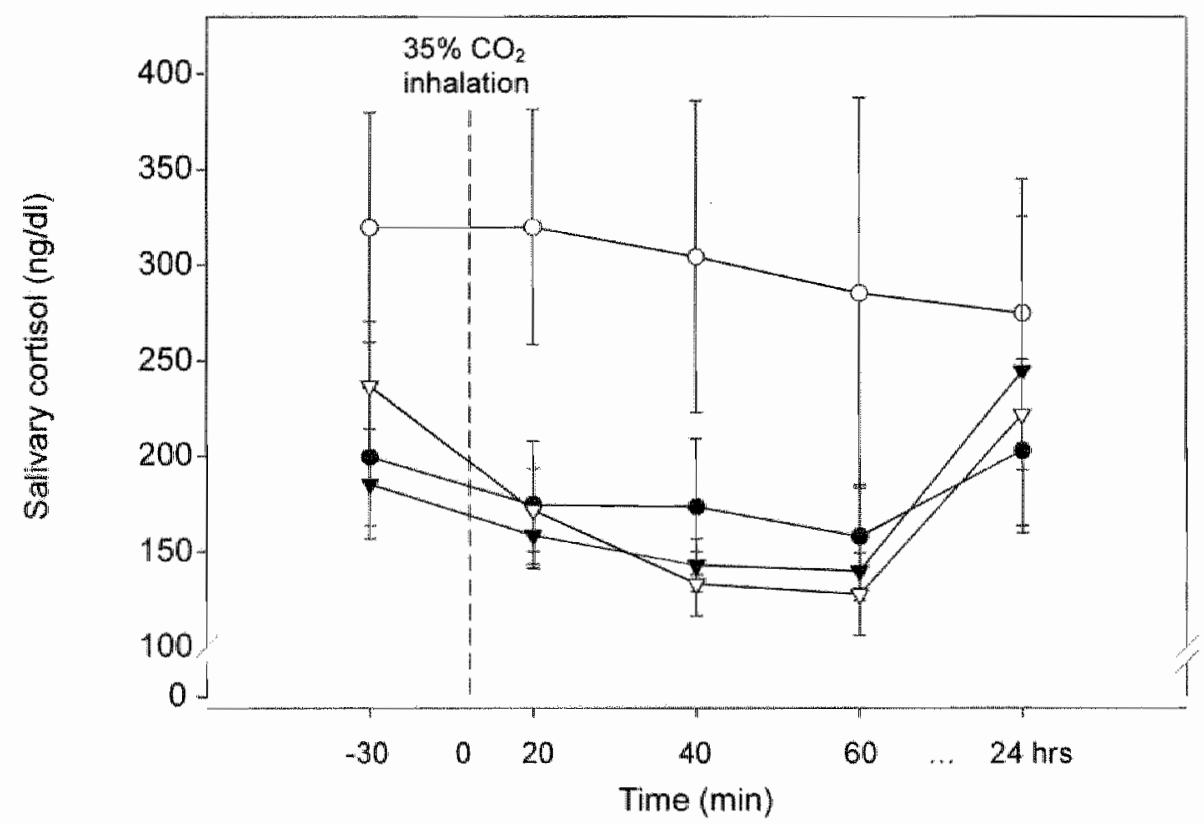

Figure 1. Salivary cortisol values following $35 \% \mathrm{CO}_{2}$ inhalation in panic disorder patients and henlthy volunteers. $\bullet=P D$ females $(n=13) ; O=$ PD males $(n=10) ; \nabla=$ control femalles $(n$ $=10) ; \nabla=$ control males $(n=10)$. 


\section{Gender differences in Panic Disorder patients}

When comparing the male and female patients using GLM for repeated measurements, a significant effect was found for gender $\left(\mathbb{F}_{120}=5.3 ; \mathrm{p}=0.03\right)$ with male cortisol values always being higher. However, the interaction effect between gender and time was not significant ( $F$ ${ }_{1,20}=0.3 ; \mathrm{p}=0.7$ ), which indicates that the cortisol response to the $\mathrm{CO}_{2}$ inhalation between males and females was not different. In total, 14 PAs were reported. Of these, 8 were reported by men $(80 \%)$ and 6 by women $(46 \%)\left(\chi^{2}\right.$ value $\left.=2,7 ; \mathrm{df}=1 ; \mathrm{p}=0.1\right)$. However, taking the VAAS data alone, no differences were found between male and female responses ( $Z=-1.3 ; p$ $=0.2$ ). Comparing the cortisol response of patients who actually panicked with the response of those patients who did not panic revealed no differences between these two groups $\left(\mathrm{F}_{1,30}=0.9\right.$; $\mathrm{p}=0.4$ ). The results are presented in figure 1 .

\section{Discussion}

In the present study, no significant increase in salivary cortisol was found following the $35 \%$ $\mathrm{CO}_{2}$ inhalation in PD patients. These data add to the results of Sinha ef al (1999) and Sasaki et al. (1996) who reported no HPA-axis activation following $\mathrm{CO}_{2}$-induced panic.

In order to be able to understand the underlying mechanisms of PD, the discussion about whether panic is qualitatively or quantitatively different from fear is essential. When PAs equate with fear they are inextricably bound up with HPA-axis activation. Fear classically follows a potential life threatening situation. Such a situation requires an appropriate stress response. Besides the sympathetic nervous system, the HPA-axis is activated. Its end product, cortisol, has among other things, the important function to provide energy necessary to react to the stressor. The cortisol response in fear is considerable, which, to say the least, is not the case with the cortisol response in the current study. This seems to be a contradiction. Panic disorder patients certainly suffer from a lot of stress during a PA. As the majority of these patients reported a PA following the $\mathrm{CO}_{2}$ inhalation, a strong cortisol response seems to be a logical consequence. The fact that the current study found no obvious cortisol response is not an exceptional case. The overall results of the present study are in concordance with former results. Sinha et al. (1999), Sasaki et al. (1996) and Woods et al. (1988) found no HPA-axis activation after $5 \%$ or $7 \% \mathrm{CO}_{2}$ inhalation, both in PD patients and controls. This may imply a dissociation between laboratory evoked PAs and the HPA-axis. However, in the study of Woods et al the subgroup of panicking PD patients showed modest but significant increases in cortisol values following the $5 \% \mathrm{CO}_{2}$ inhalation compared to the air inhalation. The current study does not find a panic related increase in cortisol and, consequently, provides no evidence for the hypothesis that panic merely is an extreme form of fear. This may imply that panic is qualitatively different from fear. Whether panic attacks cause no HPA-axis activation at all is another question which cannot be answered on basis of the results of the current study. Cortisol is the end product of an axis which includes different levels of organisation. Both the processes that lead up to the activation of this axis, as well as regulatory mechanisms within this axis can be disturbed. An initial activation will not result in cortisol secretion if the cascade is interrupted. Information about concentrations of the more upward secreted HPA-axis hormones following a $\mathrm{CO}_{2}$ inhalation is needed in order to truly answer the question whether the HPA-axis is activated. The present study shows some evidence for a gender difference in PD patients. Although the 
response to the $\mathrm{CO}_{2}$ inhalation was not different, male patients showed higher cortisol values throughout the experiment. Increased cortisol levels in male PD patients have been found before during overnight rest, but this study included no female patients [14]. In search for an neuroendocrinological explanation for this gender difference the gonadal steroids are a possible candidate. In fact, estradiol is known to have a dose-related stimulatory effect on the HPA-axis [15]. However, we find male subjects to have increased cortisol levels, whereas the amount of estradiol produced in men is about one fifth of the amount in non-pregnant women. This seeming contradiction can be explained by the fact that, in the brain, testosterone is converted to estradiol [16]. Therefore, it is suggested that the HPA-axis stimulation induced by converted testosterone in men is larger than the stimulation induced by estradiol in women [17]. Furthermore, increased adrenaline levels in male PD patients compared to female patients have been found, which is indicative for increased sympathic activity, the other major system involved in the stress response [18]. The gender difference in PD is of course further emphasized by the difference in prevalence. Women suffer from PD twice as often as men. Furthermore, gender differences in PD have been described previously at the symptom level. For example, women reported more respiratory symptoms during a PA than men and therefore gender difference in sensitivity to $\mathrm{CO}_{2}$ was suggested [19]. Interestingly, in the current study, male PD patients reported more PAs than female patients did, but this finding should be interpreted with caution, as these data are very preliminary and need to be confirmed in a larger group. Furthermore, applying an anxiogenic challenge, namely oral $\mathrm{m}-\mathrm{CPP}$ administration, gender differences in HPA-axis activation were found in PD patients. Compared with healthy controls, female patients had an augmented adrenocorticoidhormone (ACTH) response, whereas male patients and male controls did not differ in their response [20]. Results from studies in which endogenous stimulation of the HPA-axis was applied to healthy volunteers showed no gender differences with regard to cortisol secretion. It is remarkable that in those studies differences in ACTH levels were reported $[21,22]$. A difference in ACTH levels would normally result in a difference in cortisol levels unless a compensatory mechanism would counterbalance this. Logically, the suggested compensatory mechanism would be at the level of the adrenals, for example more or less sensitive ACTH receptors. Studies measuring HPAaxis activation following $\mathrm{CO}_{2}$ inhalation thus far [7-9] only made the division of panicking versus non-panicking subjects and paid no attention to possible gender differences.

In conclusion, this study provides indications for an aberrant cortisol secretion in male PD patients. Whether this can be ascribed to altered stress reactivity needs further investigation. However, taking into account the patient group as a whole, this study is in accordance with the view that a laboratory evoked panic attack is not accompanied by an important HPA-axis activation. Thus, the current study does not reject the hypothesis that panic is quantitatively different from fear, but replication is warranted. 


\section{References}

1. Griez E, de Loof C, Pols H, Zandbergen J, Lousberg H. Specific sensitivity of patients with parvic attacks to carbon dioxide inhalation. Psychiatry Res 1990;31(2):193-9.

2. Graeff FG, Audi EA, Almeida SS, Graeff EO, Hunziker MH. Behavioral effects of 5-HT receptor ligands in the aversive brain stimulation, elevated plus-maze and learned helplessness tests. Neurosci Biobelavi Rev $1990 ; 14(4): 501-6$.

3. Deakin F, Graeff F. 5-HT and mechanisms of defence. J Psychopharmacol 1991;5(4):305-315.

4. Gorman JM, Kent JM, Sullivan GM, Coplan JD. Neuroanatomical hypothesis of panic disorder, revised. An $J$ Psychiatry 2000; 157(4):493-505.

5. Miller DB, O'Callaghan JP. Neuroendocrine aspects of the response to stress. Metabolism 2002;51(6 Suppl 1 1) $5-10$.

6. Klein DF. False suffocation alarms, spontaneous panics, and related conditions. An integrative hypothesis. Arch Gen Psychiatry 1993;50(4):306-17.

7. Woods SW, Charney DS, Goodman WK, Heninger GR. Carbon dioxide-induced anxiety. Behavioral, physiologic, and biochemical effects of carbon dioxide in patients with panic disorders and healthy subjects. Arch Gen Psychiatry 1988:45(1):43-52.

8. Sinha SS, Coplan JD, Pine DS, Martinez JA, Klein DF, Gorman JM. Panic induced by carbon dioxide inhalation and lack of hypothalamic-pituitary-adrenal axis activation. Psychiatry Res 1999;86(2):93-8.

9. Sasaki I, Akiyoshi J, Sakurai $R_{\text {, }}$ Tsutsumi T, Ono H, Yamada $\mathrm{K}$, et al Carbon dioxide induced panic attack in panic disorder in Japan. Prog Neuropsychopharmacol Biol Psychiatry 1996;20(7):1145-57.

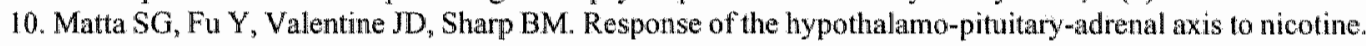
Psychoneuroendocrinology 1998;23(2):103-13.

11. Ansseau M, Sulon J, Doumont A, Cerfontaine JL, Legros JJ, Sodoyez JC, et al. Use of saliva cortisol in the dexamethasone suppression test. Psychiatry Res 1984;13(3):203-11.

12. Verburg $K_{\text {, }}$ Perna G, Griez EJL. A case study of the $35 \% \mathrm{CO} 2$ challenge. In: Griez EJL, Faravelli $\mathrm{C}$, Nut D, Zohar J, editors. Anxiety disorders. An introduction to clinical management and research. 1 ed. Chichester: John Wiley \& Sons, Itd; 2001. p. 341-57..

13. Schruers $\mathrm{K}_{\text {, Pols }} \mathrm{H}_{*}$ Overbeek T, Griez E. 10 microg CCK-4 premedication and $35 \% \mathrm{CO} 2$ challenge in thealthy volunteers. Prog Neuropsychopharmacol Biol Psychiatry 2000;24(3):409-18.

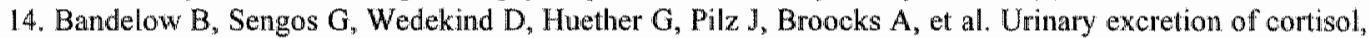
norepinephrine, testosterone, and melatonin in panic disorder. Pharmacopsychiatry 1997;30(4):113-7.

15. Wood CE, Gridley KE, Keller-Wood M. Biological activity of 17 beta-estradiol-3-sulfate in ovine fetal plasma and uptake in fetal brain. Endocrinology 2003;144(2):599-604.

16. Lombardi G, Zarrilli S, Colao A, Paesano L, Di Somma C, Rossi F, et al. Estrogens and heallth in males. Mol Cell Endocrinol $2001 ; 178(1-2): 51-5$.

17. Kirschbaum C, Kudielka BM, Gaat J, Schommer NC, Hel hammer DH. Impact of gender, memstrual cycle phase, and oral contraceptives on the activity of the hypothalamus-pituitary-adrenal axis. Psychosom Med 1999;61(2):154-62.

18. Braune $\$$, Albus M, Frohler M, Hohn T, Scheibe G. Psychophysiological and biochemical clinanges in patients with panic attacks in a defined situational arousal. Eur Arch Psychiatry Clin Neurosici $1994 ; 244(2): 86-92$.

19. Sheikh J1, Leskin GA, Klein DF. Gender differences in panic disorder: findings from the National Comorbidity Survey. Am J Psychiatry 2002;159(1):55-8.

20. Kahn RS, Wetzler S, Asnis GM, Kling MA, Suckow RF, van Praag HM. Pituitary hormone responses to meta-chlorophenylpiperazine in panic disorder and healthy control subjects. Psychiatry Res $1991 ; 37(1): 25-34$.

21. Gallucci WT, Baum A, Laue L, Rabin DS, Chrousos GP, Gold PW, et al. Sex differences in sensitivity of the hypothalamic-pituitary-adrenal axis. Health Psychol 1993;12(5):420-5.

22. Roelfsema $F$, van den Berg $G$, Frolich $M$, Veldhuis JD, van Eijk $A$, Buurman $M M$, at. Sex-dependent alteration in cortisol response to endogenous adrenocorticotropin. I Clin Endocrinol Metab $1993 ; 77(1): 234-40$. 



\title{
CHAPTER 4
}

\section{$\mathrm{CO}_{2}$ challenge results in hypothalamic-pituitary- adrenal activation in healthy volunteers}

\begin{abstract}
The $35 \% \mathrm{CO}_{2}$ challenge is known for its quality to induce symptoms of a panic attack both in Panic Disorder (PD) patients and healthy volunteers. Although the challenge applies more to PD patients, studies in healthy volunteers provide the opportunity to isolate the physical symptoms from the disorder and focus on the direct effect from the challenge on stress responsive systems. One of the main stress responsive systems is the hypothalanic-pituitaryadrenal (HPA-) axis. It remains unclear if panic symptoms are accompanied by HPA-axis activation. Differences in design have hampered the comparison between studies, for example both serum and salivary cortisol have been used to provide an index of HPA-axis activation. Furthermore, indications for central HPA-axis disturbance have been suggested. The current study aimed to study the IPA-axis response following the induction of panic symptoms in healthy volunteers both at the pituitary level and at the adrenal level. Furthermore, both serum and salivary cortisol levels were determined.

Subjective feelings of anxiety and, correspondingly, cortisol and ACTH levels were found to be significantly increased following the $35 \% \mathrm{CO}_{2}$ challenge. Cortisol and $\mathrm{ACTH}$ responses to $\mathrm{CO}_{2}$ were associated. A significant cortisol increase was observed in both serum and saliva samples, although more pronounced when considering the free fraction serum values. We can conclude that the induction of panic symptoms results in HPA-axis activation, both at the pituitary and adrenal level. The question remains whether positive responders to the $35 \% \mathrm{CO}_{2}$ inhalation, more specifically PD patients, show a more pronounced HPA-axis response.
\end{abstract}




\section{Introduction}

Cortisol secretion is considered an important indication of the extent of activation of the stress response. A number of studies in the field of panic have assessed cortisol. So far, results, either from experimental or real-life panic attacks (PAs) have not been conclusive. Most studies provoking panic in the laboratory by means of $\mathrm{CO}_{2}$ inhalation or lactate infusion did not find a cortisol increase (Kellner et al., 1998; Peskind et al., 1998; Sinha et al., 1999), some however did (Liebowitz et al., 1985; Woods et al., 1988; Argyropoulos et al., 2002). On the other hand, in the three studies conducted to date in naturally occurring PAs, apparently elevated plasma cortisol levels have been found (Cameron et al., 1987; Woods et al., 1987; Bandelow et al., 2000). Panic attacks are the core feature of panic disorder (PD) and $\mathrm{CO}_{2}$ inhalation is a sound method that offers the opportunity to study the neuroendocrinology of panic in standardized conditions. Both low concentration $\mathrm{CO}_{2}$ inhalation over a period of 15 to 30 minutes (Woods et al., 1988) and single breath $35 \% \mathrm{CO}_{2}$ inhalation (Griez et al., 1990; Perna et al., 1994) quite consistently induce panic in PD patients. Despite the selectivity of the $\mathrm{CO}_{2}$ challenge and the seemingly uniformous reaction in PD patients, the neuroendocrinological correlates of this reaction remain unclear. Even more, no consensus has been reached about the normal endocrinological reaction in healthy volunteers. The $\mathrm{CO}_{2}$ inhalation is an important tool in the evaluation of the underlying mechanisms of panic. In order to be able to comment on patient values it is essential to reach clarity about values in healthy people. Recently, we performed a study using the $35 \% \mathrm{CO}_{2}$ paradigm to investigate the cortisol response in healthy volunteers (van Duinen et al., 2004). Assessing only salivary cortisol, no differences were found between the $\mathrm{CO}_{2}$ and placebo condition. Yet, it should be noted that the hypothalamic-pituitary-adrenal (HPA-) axis consists of three secretional levels. Several neurotransmitters, including noradrenaline and serotonin, stimulate the hypothalamus to secrete corticotropin releasing hormone (CRH). CRH stimulates the pituitary to secrete adrenocorticotropic hormone (ACTH), which is released in the blood stream. Stimulation of ACTH receptors on the adrenal cortex eventually leads to cortisol secretion. In other words, cortisol is the end product of this physiological axis. Disturbance at higher levels, such as hyposensitive ACTH receptors, can prevent an mitial activation from being expressed in increased cortisol levels. As a matter of fact, Strohle et al (2000) suggested that ACTH levels and cortisol levels may be dissociated in Panic Disorder patients (Strohle et al., 2000).

Referring to the above described inconsistencies in cortisol findings, the present study includes, besides methodological improvements, data on both serum and salivary cortisol following $35 \%$ $\mathrm{CO}_{2}$ inhalation in healthy volnteers. Also taking into consideration the suggested disturbance at the pituitary level in PD patients, ACTH measurements were included.

\section{Methods}

\section{Subjects}

Twenty healthy volunteers ( 11 women; mean age: 23 years \pm 6.7 ) were recruited by means of advertisements and mouth to mouth information. Subjects underwent a standard physical examination, filled out a complete medical history inventory. The Mini International Neuropsychiatric Interview (MINI: Sheehan et al., 1994) and the Family History Research 
Diagnostic Criteria (FHRDC) interview were taken off to exclude any psychiatric diagnosis in the subjects or their first degree relatives.

All women were tested in the follicular phase of their menstrual cycle. Subjects were told to smoke as little as possible on the test day, as nicotine activates the HPA-axis at physiologically relevant doses. On the other hand, abstinence can evoke a cortisol increase as well (Hughes et al., 1988). The two subjects that were smokers, smoked less than 15 cigarettes per day and smoked maximally 2 cigarettes on a test day, more than four hours before the experiment started. The study was approved by the local medical ethics committee and written informed consent was obtained from all participants.

\section{Methods}

The participants arrived at the laboratory at 13.00. An intravenous catheter was inserted in the forearm. At 13.30 the first samples were taken, including both saliva, using cotton dental roles (Salivette $(\mathbb{B}$ ), and blood. Directly before the inhalation a second sample was taken. At 14.00 the challenge was performed. The study was performed according to a fixed-order double-blind design, with the placebo inhalation always on the first test day. The second day was separated from the first day by on average 10.8 days ( \pm 11.5 ). The placebo inhalation consisted of $80 \%$ $\mathrm{N}_{2}$ and $20 \% \mathrm{O}_{2}$, the active inhalation consisted of $35 \% \mathrm{CO}_{2}$ and $65 \% \mathrm{O}_{2}$. All subjects had to inhale at least $80 \%$ of their vital capacity to consider the inhalation valid. The researcher who prepared the gas mixture was not present in the room during the inhalation procedure. The procedure was performed by a trained research nurse who was not aware of the fixed order design of the study. The inhalation procedure has been described in detail by Verburg et al. (Verburg et al., 2001). Following the inhalation physiological and psychological symptoms were assessed using the Visual Analogue Scale of Anxiety (VAAS), the Panic Symptom List (PSL), the State Trait Anxiety Inventory for state anxiety (STAI-1) and the Profile of Mood States (POMS). An increase in at least 4 physical symptoms of the PSL together with an increase of at least 25 units at the VAAS were used as criteria for an experimental PA (Verburg et al,, 2001). The VAAS was marked on the left side with ' 0 ' and on the right side with ' 100 ', stating: $0=$ no anxiety, $100=$ worst anxiety imaginable'. Besides baseline samples, saliva and blood was sampled 15, 30 and 60 minutes following the inhalation for both cortisol and ACTH. Additional samples were taken at 45,90120 minutes following the inhalation for cortisol determination. At every point in time, the questionnaires were filled out as well. Saliva was stored at $-20^{\circ} \mathrm{C}$ until analysis. Direct radioimmunoassay using the ${ }^{125} \mathrm{I}-\mathrm{cortisol}$ and antiserum against the 3-CMO-BSA conjugate was used to determine cortisol levels. The mean intra assay coefficient of variance was $4.8 \%$. Blood was centrifuged at 3000 rpm for 10 minutes at $4^{\circ} \mathrm{C}$. The serum was stored at $-20^{\circ} \mathrm{C}$, and EDTA plasma was stored at $-80^{\circ} \mathrm{C}$ until analysis. Serum cortisol levels were determined using a luminescence immunoassay (LIA; Chiron Diagnostics, Fernwald, Germany). ACTH levels were determined using a two-site enzyme-linked immunosorbent assay (ELISA; Biomerica, Newport Beach, California). The sensitivity of this assay was $0.46 \mathrm{pg} / \mathrm{mL}$. The mean intra assay coefficient of variance was $3.7 \%$.

\section{Statistical analyses}

To normalize salivary cortisol distributions and to stabilize variances as required for statistical procedures, we applied natural log transformations. After transformation, distributions were normal as assessed with one-sample Kolomogorov-Smirnov goodness of fit tests. Statistical 
analyses were performed using General Linear Models (GLM) for repeated measurements (SPSS 10 for Windows) with time (cortisol: 7 levels, ACTH: 4 levels) and condition (placebo or $35 \% \mathrm{CO}_{2}$ ) as within subjects factors. Greenhouse-Geisser correction was used when appropriate. The correlation between serum free fraction, total serum and salivary cortisol was studied using Pearson correlation coefficient and the accompanying two-tailed significance values. The number of PAs was calculated for each condition and was analysed using the chisquare test. Scores following the challenge on the VAAS, PSL, STAI and POMS in the placebo and the $\mathrm{CO}_{2}$ condition were compared using the Mann-Whitney $U$ test for nonparametric data sets. Increases in VAAS, PSL, STAI and POMS scores within the groups were analysed using the Wilcoxon signed rank test.

\section{Results}

\section{Questionnaimes}

The $\mathrm{CO}_{2}$ inhalation induced a significant increase on the VAAS $(z=-3.20 ; p=0.001)$. The median VAAS increased from 0.0 units pre-challenge to 11.5 units post-challenge. In the placebo condition no significant increase was found (pre: 0.0 units, post 1.0 units; $z=0.000$; $p=1,00)$. The delta scores revealed a significant difference between the placebo condition and the $\mathrm{CO}_{2}$ condition $(\mathrm{z}=-3.097 ; \mathrm{p}=0.002)$. The physical symptoms also increased significantly as a result of the $\mathrm{CO}_{2}$ inhalation (PSL scores: $\mathrm{z}=-3,89 ; \mathrm{p}<0.001$ ). In the placebo condition, the physical symptoms increased as well $(z=-2.11 ; p=0.035)$. Possibly because of this, blindness could be kept. Following the inhalation subjects were asked whether they thought they inhaled $\mathrm{CO}_{2}$ or air. Following the placebo condition $25 \%$ of the subjects wrongly reported $\mathrm{CO}_{2}$. In the $\mathrm{CO}_{2}$ condition all subjects (afterwards) correctly answered that it was the active condition. Two male subjects and one female subject reported a PA in the $\mathrm{CO}_{2}$ condition, none in the placebo condition. Furthermore, STAI scores significantly increased in the $\mathrm{CO}_{2}$ condition $(z=-3.23 ; p=0.001)$, but not in the placebo condition $(z=-1.51 ; p=0.13)$. Comparable results were found analysing the POMS data. Subjects were more tense $(z=-2.76 ; p=0.006)$, more depressed $(\mathrm{z}=-2.41 ; \mathrm{p}=0.016)$ and less vigorous $(\mathrm{z}=-2.03 ; \mathrm{p}=0.043)$ following $\mathrm{CO}_{2}$ inhalation compared to the reaction to the air inhalation. Anger and thedness did not change.

Table 1. Effecs of $35 \%$ CO and placebo inhalation on VAS, PSL, STAI, and PONS scores in healthy volunteers.

\begin{tabular}{|c|c|c|c|c|c|c|c|c|}
\hline & VAAS & PSL & STAL & depr & anger & $\begin{array}{l}\text { POMS } \\
\text { tension }\end{array}$ & tired & vigour \\
\hline Prepucebo & 0 & 0 & 26 & 0 & 0 & 0 & 0 & 20 \\
\hline Post puncebo & 1 & 娄 & 28 & 0 & 0 & 0 & 0 & 20 \\
\hline $\mathrm{PreCO}_{2}$ & 0 & 0 & 26 & 0 & 0 & 0 & 0 & 13 \\
\hline Past $\mathrm{CO}_{2}$ & 12 & 7 & 35 & 0 & 0 & 1 & 0 & 11 \\
\hline
\end{tabular}

Values represent median watues. VAAS = VisualAnatogue Scake of Anxiety, PSL= Panic Symptom List, STAI $=$ State Trat Anxiety Imventory, POMS = Profle of Mood States, depr $=$ depression. 


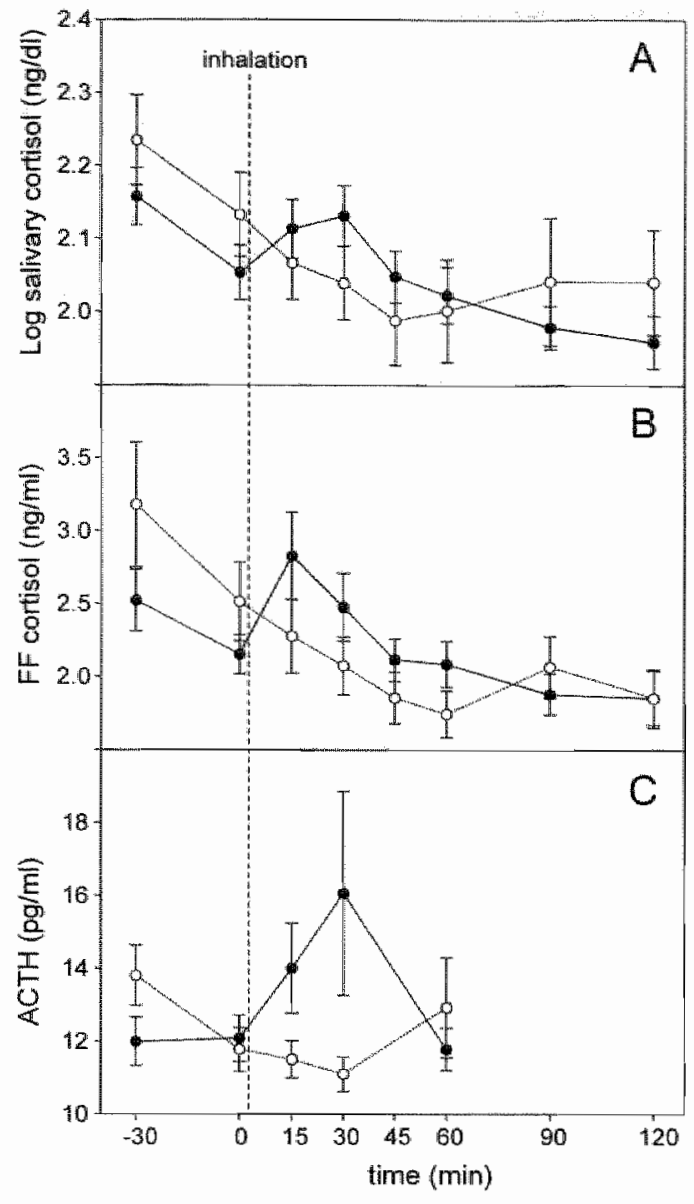

Figure 1. Effects of $35 \% \mathrm{CO}_{2}$ and placebo inhalation on salivary cortisol, free fraction serum cortisol and adrenocorticotropic hormone levels in healthy volunteers. Data are mean sem. Values on the challenge day ( ) were increased compared to values from the placebo day (o).

\section{Cortisol}

Analysis of the salivary cortisol data showed a significant Time $\mathrm{x}$ Condition effect $(F=4.67 ; p=0.010)$, which indicates that the course of cortisol secretion differed between the air and $\mathrm{CO}_{2}$ condition. The Time $\mathrm{x}$ Condition interaction effect for total serum cortisol was also significant $(\mathrm{F}=5.63 ; \mathrm{p}=$ $0.004)$. The free fraction of serum cortisol should correspond with salivary cortisol. Indeed, the Time $x$ Condition interaction effect was significant $(\mathrm{F}=$ $3.92 ; \mathrm{p}=0.030$ ). No condition effect was found, but a significant time effect was found in all analyses. Salivary cortisol values and free fraction serum cortisol values were significantly correlated, with all correlation coefficients being higher than 0.74 , all significant at the 0.001 level. The correlations between these two parameters and total serum cortisol were weaker, but still significant. Peak FF serum cortisol values $(t=3)$ showed no correlation with post inhalation VAAS values $\left(r^{2}=0.28\right)$.

\section{$A C T H$}

ACTH levels increased following the $\mathrm{CO}_{2}$ inhalation, but not in the placebo condition. The interaction effect between time and condition showed was not significant $(F=2.08 ; p=0.169$ ). The Greenhouse-Geisser correction was applied as Mauchly's test of sphericity was significant. There were no significant time or condition effects. Baseline $A C T H$ values did not differ $\left(\mathrm{t}_{15}\right.$ $=-0.56 ; p=0.58$ ). Cortisol and ACTH data are presented in Figure 1.

Two subjects fainted on the first test day (placebo condition) during insertion of the intravenous cannula. Because of this, their results were out of range (cortisol: $>900 \mathrm{ng} / \mathrm{dl}$ ) and, therefore, their results were not taken into consideration. Also, in some instances, blood could not be drawn at all points in time, or analyses of the ACTH levels could not be performed. 


\section{Discussion}

The present study found a significant increase in cortisol levels following $35 \% \mathrm{CO}_{2}$ inhalation in healthy volunteers. This increase was apparent both in saliva and in serum. ACTH data supported this sign of $\mathrm{HPA}$-axis activation. Furthermore, the $35 \% \mathrm{CO}_{2}$ inhalation induced a significant increase in anxiety as measured on the VAAS and the STAI. Feelings of tension and depression were significantly increased and feelings of vigour were decreased as measured with the POMS.

At first sight, the current study contradicts with our former study in healthy volunteers in which no cortisol increase was found (van Duinen et al., 2004). However, improvements in our methodological design can largely account for this discrepancy. An important improvement was the addition of a second baseline sample directly before the inhalation, in order to assess the direct effect of the challenge as accurately as possible. During the first half hour cortisol levels decreased significantly, probably due to habituation or the course of the normal circadian rhythm. When we consider the salivary cortisol data, the cortisol increase we find in the current study would disappear if we would remove the second baseline value, which is consistent with the data from our former study.

In addition to a second baseline sample, we measured both salivary and serum cortisol. Serum cortisol values tend to show smaller SD's and in case of small subject groups or small effects, as is the case with $35 \% \mathrm{CO}_{2}$ inhalation in healthy volunteers, measuring serum cortisol levels might be the method of preference (Reynolds et al., 1998). Indeed, in the current study the increase in free fraction serum cortisol is more pronounced than the salivary cortisol increase. However, the two sampling methods show similar cortisol courses, and the correlations between the data are strong. The advantage of using salivary cortisol is that there is no need to perform venapuncture. Venapuncture potentially causes stress and can thus induce cortisol release. The current study was partly designed to compare salivary and serum cortisol values which made venapuncture inevitable. Despite this, the baseline cortisol values from the current study are comparable with those of our former study in which venapuncture was not necessary. In other words, the suggested effects on cortisol secretion induced by venapuncture do not influence baseline cortisol levels in the current design.

From a clinical point of view, the magnitude of the cortisol reaction found in the present study is not very impressive. For instance, fear for public speaking is the most frequent social fear in healthy subjects (Stein et al., 1994; Furmark et al., 1999). Social stress tests, for example the Trier Social Stress Test (TSST), have frequently been used to induce stress in healthy volunteers. Generally, cortisol secretion was strongly stimulated by public performance, resulting in cortisol levels that by far exceeded the levels measured in the current study (Kirschbaum et al., 1993; Heinrichs et al., 2003). In other words, although significantly increased, the cortisol reaction in the current study is modest. Furthermore, the levels of anxiety induced in this study are within normal ranges as well. It should be noted that despite the fact that the increase on the VAAS scores was found to be statistically significant, the data differed from results that are considered to be positive. In fact, a VAAS increase of less than 20 units is distinctive for negative responders to the $35 \% \mathrm{CO}_{2}$ inhalation (Battaglia and Perna, 1995). With the exception of one single study in which robust cortisol increases and concomitant high fear scores were found (Argyropoulos et al., 2002), results from former studies applying $\mathrm{CO}_{2}$ inhalation in healthy volunteers are in concordance with the current study (Woods et al., 1988; 
Kirschbaum et al., 1993; Heinrichs et al., 2003). It thus appears that the current study induced only minor anxiety levels, which expectantly was accompanied by minor cortisol increases. Furthermore, the statistically significant increases found in POMS scores when comparing the post placebo and the post $\mathrm{CO}_{2}$ data, are clinically very insignificant when considering the median values.

Consistent with the cortisol values, the $\mathrm{ACTH}$ levels increased following the $35 \% \mathrm{CO}_{2}$ inhalation. This corresponds with the findings of Kaye et al. (Kaye et al., 2004). Since the pituitary is stimulated early in the HPA-axis, the ACTH peak is reached earlier than the cortisol peak. Generally, the peak ACTH value is measured within 10 minutes following acute stress induction (Koszycki et al., 1998; Zwanzger et al., 2001). For technical reasons, our first measurement was performed 15 minutes following the $35 \% \mathrm{CO}_{2}$ inhalation, so it would be expected that we missed the ACTH peak. Nevertheless, at 15 minutes ACTH values showed an increase compared to baseline values, and at 30 minutes following the inhalation ACTH values reached a peak. Due to missing data the remaining groups were small and significance was not reached. However, the degree to which ACTH levels were increased can explain the increase in cortisol values.

In contrast with the dissociation between cortisol and ACTH increase found by some investigators as mentioned in the introduction (Strohle et al., 2000), the current study provides no evidence for such a dissociation in healthy volunteers.

Our present results are in line with reports on sodium lactate-induced panic which also show this modest pituitary-adrenocortical response (Kellner et al., 1998; Peskind et al., 1998; Otte et al., 2002), together with the corresponding ACTH and cortisol values. However, applying CCK4 infusion, another panicogenic challenge, healthy subjects who panicked showed increased ACTH levels compared to those who did not, whereas considering cortisol values, there were no differences (Koszycki et al., 1998). Possibly, different neuroendocrine pathways are involved in the response to these challenges. With the current data it is not possible to address the issue of the discrepancy between panicking and non-panicking subjects, as only three subjects panicked.

In conclusion, the present study shows $35 \% \mathrm{CO}_{2}$ inhalation to increase, be it modestly, subjective feelings of anxiety in healthy volunteers and correspondingly cortisol and $\mathrm{ACTH}$ levels. Cortisol and ACTH values corresponded well, in other words we did not find evidence for a dissociation between pituitary and adrenal cortex hormones, which is consistent with results from sodium lactate infusion studies. The question remains whether this dissociation is absent in positive responders to the $35 \% \mathrm{CO}_{2}$ inhalation, more specifically PD patients. Future research should focus on those individuals who suffer from genuine pathological anxiety. It should be born in mind that the present study was performed in healthy volunteers. It leaves the picture open for results obtained with patient studies.

\section{Acknowlegdements}

The authors wish to thank Professor J. Sulon (University of Liege) and dr. R. van Diest (Maastricht University) for their scientific support. 


\section{References}

Argyropoulos S V, Batley J E, Hood S D, Kendrick A H, Rich A S, Laszlo G, Nash J R, Lightman S L, Nutt D $\mathrm{J}(2002)$ lnhalation of $35 \% \mathrm{CO}(2)$ results in activation of the HPA axis in healthy volunteers. Psychoneuraendocrinology 27(6): 715-729

Bandelow B, Wedekind D, Pauls J, Broocks A, Hajak $\mathrm{G}$, Ruther $\mathrm{E}$ (2000) Salivary cortisol in panic attacks. Am If Pychiatry $157(3): 454-456$

Battaglia $M_{3}$ Pena $G(1995)$ The 35\% CO2 challenge in panic disorder: optimization by receiver operating characteristic (ROC) analysis. J Psychiatr Res 29(2): 111-119

Cameron $O \mathrm{G}$, Lee $M$ A, Curtis G C, MeCamn D $\mathrm{S}$ (1987) Endocrine and physiological changes during "spontaneows" panic attacks. Psychoneuroendocrinology 12(5): $321-331$

Furmark $T$, Till fors M, Everz $P$, Marteinsdottir I, Gefvert $O$, Fredrikson M (1999) Social phobia in the general population: prevallence and sociodemographic profile. Soc Psychiatry Psychiatr Epidemiol 34(8): 416424

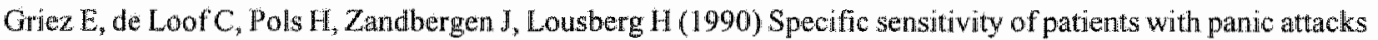
to carbon dioxide inhalation. Psychiatry Res 3/(2): 193-199.

Heinrichs $M$, Baumgartner T, Kirschbaum $C$, Ehlert $U$ (2003) Social support and oxytocin interact to suppress cortisol and subjective responses to psychosocial stress. Biol Psychiatry 54(12): 1389-1398

Hughes $J \mathbb{R}$, Arana $G$, Amori $G$, Stewart $F$, Workman $R$ (1988) Effect of tobacco withdrawal on the dexamethasone suppression test. Biol Psychiatry 23(1): 96-98

Kaye J, Buchanan F, Kendrick A, Johnson P, Lowry C, Bailey J, Nutt D, Lightman S (2004) Acute carbon dioxide exposure in healthy adults: evaluation of a novel means of investigating the stress response. J Neuroendocrinol 16(3): 256-264

Kellner $M$, Knaudt $K$, Jahn $H$, Holsboer F, Wiedemann $\mathrm{K}$ (1998) Atrial natriuretic hormone in lactate-induced panic attacks: mode of release and endocrine and pathophysiological consequences. J Psychiatr Res $32(1): 37-48$

Kirschbaum C, Pirke K. M, Hellhammer D H (1993) The 'Trier Social Stress Test'--a tool for investigating psychobiological stress responses in a laboratory setting. Neuropsychobiology 28(1-2): 76-81

Koszycki D, Zacharko R M, Le Melledo J M, Bradwejn J (1998) Behavioral, cardiovascular, and neuroendocrine profiles following CCK-4 challenge in healthy volunteers: a comparison of panickers and nonpanickers. Depress Anxiety $8(1): 1-7$

Liebowitz M R, Gorman J M, Fyer A J, Levitt M, Dillon D, Levy G, Appleby 1 L, Anderson S, Palij M, Davies $\mathrm{SO}$, et al. (1985) Lactate provocation of panic attacks. II. Biochemical and physiological findings. Arch Gen Psychiatry 42(7): 709-719.

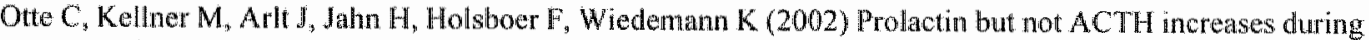
sodium lactate-induced panic attacks. Psychiatry Res 109(2): 201-205

Perna $G$, Battaglia $M$, Garberi A, Arancio C, Bertani $A_{4}$ Bellodi L (1994) Carbon dioxide/oxygen challenge test in panic disorder. Psychiatry Res 52(2): 159-171.

Peskind E R, Jensen C F, Pascualy M, Tsuang D, Cowley D, Martin D C, Wilkinson C W, Raskind M A (1998) Sodium lactate and hypertonic sodium chloride induce equivalent panic incidence, panic symptoms, and hypernatremia in panic disorder. Biol Psychiatry 44(10): 1007-1016

Reynolds R M, Bendall H E, Whorwood C B, Wood P J, Walker B R, Phillips D I (1998) Reproducibility of the low dose dexamethasone suppression test; comparison between direct plasma and salivary cortisol assays. Clin Endocrinol (Ox) 49(3): 307-310.

Sheehan D, Lecrubier Y, Janaws J, Knapp E, Weiller E, (1994). MNI Intermational Neuropsychiatric Interniew. Tampa: University of South florida.

Sinlua S S, Coplan J D, Pine D S, Martinez J A, Klein D F, Gorman J M (1999) Panic induced by carbon dioxide inhalation and lack of hypothalamic-pituitary-adrenal axis activation. Psychiatry Res 86(2): 93-98.

Stein M B, Walker J R, Forde D R (1994) Setting diagnostic thresholds for social phobia: considerations from a community survey of social anxiety. Am J Psychiatry $15 /(3): 408-412$

Strohle A, Holsboer F, Rupprecht R (2000) Increased ACTH concentrations associated with cholecystokinin tetrapeptide-induced panic attacks in patients with panic disorder. Neuropsychopharmacology $72(3)$ : $251-256$ 
van Duinen M A. Schruers K R, Jaegers E, Maes M, Griez E J (2004) Hypothalamic-pituitary-adrenal axis function following a $35 \% \mathrm{CO}(2)$ inhalation in healthy volunteers. Prog Neuropsychopharmacol Biol Psychiatry 28(2): 279-283

Verburg K, Perna G, Griez E J L (2001) A case study of the $35 \%$ CO2 challenge. In Griez E I L, Faravelli $C_{\text {, }}$ Nutt D, Zohar J(eds), Anxiety disorders. An motuction to clinical management and research (I ed., Voll 1), John Wiley, Chichester

Woods S W, Chamey D S, Goodman W K K, Heninger G R (1988) Carbon dioxide-induced anxiety. Behavional, physiologic, and biochemical effects of carbon dioxide in patients with panic disorders and healthy subjects. Arch Gen Psychiatry 45(1): 43-52

Woods S W, Charney D S, McPherson C A, Gradman A H, Heninger G R (1987) Situational panic attacks. Behavioral, physiologic, and biochemical characterization. Arch Gen Psychiatry 44(4): 365-375.

Zwanzger P, Baghai T C, Schuele C, Strohle A, Padberg F, Kathmann N, Schwarz M, Moller HI J, Rupprecht R (2001) Vigabatrin decreases cholecystokinin-tetrapeptide (CCK-4) induced panic in healthy volunters. Neuropsychopharmacology 25(5): 699-703. 



\title{
CHAPTER 5
}

\section{$\mathrm{CO}_{2}$ challenge induced HPA-axis activation in panic}

\begin{abstract}
The hypothalamic-pituitary-adrenal axis (HPA-axis) plays a critical role in stress management. Involvement of this physiological axis in the underlying mechanisms of panic disorder (PD) has been suggested. Studies using $35 \% \mathrm{CO}_{2}$ inhalation to provoke panic found no evidence for robust increases in cortisol levels in PD. However, cortisol levels alone may not be conclusive, as this hormone is merely the end product of a complex physiological axis.

Sixteen PD patients and sixteen healthy control subjects underwent a $35 \% \mathrm{CO}_{2}$ inhalation and a placebo inhalation on separate days according to a fixed order, double-blind design. Both serum and salivary cortisol as well as ACTH were measured at regular time intervals. Cortisol and ACTH levels increased significantly in the patient and control groups following $35 \% \mathrm{CO}_{2}$ inhalation. The magnitude of the increase was similar in patients and controls despite marked differences in anxiety.

The present study is the first to document a clear $\mathrm{HPA}$ response following $35 \% \mathrm{CO}_{2}$ inhalation in both PD patients and controls. This effect occurs independently of the specific panicogenic properties of the $\mathrm{CO}_{2}$ challenge. It remains to be clarified whether panic is initially accompanied by major HPA-axis activation or whether other stress-responsive systems underlie panic:
\end{abstract}




\section{Introduction}

Despite many years of research, there is still debate about the underlying mechanisms of panic disorder (PD). One explanatory concept is that panic is a specific type of anxiety, linked to an oversensitive inborn, phylogenetically evolved internal alarm system (Klein 1993). The major specific threat that the alarm system should warn us of is suffocation, a potentially lifethreatening event. Klein assumes that the hypothalamic-pituitary-adrenal (HPA) axis is not stimulated during the course of a panic attack (PA), in line with the hypothesis that the lack of an HPA-axis response is a characteristic feature of panic. In contrast, other authors make no distinction between panic, other kinds of fear, and stress in general (Deakin and Graeff 1991; Gorman et al 2000). Any stressor that is perceived to involve an immediate threat is believed to be relayed directly to the paraventricular nucleus (PVN) of the hypothalamus (Herman and Cullinan 1997). The cascade that follows from this initial stimulation is characteristic of the classical stress response (Miller and O'Callaghan 2002).

Several attempts have been made to determine whether HPA-axis activity is increased following panic. The assessment of cortisol levels, following laboratory-induced panic using $\mathrm{CO}_{2}$ inhalation or lactate infusion, has led to the conclusion that panic is not accompanied by a clinically significant increase in cortisol (Kellner et al 1998; Peskind et al 1998; Sinha et al 1999; Woods et al 1988). In other words, no robust evidence supporting HPA-axis activation following panic is available to date. However, measurement of cortisol levels may not be conclusive, as this hormone is merely the end product of a complex physiological axis. In fact, Kaye er al. (2004) recently determined ACTH levels following $35 \% \mathrm{CO}_{2}$ inhalation in healthy volunteers. A significant increase in ACTH was found, which was not the case with lower doses of $\mathrm{CO}_{2}$ (Kaye $e$ t al 2004). Studies on HPA-axis activation in our laboratory have yielded conflicting results thus far. Two previous studies assessing sallivary cortisol failed to document a pronounced HPA-axis response following $35 \% \mathrm{CO}_{2}$ inhalation (van Duinen et al 2004a; van Duinen et al 2004b). Questions that arose from those studies were addressed in a methodologically improved subsequent investigation. Total serum and serum free fraction cortisol levels were assessed in addition to salivary cortisol. Although salivary cortisol levels provide a reliable reflection of serum free fraction cortisol levels (Kirschbaum and Hellhammer 1989), saliva sampling results in increased variability (Reynolds et al 1998), which can mask subtle responses. Furthermore, measurements of HPA-axis activation were extended with determinations of pituitary ACTH. Both salivary and serum free fraction cortisol and ACTH release were found to be increased following $35 \% \mathrm{CO}_{2}$ inhalation (van Duinen ef al 2005). However, this study was performed in healthy volunteers who, as a rule, do not panic. In order to address the subject of the role of the HPA-axis in panic, the current research was performed. The aim of the present study was to assess HPA-axis activity following laboratory-evoked panic attacks in PD patients compared to healthy volunteers. In order to acquire a broad view, both serum and salivary cortisol as well as ACTH were included, together with different parameters that can be used to assess anxiety. 


\section{Materials and methods}

\section{Subjects}

Sixteen PD patients (10 men, 6 women; mean age $39 \pm 13$ years) were enrolled in the study. Diagnosis of PD was made based on the DSM-IV criteria, supported by the Mini International Neuropsychiatric Interview (MTNI) (Sheehan et al, 1994), and confirmed by an experienced psychiatrist (KS). Initially, another wo female patients were included, but they had to refrain from further involvement due to personal circumstances following the first test day; therefore, their data were not taken into consideration. On average, patients suffered from PD for 10 years, with a mean of four panic attacks per week. In order to gain insight into the severity of the disorder, state and trait anxiety was measured using the STAI (Spielberger et al 1970) (state: $49.3 * 11.3$; trait: $48.7 \pm 10.8$ ). A diagnosis of depression was an exclusion criterion, although depressive symptoms were present in some patients (mean score on the MADRS: $11.8 \pm 6.7$ ). None of the patients had a concurrent axis I disorder and a1] had been free of psychotropic medication for at least three weeks before entering the study. The control group was carefully matched for gender, age, and smoking habits and consisted of 10 men and 6 women (mean age $39: 14$ years). In both groups seven subjects smoked, with a mean of 8.4 cigarettes per day in the patient group and 8.7 in the control group. The maximum number of cigarettes allowed per day was 15 .

All subjects filled out a complete medical history inventory and underwent a standard physical examination. The MINI and the Family History Research Diagnostic Criteria (FHRDC) interview were administered to exclude any psychiatric diagnosis in the subjects (except for PD in the patient group) or in their first-degree relatives.

All women were tested in the follicular phase of their menstrual cycle. Subjects were told to smoke as little as possible on the test day, as nicotine activates the HPA-axis at physiologically relevant doses. Subjects were not told to refrain from cigarette smoking as complete abstinence can evoke a cortisol increase as well (Hughes et al, 1988). All subjects were told that they would receive an air inhalation and a $35 \% \mathrm{CO}_{2}$ inhalation on different occasions. They were informed that the $\mathrm{CO}_{2}$ inhallation could evoke symptoms such as hyperventilation, dizziness, palpitations, and, depending on the individual vulnerability, symptoms of anxiety. These symptoms would subside within a matter of minutes. The words 'panic attack' were avoided. The local medical ethics committee approved the study, and written informed consent was obtained from all participants before participation.

\section{Procedure}

The participants arrived at the laboratory at 13.00. The experiment was performed in the afternoon to avoid the irregular secretory pattern of the HPA-axis in the morning hours. Upon arrival, an intravenous catheter was inserted into the forearm. After half an hour of habituation, the first blood and saliva samples were taken. Saliva was collected using cotton dental roles (Salivette (B), Sarstedt, Nümbrecht). Directly before the inhalation, the next samples were taken. At 14.00, subjects were given the inhalation. The study was performed according to a fixedorder, double-blind design, with the placebo inhalation always given on the first test day. "The placebo inhalation consisted of $80 \% \mathrm{~N}_{2}$ and $20 \% \mathrm{O}_{2}$, whereas the active inhalation consisted of $35 \% \mathrm{CO}_{2}$ and $65 \% \mathrm{O}_{2}$. All subjects had to inhale at least $80 \%$ of their vital capacity to consider the inhalation valid. The inhalation procedure has been described in detail before 
(Griez et al 1990). Following the inhalation, physiological and psychological symptoms were assessed using the Visual Analogue Scale of Anxiety (VAAS), the Panic Symptom List (PSL), the State Trait Anxiety Inventory for state anxiety (STAI-1), and the Profile of Mood States (POMS) (McNair et al 1971). Subjects had to recall the worst moment following the inhalation. An increase in at least four physical symptoms of the PSL, together with an increase of at least 25 units on the VAAS, were used as criteria for an experimental PA (Verburg et al 2001). In addition to baseline samples, saliva and blood were sampled 15,30, and 60 minutes following the inhalation to assess both cortisol and ACTH. Additional samples were taken at 45,90, and 120 minutes post-inhalation to determine cortisol levels. At every point in time, the questionnaires were filled out as well. Saliva was stored at $-20^{\circ} \mathrm{C}$ until analysis. Direct radioimmunoassay using the ${ }^{125}$ I-cortisol and antiserum against the $3-\mathrm{CMO}-\mathrm{BSA}$ conjugate was used to determine cortisol levels. The mean intra-assay coefficient of variance was $4.8 \%$. Blood was centrifuged at $3000 \mathrm{rpm}$ for 10 minutes at $4^{\circ} \mathrm{C}$. Serum was stored at $-20^{\circ} \mathrm{C}$ and EDTA plasma at $-80^{\circ} \mathrm{C}$ until analysis. Serum cortisol levels were determined using a luminescence immunoassay (LIA; Chiron Diagnostics, Fernwald, Germany). ACTH levels were determined using a two-site enzyme-linked immunosorbent assay (ELISA; Biomerica, Newport Beach, California). The sensitivity of this assay was $0.46 \mathrm{pg} / \mathrm{mL}$. The mean intra-assay coefficient of variance was $3.7 \%$.

\section{Statistical analyses}

Salivary cortisol and ACTH values were transformed using the natural logarithm in order to approach normality of the data. Statistical analyses were performed using general linear models (GLM) for repeated measurements (SPSS 10 for Windows) with time as within-subjects factor ( 7 levels) and group (patient or control) as between-subjects factor. The within-group effects were also compared using a GLM, with both time and condition as within-subjects factors. Greenhouse-Geisser correction was used when appropriate. Baseline samples were compared using the $t$-test for independent samples. The number of PAs was calculated for each condition and was analyzed using the chi-square test. Post-challenge scores on the VAAS, PSL, STAI, and POMS in the placebo and $\mathrm{CO}_{2}$ conditions were compared using the Mann-Whitney U-test for nonparametric data sets or with Student's $t$-test for independent samples, depending on whether distributions were normally divided, as assessed with the one-sample KolmogorovSmirnov goodness-of-fit test. Increases in VAAS, PSL, STAI, and POMS scores within the groups were analyzed using the Wilcoxon signed rank test or with Student's $t$-test for paired samples, also depending on the normality of the distributions of the different variables.

\section{Results}

\section{Behavional effects}

The $35 \% \mathrm{CO}_{2}$ challenge induced a significant increase in subjective anxiety in both the patient group and the control group as measured with the VAAS (patients: $Z=-3.30 ; p=0.001$, controls: $Z=-3.06 ; p=0.002)$, with the patient delta scores being significantly higher $(Z=-$ $2.50 ; p=0.012$ ). The median scores in the patient group increased from 4 units pre-challenge to 51 units post-challenge. In the control group, there was an increase from 0 to 15 units. The PSL data showed a somewhat different pattern (increase patients: $Z=-3.41 ; p=0.001$; increase 


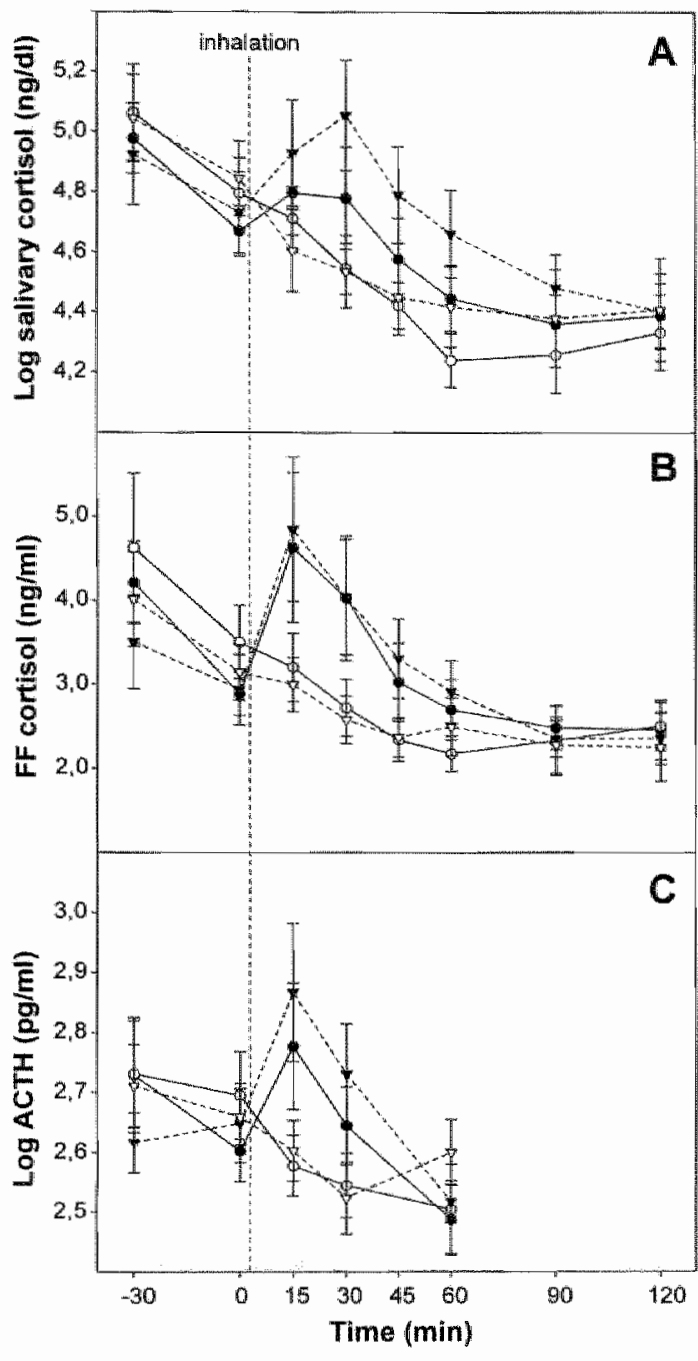

Figure 1. Effects of $35 \% \mathrm{CO}_{2}$ and placebo inhalation on salivary cortisol, free fraction serum cortisol and adrenocorticotropic hormone levels in panic disorder $(\mathbb{P D})$ patients and healthy volunteers. Data are mean \pm sem. Values on the challenge day were increased compared to values from the placebo day in both groups. No differences were found between the responses of the patient and the control group. $=\mathrm{PD}$ $\mathrm{CO}_{2} ; \mathrm{O}=$ PD placebo; $\mathbf{\nabla}=$ control $\mathrm{CO}_{2} ; \nabla=$ control placebo. controls: $Z=-3.52 ; \mathrm{p}<0.001)$. The difference in symptoms induced by the $35 \% \mathrm{CO}_{2}$ inhalation between patients and controls was not statistically significant ( $Z$ $=-1.36 ; p=0.17$ ). In both groups there was an increase in physical symptoms. In the patient group there was an increase from score 1 before the inhalation to 14 afterwards; in the control group, this was 0 and 11 , respectively. In the patient group $13 \mathrm{PAs}(81 \%)$ were reported versus 4 $(25 \%)$ in the control group. This difference was statistically significant $\left(\chi^{2}\right.$ $=10.17 ; \mathrm{p}=0.001$ ).

STAI scores approached a normal distribution (Kolmogorov-Sminov $\mathrm{Z} z$ $1.14 ; p \geq 0.15)$. On the placebo day, the scores following the inhalation were not increased in either the patient group $\left(t_{15}=\right.$ $-1.096 ; p=0.290)$ or the control group $\left(t_{15}\right.$ $=-1.546 ; \mathrm{p}=0.143)$, compared to the scores directly before the inhalation. On the second test day, the $35 \% \quad \mathrm{CO}_{2}$ inhalation significantly increased STAI scores in both groups (patients: $t_{15}=$ $5.080 ; \mathrm{p}<0.01$, controls: $t_{15}=-6.037 ; \mathrm{p}<$ 0.01). Before both inhalations, patient STAI scores were significantly higher than control scores (air: $\mathrm{t}_{20.6}=-3.377 ; \mathrm{p}=$ $0.003,35 \% \quad \mathrm{CO}_{2}: t_{30}=-0,-3.389 ; \mathrm{p}=$ 0.002 ). Following the $35 \% \mathrm{CO}_{2}$ inhalation, STAI scores were not significantly different $\left(\mathrm{t}_{30}=-0.779 ; \mathrm{p}=0.442\right)$.

\section{Cortisol}

We found an increase in salivary cortisol levels induced by the $35 \% \mathrm{CO}_{2}$ inhalation as compared to the placebo inhalation in both the patient group $\left(F_{2.22}=3.21 ; p=\right.$ $0.052)$ and the control group $\left(F_{2.35}=5.58\right.$; $p=0.007)$. There were no baseline differences. Comparing the reactions of the patient and the control groups, the interaction term "time * group" was not significant in either the $\mathrm{CO}_{2}$ condition 
$\left(\mathrm{F}_{2.29}=1.07 ; \mathrm{p}=0.36\right)$ or the placebo condition $\left(\mathrm{F}_{2.60}=1.13 ; \mathrm{p}=0.34\right)$ when looking at the salivary cortisol data.

Total serum cortisol values yielded similar results; no differences were found in the cortisol response following the $35 \% \mathrm{CO}_{2}$ inhalation between $\mathrm{PD}$ patients and healthy controls. However, considering the patient data, the difference between the $\mathrm{CO}_{2}$ and the placebo test day was significant $\left(\mathrm{F}_{2.18}=5.07 ; \mathrm{p}=0.013\right)$. Furthermore, there was a difference between the baseline values of the placebo and the $\mathrm{CO}_{2}$ test day in the patient group. The placebo day was always first. The increased values on this test day seem to be related to novelty effects.

Free fraction serum values represent the biologically active fraction and should correspond closely to salivary cortisol values. Indeed, there was no difference between PD patients and healthy controls in the cortisol response to the $35 \% \mathrm{CO}_{2}$ inhalation $\left(F_{1.48}=0.15 ; \mathrm{p}=0.79\right)$ or to the placebo inhalation $\left(\mathrm{F}_{2,57}=0.97 ; \mathrm{p}=0.41\right)$. Overall, we did not find any evidence for an increased secretion of cortisol following $\mathrm{CO}_{2}$ inhalation in $\mathrm{PD}$ patients compared to healthy controls. PD patients showed an increased cortisol response following the $35 \% \mathrm{CO}_{2}$ inhalation compared to the air inhalation $\left(F_{1.45}=3.68 ; p=0.063\right)$. In the patient group baseline free fraction cortisol values were significantly higher on the placebo day than on the $\mathrm{CO}_{2}$ inhalation day $\left(\mathrm{t}_{13}=2.46 ; \mathrm{p}=0.028\right)$. An increase was also found in the control group $\left(\mathrm{F}_{2.65}=3.87 ; \mathrm{p}=\right.$ $0.024)$, although in this group there were no baseline differences $\left(t_{15}=0.52 ; p=0.61\right)$.

A second analysis compared the cortisol response of the panickers and the non-panickers. Although most PD patients react quite strongly to $35 \% \mathrm{CO}_{2}$ inhalation, it is known that some patients react to a lesser extent. Using the criteria for a PA, not all of the patients experienced a PA following the inhalation. On the other hand, some of the control subjects did. In order to assess the effect of a PA on HPA-axis activation, all subjects who experienced a PA, both patients and controls, were grouped and compared with the non-panickers, both patients and controls. There was no difference in cortisol response between the panickers and non-panickers $\left(F_{1.46}=0.92 ; p=0.38\right)$ based on the free fraction serum cortisol values.

\section{ACTH}

In both the patient and the control groups we found an increase in ACTH levels induced by the $35 \% \mathrm{CO}_{2}$ inhalation as compared to the placebo inhalation. It reached significance in both the patient group $\left(\mathrm{F}_{1.83}=5.32 ; \mathrm{p}=0.014\right)$, and in the control group $\left(\mathrm{F}_{1.79}=7.73 ; \mathrm{p}=0.003\right)$. There was no significant difference in the interaction term 'time * group' between patients and controls in either the $\mathrm{CO}_{2}$ condition $\left(\mathrm{F}_{1.62}=0.17 ; \mathrm{p}=0.80\right)$ or the placebo condition $\left(\mathrm{F}_{1.87}=\right.$ $1.50 ; p=0.23)$. There were no baseline differences between patients and controls on either of the days or within the two groups when comparing the placebo and the $\mathrm{CO}_{2}$ test days. The within-group effects were also compared using a GLM, with both time and condition as withinsubjects factors. 


\section{Discussion}

The present study shows that $35 \% \mathrm{CO}_{2}$ inhalation induces IPPA-axis activation both at the pituitary level and at the adrenal level. Increases in ACTH and cortisol were apparent in both PD patients and healthy volunteers. However, despite marked differences in subjective anxiety and the occurrence of PAs, the HPA-axis response showed no difference between the two groups.

Peak values for $\mathrm{ACTH}$ and cortisol were both found at 15 minutes following the inhalation. For cortisol values, this is the normal time frame in which peak values can be measured in venous blood. Our first measurement was performed 15 minutes following the $35 \% \mathrm{CO}_{2}$ inhalation, for technical reasons. As the pituitary is directly connected to the hypothalamus by the infundibulum, the ACTH peak is most commonly measured within 10 minutes following acute stress induction (Koszycki et al 1998; Zwanzger et al 2001). Therefore, one can expect ACTH levels to reach even higher values than those that were measured.

Free fraction serum levels showed a clear increase following $\mathrm{CO}_{2}$ inhalation in both groups. Serum and salivary cortisol levels showed very good correlations. The use of free fraction serum cortisol is preferred in cases of small groups or subtle differences. As the action of venapunction itself can evoke HPA-axis activation, in some instances the collection of saliva may be preferable. However, especially in cases where blood sampling is already implemented in the protocol for determining other variables, it is recommended that serum be collected for more accurate cortisol determination.

From the above we can conclude that cortisol and ACTH values were increased in both PD and healthy control subjects following $35 \% \mathrm{CO}_{2}$ inhalation. However, from a clinical point of view, the magnitude of these responses is not very impressive.

In sharp contrast to the modest cortisol and ACTH response in both groups, subjective anxiety scores, as measured with the VAAS, were significantly higher in patients than in controls following the $35 \% \mathrm{CO}_{2}$ inhalation. This significantly higher level of anxiety was not translated into higher cortisol or ACTH levels. Taking into account the classical theories of stress, it might seem counterintuitive that panic is not accompanied by strong HPA-axis activation.

Naturally occurring PAs can be considered as stressors, even traumatic stressors, according to some authors (McNally and Lukach 1992). As one would expected, such stressors should trigger robust ACTH and cortisol release. Yet, this is obviously not the case. It is conceivable that the HPA-axis becomes subsensitized in PD patients in the course of time. In other words, following the first PAs the HPA-axis might still respond strongly, but subsensitization may occur progressively after repeated exposure. Desensitization of the HPA-axis is not an uncommon phenomenon in anxiety. People suffering from post-traumatic stress disorder (PTSD) exhibit chronically decreased cortisol levels (Yehuda 2002), even though, cortisol levels in this disorder are initially increased (Delahanty et al 2005; Delahanty et al 2003). In the current study, patients had suffered from PD for an average for 10 years, a period of time long enough for desensitization processes to have taken place.

The former explanation assumes that strong HPA-axis activation would initially be the normal reaction following panic, but there is yet another possibility. Different stress response systems have been shown to be initiated by different stressors. Some of the most convincing evidence for distinctive neuroendocrine stress response patterns is provided by differences in the activation of the adrenomedullary and sympathoneural systems in response to different stressors 
(Pacak 2000). The activation of other systems, such as the noradrenergic system, with or without an elevation in HPA-axis activation, may also reflect a stress-induced disturbed homeostasis. In fact, Coplan et al. (1995) suggested uncoupling of the HPA-axis and the noradrenergic system in PD. Overall, and according to the present results, it appears that panic does not induce the classic fight-flight response, as expressed by major increases in HPA-axis activation. In addition, a definite noradrenaline response has been found following $35 \% \mathrm{CO}_{2}$ inhalation (Kaye et al 2004). This might support the hypothesis that another, no less important, stress system, such as the noradrenergic system, could be involved. We still need to find ways to determine whether the neuroendocrinological response of a PA is originally accompanied by strong HPA-axis activation or whether another stress pathway is involved in this reaction. Studies of subjects who recently experienced their first PA may be one way to approach this problem. Prospective studies of subjects at a higher risk of developing PD, such as first-degree relatives of PD patients, could be an important strategy in this regard.

The present study shows that experiencing panic does not add to the HPA-axis activation induced by $35 \% \mathrm{CO}_{2}$ inhalation. However, since $35 \% \mathrm{CO}_{2}$ inhalation did induce HPA-axis activation in both the patient and the control groups, we can now confirm that a $35 \% \mathrm{CO}_{2}$ inhalation does induce HPA-axis activation in healthy volunteers, even though the anxiety levels induced in those subjects are minimal. Despite earlier negative findings from our group (van Duinen et al 2004b), the results of the present study, which include both salivary and serum cortisol, as well as ACTH values, are in line with the most recent studies on HPA-axis activation following $35 \% \mathrm{CO}_{2}$ inhalation (Argyropoulos et al 2002; Kaye et al 2004). Moreover, with the current study we replicate and extend our latest findings (van Duinen et al 2005). It seems that the disturbance in homeostasis caused by $35 \% \mathrm{CO}_{2}$ inhalation induced hypercapnia induces HPA-axis activation in both patients and healthy controls. Other provocative agents that have been used to study panic or anxiety in the laboratory have delivered mixed results. Caffeine (Klein et al 1991; Lin et al 1997), m-CPP (Germine et al 1994) and yohimbine (Gurguis et al 1997) induce cortisol secretion. Infusion of CCK or its synthetic analogue, pentagastrin, has been reported not to induce cortisol release in PD by some authors (Strohle et al 2000; van Megen et al 1996), but most have found increased cortisol levels in both PD patients and healthy controls (Abelson et al 1994; McCann et al 1997; Wiedemann er al 2001). On the other hand, studies using classic panic induction with sodium lactate infusion quite consistently found that panic is not accompanied by marked increases in cortisol levels (Liebowitz et al 1985; Targum 1992). In addition, low concentration $\mathrm{CO}_{2}$ challenges, mostly $5 \%$ or $7 \%$, show no HPA-axis response either (Sasaki et al 1996; Sinha et al 1999; Woods et al 1988). According to Klein (1993), these last two challenge methods elicit a state close to the distinctive spontaneous panic in PD. Failure of a cortisol response to occur would be a characteristic feature of panic. Provocative agents that do induce HPA-axis activation would be more similar to fear. Since the current study shows a cortisol increase, if we were to strictly follow this definition, a $35 \% \mathrm{CO}_{2}$ inhalation would not be a true panicogen. However, if the cortisol response found in the current study is attributed to fear, it would seem contradictory for a similar response to be found in control subjects who report low levels of fear.

It is worth noting that stress has been equated with HPA-axis activation to the extent that stress would be an occasion on which the HPA-axis is activated (Ganong 1995). If we use this definition, the inhalation of high $\mathrm{CO}_{2}$ concentrated gas could be considered a stress test and could be used to study the stress response in humans as suggested by Kaye ef al. (2004). 
In conclusion, the current study shows that $35 \% \mathrm{CO}_{2}$ inhalation induces $\mathrm{HPA}$-axis activation both in PD patients and in healthy controls. However, the significantly higher level of anxiety in patients was not accompanied by higher ACTH or cortisol values in this group. This is a potentially important finding in light of the discussion regarding the underlying mechanisms of panic. The finding that these neurohormones do not distinguish between panicking patients and non-panicking controls points to the possibility that HPA-axis activation is not characteristic for panic. Future research should focus on alternative mechanisms underlying panic and HPAaxis functioning in the early stages of PD. 


\section{References}

Abelson JL, Nesse RM, Vinik AI (1994). Pentagastrin infusions in patients with panic disorder. HI. Neuroendocrinology. Biol Psychiatry 3:644-96.

Argyropoulos SV, Bailey JE, Hood SD, Kendrick AH, Rich AS, Laszlo G, et al (2002). Inhalation of 35\% CO(2) results in activation of the HPA axis in healtthy volunteers. Psychonewroendocrinology 27:715729 .

Coplan JD, Pine D 5 Papt L, Martinez J, Cooper T, Rosenblum LA, Gorman JM (1995). Uncoupling of the noradrenergic-hypothalamic-pituitary-adrenal axis in panic disorder patients. Neuropsychopharmacology 13:65-73.

Deakin F, Graeff F (1991). 5-HT and mechanisms of defence. $J$ Psychopharmacol 5:305-315.

Delahanty DL, Nugent NR, Christopher NC, Walsh M (2005). Initial urinary epinephrine and cortisol levells predict acute PTSD symptoms in clvild trauma victims. Psychoneuroendocrinology 30:121-128.

Delahanty DL, Raimonde AJ, Spoonster E, Cullado M (2003). Injury severity, prior trauma history, urinary cortisol levels, and acute PTSD in motor vehicle accident victims. $J$ Amiety Disord 17:149-164.

Ganong WF (1995). The adrenal medulla \& adrenal cortex. In: Langan C (ed). Review of medical physiology. $17 / h$ ed. Appleton \& Lange: Norwalk, Conneticut. pp 327-351.

Germine M, Goddard AW, Sholomskas DE, Woods SW, Charney DS, Heninger GR (1994). Response to metachlorophenylpiperazine in panic disorder patients and healthy subjects: influence of reduction in intravenous dosage. Psychiatiy Res 54:115-133.

Gorman JM, Kent JM, Sullivan GM, Coplan JD (2000). Neuroanatomical hypothesis of patnic disorder, revised. Am J Psychiotiry 157:493-505.

Griez $\mathrm{E}$, de Loof C, Pols $\mathrm{H}$, Zandbergen J, Lousberg $\mathrm{H}$ (1990). Specific sensitivity of patients with panic attacks to carbon dioxide inhalation. Psychiatry Res 31:193-199.

Gurguis GN, Vitton BJ, Uhde TW (1997). Behavioral, sympathetic and adrenocortical responses to yolnimbine in panic disorder patients and normal controls. Psychiatry Res 71:27-39.

Heinrichs M, Baumgartner T, Kirschbaum C. Ehlert U (2003). Social support and oxytocin interact to suppress cortisol and subjective responses to psychosocial stress. Biol Psychiary 54:1389-1398.

Herman JP, Cullinan WE (1997). Neurocircuitry of stress: central control of the hypothalamo-pituitaryadrenocortical axis. Trends Neurosei 20:78-84.

Kaye J, Buchanan F, Kendrick A, Johnson P, Lowry C, Bailey J, et al (2004). Acute carbon dioxide exposure in healthy adults: evaluation of a novel means of investigating the stress response. I Neuraendocrinol 16:256-264

Kellner M, Knaudt K, Jahn H, Holsboer F, Wiedemann K (1998). Atrial natriuretic hormone in lactate-induced panic attacks: mode of release and endocrine and pathophysiological consequences. I Psychar Res $32: 37-48$.

Kirschbaum C, Hellhammer DH (1989). Salivary cortisol in psychobiological research: an overview. Neuropsychobiology 22:150-169.

Kirschbaum C, Pirke KM, Hellhammer DH (1993). The "Trier Social Stress Test--a tool for investigating psychobiological stress responses in a laboratory setting. Newropsychobiology 28:76-81.

Klein DF (1993). False suffocation alarms, spontaneous panics, and related conditions. An integrative hypothesis. Arch Gen Psychiatry 50:306-317.

Klein E, Zohar J, Geraci MF, Murphy DL, Uhde TW (1991). Anxiogenic effects of m-CPP in patients with panic disorder: comparison to caffeine's anxiogenic effects. Biol Psychiatry 30:973-984.

Koszycki D, Zacharko RM, Le Melledo JM, Bradwejn J (1998). Behavioral, cardiovascular, and neuroendocrine profiles following CCK-4 challenge in healthy volunteers: a comparison of panickers and nonpanickers. Depress Anxiey 8:1-7.

Liebowitz MR, Gorman IM, Fyer AJ, Levitt M, Dillon D, Levy G, et al (1985). Lactate provocation of panic attacks. II. Biochemical and physiological findings. Arch Gen Psychiary 42:709-719.

Lin AS, Uhde TW, Slate SO, McCann UD (1997). Effects of intravenous caffeine administered to healthy males during sleep. Depress Anxiety 5:21-28. 
McCann UD, Morgan CM, Geraci M, Slate SO, Murphy DL, Post RM (1997). Effects of the 5-HT3 antagonist, ondansetron, on the behavioral and physiological effects of pentagastrin in patients with panic disorder and social phobia. Neuropsychopharmacology $17: 360-369$.

McNair DM, Lorr M, Droppelman LF (1971). Mamal for the Profile of Mood States. Education and Industrial Testing Service: San Diego.

McNally RJ, Lukach BM (1992). Are panic attacks traumatic stressors? Am J Psychiatty 149:824-826.

Miller DB, O'Callaghan JP (2002). Neuroendocrine aspects of the response to stress. Metabolism $51: 5-10$.

Pacak K (2000). Stressor-specific actiwation of the hypothalamic-pituitary-adrenocortical axis. Physio/ Res 49 Suppl 1:S1 1-17.

Peskind ER, Jensen CF, Pascualy M, Tsuang D, Conwley D, Martin D, et al (1998). Sodium lactate and hypertonic sodium chloride induce equivalent panic incidence, panic symptoms, and hypernatrema in panic disorder. Biol Psychiatry 44:1007-1016.

Reynolds RM, Bendall HE, Whorwood CB, Wood PJ, Walker BR, Phillips DI (1998). Reproducibility of the low dose dexamethasone suppression test: comparison between direct plasma and salivary cortisol assays. Clin Endocrinol $(O x f)$ 49:307-310.

Sasaki I, Akiyoshi J, Sakurai R, Tsutsumi T, Ono H, Yamada K, Fuil I (1996). Carbon dioxide induced panic attack in panic disorder in Japan. Prog Newropsychopharmacol Biol Psychiary 20:1145-1157.

Sinha SS, Coplan JD, Pine DS, Martinez JA, Klein DF, Gorman JM (1999). Panic induced by carbon dioxide inhalation and lack of hypothalamic- pituitary-adrenal axis activation. Psychiatry Res 86:93-98.

Spielberger CD, Gorsuch RL, Lushene RE (1970). STAI Manual for the State-Trait Antiety Inentory. Consulting Psychologists Press: Palo Alto, California.

Strohle A, Holsboer F, Rupprecht R (2000). Increased ACTH concentrations associated with cholecystokinim tetrapeptide-induced panic attacks in patients with panic disorder. Neuropsychopharmacology 22:251. 256.

Targum SD (1992). Cortisol response during different anxiogenic challenges in panic disorder patients. Psychoneuroendocrinology 17:453-458

van Duinen MA, Schruers KR, Jaegers E, Maes M, Griez EJ (2004a). Hypothalamic-pituitary-adrenal axis function following a $35 \% \mathrm{CO}(2)$ inhalation in healthy volunteers. Prog Neuropsychopharmacol Biol Psychloty 28:279-283.

van Duinen MA, Schruers KR, Maes M, Griez EJ (2004b). Salivary cortisol in panic: are males more vulnerable? Newroendocrinology Letters 25:285-289.

van Megen HJ, Westenberg HG, Den Boer JA, Kahn RS (1996). The panic-inducing properties of the cholecystokinin tetrapeptide CCK 4 in patients with panic disorder. Eur Neuropsychopharmacol 6:187 194.

Verburg K, Pena G, Griez EJL (2001). A case study of the $35 \%$ CO2 challenge. In: Griez EJ, Faravelli $\mathrm{C}$, Nuti D, Zohar J(eds). Amatety disorders. An introduction wo clinical wanogemen and reseanch, Ist ed., Vol 1. John Wiley \& Sons, Itd: Chichester. pp 341-357.

Wiedemann $K$, Jahn $H$, Yassouridis A, Kellner M (2001). Anxiolyticlike effects of atrial natriuretic peptide on cholecystokinin tetrapeptide-induced panic attacks: preliminary findings. Arch Gen Psychiatry $58: 371$ 377.

Woods SW, Charney DS, Goodman WK, Heninger GR (1988). Carbon dioxide-induced anxiety. Behavioral, physiologic, and biochemical effects of carbon dioxide in patients with panic disorders and healthy subjects. Arch Gen Psychiaty 45:43-52.

Yehuda R (2002). Current status of cortisol findings in post-traumatic stress disorder. Psychiat Chin North Am 25:341-368, vii.

Zwanzger P, Baghai TC, Schuele C. Strohle A, Padberg F, Kathmann N, ef al (2001). Vigabatrin decreases cholecystokinin-tetrapeptide (CCK-4) induced panic in healthy volunteers. Newropsychopharmacology 25:699-703. 



\title{
CHAPTER 6
}

\section{Desynchrony of fear: phobic exposure is not stressful}

\begin{abstract}
Intuitively, phobic exposure seems to be a very stressful experience. However, it is not clear whether the characteristic feature of a classic stress response, activation of the thypothalamicpituitary-adrenal (HPA-) axis, is present in phobic fear. Some instances of phobic fear have found to be accompanied by robust increases in cortisol, whereas in other instances dissociation between subjective-behavioural arousal and the HPA-axis was found, also referred to as desynchrony of fear. The current study aimed to test the hypothesis that phobic fear is similar to normal fear and as such is accompanied by a robust increase in cortisol values.

Sixteen spider phobic subjects and sixteen healthy controls participated in the study. During and following a standardised step-wise exposure paradigm saliva samples were collected for cortisol determination. In contrast to the controls, the spider phobics reacted with a strong fear reaction to the spiders. However, cortisol levels remained unaffected.

In case of exposure, the phobic response does not resemble a classic fight flight response. It is suggested that the HPA-axis response has extinguished in modern man. Yet, it is possible that phobic fear is not a derivative of an ancient fear, but rather is a separate entity relying on other neuroendocrinological systems.
\end{abstract}




\section{Introduction}

Specific phobias are characterised by a circumscribed, persistent, and unreasonable fear of a particular object or situation. Exposure to the phobic stimulus induces an acute and severe emotional reaction and has shown to be accompanied by activation of the autonomic nervous system (Fredrikson, Sundin, \& Frankenhaeuser, 1985). With the exception of the irrationality, phobic fear largely resembles normal fear. Fear has been defined as the emotional response when encountering a clearly identified threat. When the threat is imminent, fear can motivate defensive behaviour known as the classical stress response, or fight and flight response (Rosen \& Schulkin, 1998). During phobic exposure, fear is induced by presenting a phobic stimulus, in other words, by exposure to a stimulus that is perceived as an imminent threat. Characteristic of the normal stress response is activation of the hypothalamic-pituitary-adrenal (HPA)-axis (Ganong, 1995). Affective arousal has also shown to induce HPA-axis activation (Codispoti et al., 2003). Activation of the HPA-axis therefore seems to be an obvious response to phobic exposure.

Surprisingly few investigations have been performed that studied HPA-axis activation in phobia. One specific phobia that received attention with regard to HPA-axis activation is driving phobia. Women suffering from this specific type of phobia showed indeed statistically significant increased cortisol release during exposure as compared to matched control subjects (Alpers, Abelson, Wilhelm, \& Roth, 2003).

Studies in social phobia found normal HPA-axis functioning in basal conditions (Uhde, Tancer, Gelernter, \& Vittone, 1994). Confrontation of socially phobic subjects with their relevant stimulus using social stress paradigms, induced a significant cortisol release that was similar in social phobics and control subjects (Martel et al., 1999). In other words, it appears that despite the marked difference in distress, there was no difference in activation of the stress-axis. In the past, dissociation between subjective-behavioural arousal and the HPA-axis has been referred to as "desynchrony of fear" (Curtis, Nesse, Buxton, \& Lippman, 1978), which indeed seems an appropriate term to describe this psychophysiological dissociation.

To answer the question whether phobic fear evokes HPA-axis activation, social phobia and driving phobia might not be ideal candidates. Social fear is the result of complex social interactions, expectations and former experiences, which might obscure the direct effects of exposure. Likewise, in driving phobia different aspects might be involved, among which social fear and anticipatory anxiety. In any case, fear for driving can not considered to be the classic primitive, innate response to a threatening situation.

In small animal phobias, fear is consistently evoked by a clearly specified animal, yielding quite a homogeneous condition. Specific phobias such as spider phobia (SP), have been explained by an evolutionarily determined biological preparedness (Ohman \& Mineka, 2001). In this view, situations are feared whose avoidance is likely to be associated with improved survival in evolutionary history. By natural selection, fear of these evolutionary dangers is supposed to be genetically coded (Seligman, 1971). In phobic persons, this fear is assumed to evoke a primitive fight flight response, characterised by HPA-axis activation.

Exposure in spider phobics is a simple paradigm that can be fully standardised with minimal interference of social aspects. It provides a straightforward possibility to test the premisses of HPA-axis activation during phobic exposure. In the current study, a stepwise exposure paradigm was used, during which saliva was collected for cortisol determination as an index of HPA-axis activity. 


\section{Methods}

\section{Subjects}

Sixteen spider phobic subjects (age: $28.8 \pm 11.1$ years; 15 females) free from any other psychiatric diagnosis or chronic physical disorder were included in the present study. Spider phobia was assessed using the MINI International Neuropsychiatric Interview (MINI; (Sheehan, Lecrubier, Janaws, Knapp, \& Weiller, 1994)). Assessment of spider phobia was supported by the Spider Phobia Questionaire (SPQ) and the Fear of Spiders Questionaire (FSQ). A score of minimally 14 on the SPQ was required in order to be included. The Spielberger Anxiety Inventory (State and Trait version) (Spielberger, Gorsuch, \& Lushene, 1970) was filled out to assess the general anxiety level not related to spiders. The control group was matched for gender and age (age: $27.4 \pm 8.7 ; 15$ females). Consumption of caffeinated beverages was not allowed on the test day, and subjects were instructed to smoke as little as possible, and had to be free of psycho-active medication. Subjects were recruited by advertisements in a local newspaper and mouth-to-mouth information. Both the control group and the patient group received a small fee upon participation.

Both oral and written information was provided to the subjects before participation. Stepwise exposure was chosen out of ethical considerations and to lower anticipatory anxiety. Subjects were explicitly told that they could choose not to continue to the next exposure when they felt they were too frightened. The local medical ethics committee approved the study and written informed consent was obtained from all subjects before participation.

\section{Procedures}

The participants arrived at the laboratory at $10.45 \mathrm{am}$. Upon arrival subjects had to fill out the STAI-1 to assess their baseline anxiety level. Next, the neutral stimulus was presented (landscape pictures). Shortly after first exposure, subjects were asked to mark their level of fear using a Visual Analogue Scale of fear (VAS-fear). After the 2 minute exposure period, a saliva sample was taken for cortisol determination using cotton dental roles (Salivette B, Sarstedt, Germany). This procedure was repeated five times thereafter with spider-related items. First, pictures of spiders were presented, then a small spider in a small transparent lidded container, then the same spider was placed in an open plastic basin for the next step of exposure. The latest two conditions were then repeated with a large domestic spider. The exposure protocol was standardised with each spider related exposure period lasting for ten minutes. Shortly after first exposure, the intensity of experienced fear was measured using VAS-fear. Following each step of exposure there was a two minute interval for saliva collection. In total, subjects were exposed for one hour. Following the last exposure, the spiders were removed from the test room and the subject remained seated for another hour. In this hour saliva samples were collected every 15 minutes. Since anticipatory anxiety could increase baseline cortisol values (Lacey et al., 2000), another two samples were taken 24 hrs before and 24 hrs following the exposure. Subjects were instructed to postpone the sampling for one day when they were in a stressful situation.

Saliva was stored at $-20^{\circ} \mathrm{C}$ untill analysis. Direct radioimmunoassay using the ${ }^{125}[-$ cortisol and antiserum against the 3-CMO-BSA conjugate was used to determine cortisol levels. The mean intra assay coefficient of variance was $4.8 \%$. 


\section{Statisfics}

To normalise salivary cortisol distributions and to stabilise variances as required for statistical procedures, natural log trans formations were applied. After transformation, distributions were nomal as assessed with one-sample Kolmogorov-Smirnov goodness of fit tests. Statistical analyses were performed using General Linear Models (GLM) for repeated measures (SPSS 10 for Windows) with Time (10 levels) as within subjects factor and Group ( 2 levels) as between subjects factor for the cortisol data. VAS-fear data were also analysed with GLM for repeated measures with Exposure (6 levels; various spider conditions) as within subjects factor and Group (2 levels) as between subjects factor. Greenhouse-Geisser correction was always applied. Bonferroni posthoc multiple comparisons were applied to determine during which exposure conditions differences between patients and controls were significant. Scores on the FSQ, SPQ, and STAl of the two groups were compared using the Mann-Whitney U test or student's t-test depending on the normality of the data distribution as assessed with one-sample KolmogorovSmirnov goodness of fit tests. Spearman correlation was used to describe the strength of the relationship between questionnaires and between questionnaires and cortisol values.

\section{Results}

The spider phobic group showed statistically higher levels of fear of spiders than the control group as measured on both the SPQ $(z=-4.85 ; p<0.001)$ and the FSQ $(z=-4.67 ; p<0.001)$. The two questionnaires showed a good correlation $(\rho=.89)$. STAI- 1 scores were increased in the phobic group on the test day compared to the control group $(t=6.34 ; \mathrm{p}<0.001)$. This difference was also present during the screening both on STAI-1 and STAI-2 (STAI-1: $t=6.11$; $p<0.001 ;$ STAI-2: $t=3.26 ; p=0.003)$. STAI-1 values in phobics were not increased on the test day as compared to their values on the screening day $\left(\mathrm{t}_{15}=-1.57 ; \mathrm{p}=0.136\right)$.

VAS-fear data were log-transformed to approach normality of the data. The repeated measures analysis revealed a significant effect for Group $(F=48.51 ; \mathrm{p}<0.001)$ and Exposure $(\mathrm{F}=$ $207.67 ; \mathrm{p}<0.001$ ). The interaction effect between Group and Exposure was also significant ( $F$ $=25.0 ; p<0.001$ ). Bonferroni posthoe multiple comparisons indicated that both groups differed significantly during exposure to all five spider conditions (all values: $p<0.001$ ). Anxiety levels peaked during the last exposure where a large spider was placed in an open plastic basin. VASfear scores measured during this condition correlated significantly with both SPQ $(\rho=0.82)$ and FSQ scores $(\rho=0.88)$. VAS-fear scores during the neutral condition did not differ between phobics and the control subjects $(z=-1.00 ; p=0.32)$. All subjects completed the full exposure schedule. VAS-fear data are presented in figure 1. 


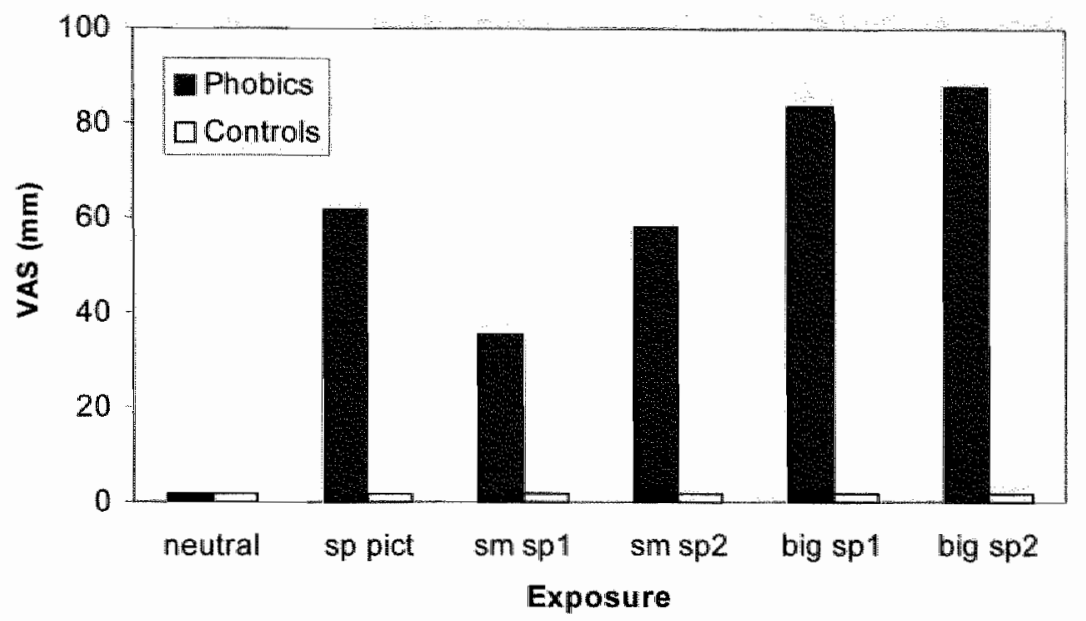

Figure 1. Subjective fear during exposure. Median VAS-fear scores are presented from spider phobic subjects and healthy controls during a stepwise exposure paradigm existing of six conditions: neutral = landscape pictures, $\mathrm{sp}$ pict $=$ spider pictures, $\mathrm{sm} . \mathrm{spl}=$ small spider condition 1 (transparant litted container), small spider condition 2 (open plastic basin), big $\mathrm{sp} 1=$ large domestic spider condition 1, big $\mathrm{sp} 2=$ large domestic spider condition 2 .

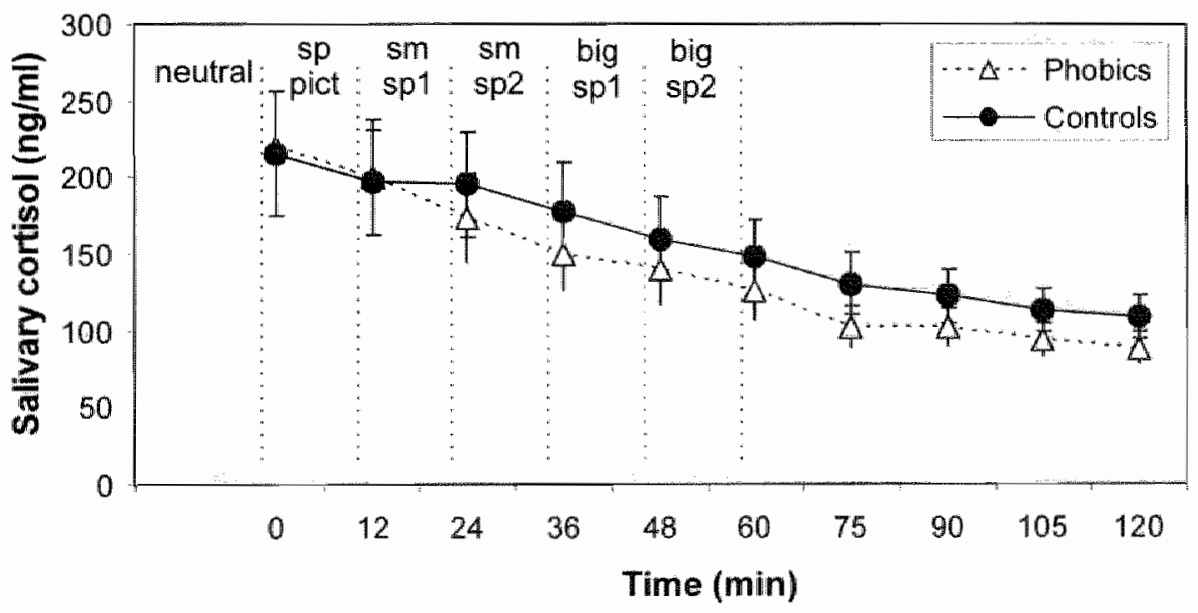

Figure 2. Salivary cortisol values (ng/ml) during spider-related exposure in spider phobics and Whealthy control subjects. Neutral = landscape pictures, sp pict $=$ spider pictures, $\mathrm{sm}$ sp $I=$ smail spider condition 1 (transparant litted container), small spider condition 2 (open plastic basin), big sp1 = large domestic spider condition 1, big $\mathrm{sp} 2=$ large domestic spider condition 2 . 
Baseline salivary cortisol values did not differ between the groups $\left(t_{30}=0.41 ; \mathrm{p}=0.687\right)$ and, within the spider anxious group, baseline salivary cortisol values on the test day did not differ from values $24 \mathrm{hr}$ before or after the test day $(\mathrm{F}=1.00 ; \mathrm{p}=0.38)$. Analysis of the salivary cortisol values during the test day showed no interaction effect between Time and Group when comparing the phobic group and the control subjects $(F=2.04 ; p=0.13$ ). No group effect was found $(\mathrm{F}=0.31 ; \mathrm{p}=0.58)$, but a significant time effect was found $(\mathrm{F}=52.24 ; \mathrm{p}<0.001)$. Cortisol values are presented in figure 2 . Correlation of cortisol values following the last exposure during which anxiety scores peaked, showed no significance directly following exposure $(\rho=-0.074)$, or 15 minutes later $(\rho=-0.18)$.

\section{Discussion}

During a standardised exposure paradigm including five steps, subjective fear, as measured on the VAS-fear, was significantly increased in spider phobic subjects as compared to matched controls. The level of fear in phobics was high, some of them describing it as the worst imaginable. Yet, salivary cortisol levels remained unaffected. This is counter-intuitive because phobic exposure obviously evokes affective arousal, and affective arousal has been shown to induce cortisol release (Codispoti et al., 2003). From a conceptual point of view, phobias may be considered as instances of fear-related behaviour induced by a proximal danger, i.e. the phobic stimulus. Behaviour triggered by a proximal threat includes the classic fight or flight stress-response with increased HPA-axis activation (Ohman \& Mineka, 2001; Selye, 1936). To this extent, our results suggest that phobic exposure is not stressful. Even though the spiders were perceived as aversive by the phobics, there was no increase in cortisol values.

In other words, the present study has found evidence which support the theory of desynchrony of fear in phobia. Originally, Curtis et al. (1978) described this phenomenon in a small sample of patients with specific phobia. Other authors (Fredrikson et al., 1985; Nesse et al., 1985) have also illustrated the concept of desynchrony of fear in phobia. In these studies cortisol values increased following phobic exposure. Evidence for desynchrony was derived from the lack of correlation between subjective distress and cortisol excretion. Dissociation between fear and HPA-axis activity in phobic situations has also been found in social phobia. (Martel et al, 1999; Uhde et al., 1994). Furlan et al. (2001) found a dichotomous change in social phobics with $39 \%$ of the phobics showing hypercortisolism following a social stress task, and the remaining subjects showing a decrease in cortisol values. This finding might be a manifestation of the heterogeneity of social phobia. A dichotomous reaction induced by a speeking task was also found by Levin et al. (1993), but this was only revealed by differences in heart rate. Cortisol values were not affected.

Stimuli that elicit fear in subjects with phobia such as spiders and social performance have in common that they are considered as aversive in many persons to some degree. Phobics however, show an exaggerated response. Spider phobia and social phobia have been explained from the same evolutionary perspective. Both are considered as defensive responses in reaction to respectively interspecific or intraspecific threat (i.e. from members of other or from one's own species) that inappropriately persisted in vulnerable subjects (Ohman \& Mineka, 2001). It has been suggested that these interspecific and intraspecific responses rely on the very same neural system (Blanchard \& Blanchard, 1988). It is remarkable then that, overall, social stress induces 
HPA-axis activation in practically all persons, whereas exposure to spiders apparently does not even exoke a HPA response in phobics. With regard to social phobia, evolutionary psychology assumes that modern humans need to be liked, valued, and approved in order to elicit parental investment, develop supportive peer relationships, attract desirable mates, and engage successfully in many types of social relationships (Ohman \& Mineka, 2001). This makes social fear a very relevant motivational state even in modern humans. In contrast, throughout the ages, fear for spiders, and in general all interspecific threats, have become less pertinent for humans. Putatively, in modern man, there is an ongoing process of progressive extinction of those phylogenetically ancient fears. The disappearance of the HPA component may be a forerunner of this process.

Phobias with ontogenetically relevant contents have received less attention than those with phylogenetically contents. While it is conceivable that the HPA-axis response in phobias with an evolutionarily important content has extinguished, it would be expected that this response is present in phobias with a ontogenetically content. Alpers et al. (2003) found a significant rise in salivary cortisol values in driving phobics during driving exposure. It was suggested that the increase was related to the fact that driving phobia is a situational phobia, which would be more akin to contextual cue-related fear, where the cue-threat link is less explicitly perceived. However, the observed increase could also be the result of anticipatory anxiety, which is know to induce HPA-axis activation (Lacey et al., 2000). HPA-axis activation does not require homeostatic disruption signalled by primary sensory stimuli. Rather, a glucocorticoid response can be generated in anticipation of the homeostatic disruption itself(Herman \& Cullinan, 1997). In the study of Alpers et al. anxiety was clearly present before commencement of the actual exposure and driving exposure did not further increase cortisol levels, despite an increase in anxiety levels. A larger study in driving phobics found that the vast majority of the phobic subjects almost always experienced anxiety symptoms during driving (Ehlers, Hofmann, Herda, $\&$ Roth, 1994), implying that these symptoms become predictable and are prone to anticipatory anxiety. In our current study it is quite obvious that anticipatory anxiety did not interfere with HPA-axis activity as shown by similar cortisol levels on the test day and the days before and thereafter. Also, baseline levels of phobic subjects and controls were similar.

Another possibility, which could account for exposure-induced cortisol increases in driving phobia as well as in social phobia but not in spider phobia, is that phobic fear in the former disorders is related to performance. Fear is evoked in situations were action is required. The major function of the HPA-axis is to redirect bodily energy resources. Not only in cases of stress, but also in physical performance in general (Ganong, 1995; Herman \& Cullinan, 1997). This could partly explain cortisol release in the above described instances.

In conclusion, although in the current study significant levels of fear were specifically evoked in spider phobics using a standardised exposure paradigm, the stress-axis was not activated in these subjects as indicated by comparable salivary cortisol levels in phobics and controls. This questions the idea that phobic fear merely equals a defensive fight flight response and consolidates the theory on desynchrony of fear. Apparently, high levels of subjective distress are not necessarily accompanied by the classic stress-response, allowing us to state that phobic fear is not necessarily stressful. In normal fear, HPA-axis activation is evident. It remains to be elucidated whether the stress-response in interspecific phobias has become extinguished, or whether these phobias truly represent a separate entity with specific pathophysiological properties. 


\section{References}

Alpers, G. W., Abelson, J. L., Wilhelm, F.H., \& Roth, W. T. (2003). Salivary cortisol response during exposure treatment in driving phobics. Psychosom Med, 65(4), 679-687.

Blanchard, D. C., Blanchard, R. J. (1988). Ethoexperimental approaches to the biology of emotion. Anmu Rev Pisychol, 39, 43-68.

Codispoti, M., Gerra, G., Montebarocci, O., Zamovic, A., Raggi, M. A., \& Baldaro, B. (2003). Emotional perception and neuroendacrine changes. Psychophysiology. 40(6), 863-868.

Curtis, G. C., Nesse, R., Buxton, M., \& Lippman, D. (1978). Anxiety and plasma cortisol at the crest of the circadian cycletreappraisal of a classical hypothesis. Psychosom Med.40(5), 368-378.

Ehlers, A., Hofmann, S. G., Herda, C. A., \& Roth, W. T. (1994). Clinical characteristics of driving phobia. $J$ Anxiety Disord, 8, 323 339 .

Fredrikson, M., Sundin, O., \& Frankenhaeuser, M. (1985). Cortisol excretion during the defense reaction in humans. Pychosom Med, 47(4), 313-319.

Furlan, P. M., DeMartinis, N., Schweizer, E., Rickels, K., \& Lucki, I. (200I). Abnormal salivary cortisol levels in social phobic patients in response to acute psychological but not physical stress. Biol Psychiatry, $50(4), 254-259$.

Ganong, W. F. (1995). The adrenal medulla \& adrenal cortex. In C. Langan (Ed.), Review of medical physiology (17 ed., pp. 327-351). Norwalk, Conneticut: Appleton \& Lange.

Herman, J. P., \& Cullinan, W. E. (1997). Neurocircuitry of stress" central control of the hypothalamo-pituitaryadrenocortical axis. Trends Neurosci, 20(2), 78-84.

Lacey, K., Zaharia, M. D., Griffiths, J., Ravindran, A. V., Merali, Z, \& Anisman, H. (2000). A prospective study of neuroendocrine and immune alterations associated with the stress of an oral academic examination among graduate students. Psychoneturoendocrinology, 25(4), 339-356.

Levin, A. P., Saoud, J. B., Strauman, T., Gorman, J. M., Fyer, A. J., Crawford, R., et al. (1993). Responses of "Generalized" and "Discrete" social phobics during public speaking. J Anxiety Disord, 7, 207-221.

Martel, F. L., Hayward, C., Lyons, D. M., Sanborn, K., Varady, S., \& Schatzberg, A. F. (1999). Salivary cortisol levells in socially phobic adolescent girls. Depress Anxien, 10(1), 25-27.

Nesse, R. M., Curtis, G. C., Thyer, B. A., McCann, D. S., Huber-Smith, M. J., \& Knopf, R. F. (1985). Endocrine and cardiovascular responses during phobic anxiety. Psychosom Med, 47(4), 320-332.

Ohman, A. \& Mineka, S. (2001). Fears, phobias, and preparedness; toward an evolved module of fear and fear learning. Psychol Rev, 108(3), 483-522.

Rosen, J. B., \& Schulkin, J. (1998). From normal fear to pathological anxiety. Psychol Rev, 105(2), 325-350.

Seligman, M. E. P. (1971). Phobias and preparedness. Behav Ther, 2, 307-320.

Selye, H. (1936). A syndrome produced by diverse noxious agents. Noture, 32, 138.

Sheahan, D. Lecrubier, Y., Janavs, J., Knapp, E., \& Weiller, E. (1994) MNI International Neuropsychiatric Irverview. Tampa: University of South Florida.

Spielberger, C. D., Gorsuch, R. L., \& Lushene, R. E. (1.970). STA Manual for the State-Trait Anxiery Imemory. Palo Alto, Califomia: Consulting Psychologists Press.

Uhde, T. W., Tancer, M. E., Geletnter, C. S., \& Vittone, B. J. (1994). Normal urinary free cortisol and postdexamethasone cortisol in social phobia: comparison to normal volunteers. J Affect Disord, $30(3)$, $155-161$. 


\title{
CHAPTER 7
}

\section{Neuroimmunological parameters in Panic Disorder}

\begin{abstract}
The interaction between immune cells, neurotransmitters and the neuroendocrinological systems plays a role in affective disorders, especially depression. Although Panic Disorder (PD) shares a lot of features with depression, it clearly is a distinct disorder. Reports on immunological parameters in PD don't provide a clear picture of the immunological status of PD patients. This can partly be subscribed to methodological differences between studies and small patient groups. The present study aims to assemble all studies on immunological parameters in $\mathrm{PD}$ in order to combine all availlable data to gain a broader perspective on this matter. Pubmed was searched for studies describing immunological parameters in $P D$ patients without comorbid disorders, or medication use. All studies had to include a healthy control group and the outcome measures had to be shared by at least one other study.

Fourteen articles were found. Although the $\mathrm{T}$ lymphocytic branch and the innate immune system were normal, the B lymphocytic branch showed some differences between PD patients and healthy controls. B cell counts were increased in PD patients, which was underlined by increased human leucocyte antigen (HLA)-DR counts and increased immunoglobulin A levels. However, B cell activity following mitogen stimulation was normall.

PD patients show increased $B$ cell numbers. The finding that $B$ cell activity is not increased can possibly be subscribed to functional exhaustion of these cells. The meaning of this finding remains unclear, although it may be potentially important in affective disorders as the same has been found in depression.
\end{abstract}




\section{Introduction}

Research in several fields of human functioning has proved that functional systems can no longer be considered separate entities. For example, the nervous system and the immune system interact both at the anatomical level and at a functional levell. Taking this into consideration, one might expect that changes in one system will affect the activity of the other $(1,2)$. Sympathetic arousal plays a prominent role in Panic Disorder (PD) (3). One might suggest that this overactivity influences immune levels, or vice versa, that this increased catecholaminergic activity is partly a result of disturbances in immune functioning. However, the literature on immunological variables in PD is scanty and controversial and has not yet resulted in clear statements.

The assumption that PD patients show immune changes is partly based on research in the field of stress. Besides a more continuous tense feeling, the core of this disorder consist of panic attacks (PAs). Panic attacks are short periods of intense anxiety and there is no doubt that this is a very stressful event. Stress is known to induces immunological changes. For example, acute mental stress increased interleukin-6 (IL-6) and interleukin-1 receptor antagonist (II-1Ra) levels (4). Chronic stressors, such as bereavement, divorce, caring for a relative with a chronic disease, anticipation of academic exams also induce immunological changes in these parameters $(1,5-8)$. Concerning other psychiatric disorders, probably the most intensive work in the field of neuroimmunology has been conducted in depression, in which systemic immune alterations have been found. Early studies suggested that depression resulted in reductions in the nonspecific innate immunity as well as cell-mediated acquired immunity, regulated by $T$ helper cells. Herbert and Cohen (1993) performed a meta-analysis on the existing literature concerning the correlation between immunological parameters and depression. Only methodologically strong studies were included and all statistics were performed using the most conservative methods in order to provide the most reliable data. Clinical depression was found to be associated with decreases in all of the measures of lymphocyte function, including proliferative responses to phytohemagglutinin (PHA), concanavalin A (Con A) and pokeweed mitogen (PWM). In other words, the proliferative response in both $\mathrm{T}$ and $\mathrm{B}$ lymphocytes to mitogens is lowered, which points to a less effective functioning. NK cell activity was also found to be significantly lowered in these patients. Furthermore, a linear relationship between the intensity of depressive affect and immune system functioning was suggested. The enumerative immune outcomes showed some changes in depression as well. A higher number of circulating white blood cells was found, primarily neurophils and monocytes. The total number of lymphocytes was decreased in depression as were the numbers of the different lymphocyte types and the different $T$ cell types. The cluster of differentiation (CD) $4+$ to $C D 8+$ ratio was also lower. PD shares many of features with depression on several levels. Approximately two-thirds of PD patients suffer from at least one lifetime major depressive episode (9). Furthermore, both the serotonergic and catecholaminergic systems are affected in both these disorders (10). For these reasons it can be expected that in PD to some extent immune alterations will be comparable with the ones found in depression. However, PD and depression still remain two separate entities which is emphasized by the finding that depressed patients with comorbid PD showed different immune values than patients with depression alone (11). Apparently, the comorbidity of these two disorders results in an interaction at some level which contributes to the immunological variance. 
Besides the facts that PD patients experience particular stress in the form of PAs, and that PD shows overlap with depression, there's a third link between immune dysregulation and PD. An increased prevalence of atopic disorders, including asthma has been found in PD (12-14). Interestingly, there's preliminary evidence that $P D$ patients reporting allergy have found to have more full-blown PAs, a more severe symptomatology and their response to antidepressants is decreased compared to non-allergic PD patients (15). Moreover, in depression, an increased incidence of allergic disorders has been found as well (16).

The aim of the current paper is to review current studies on immunological variables in PD to resolve the discrepancies in immunological findings in PD. Furthermore, by placing all findings on immune parameters together it's possible to get a broader perspective on the relationship between immune status and PD.

\section{Methods}

A computerized search was performed (Pubmed 1960-2003) using the keywords: Immunology $[\mathrm{MESH}] /$ Immun $*$ *Immun* AND panic [MESH] or panic disorder [MESH]. Furthermore, the reference lists from existing reviews and from the retrieved articles were inspected. Only English-language articles were included which were published in peer-reviewed journals.

Drawing conclusions on the basis of the results of poorly designed studies is of questionable value. To proceed in the most conservative fashion, specific criteria were defined according to which studies had to be performed in order to be included in this review. Diagnosis of panic disorder should be made according to the Diagnostic and Statistical Manual of Mental Disorders (17). Furthermore, no comorbid psychiatric disorders are allowed to be present at the time of participation, and the study must include a healthy control group. The immunological outcome must be shared by at least one other study, and the patients needed to be drug-free for at least two weeks before participation. In order to work with an approach as conservative as possible, trend significant data is reported as 'no difference'. Furthermore, studies were excluded when the data concerned 'anxiety disorders" in general and when the results from the PD patients were not specified.

\section{Results}

Fourteen articles were found that met our inclusion criteria. All studies but one (18) included both male and female PD patients. The results section will consist of an overview of the findings described in the different articles.

\section{Enumerative parameters}

Total white count and lymphocyte count do not seem to be significantly different between PD patients and controls (19-22). One report of increased leukocyte counts exists, but the reported increases is not in a clinically relevant extent (23). The same study also found decreased lymphocyte numbers, but again clinically insignificant. Considering the lymphocyte subsets, Marazziti et al. (24) found a decrease in T heiper cells which was not confirmed by others (19, $21,22,25,26)$. Studies that performed cell counts on the second subset of lymphocytes, the B- 
lymphocytes, show more differences between PD patients and healthy volunteers, although not all in the same direction. Schleifer et al. (2002) found a decrease in B lymphocyte numbers, whereas in an earlier study they reported no differences in B lymphocyte levels as did Manfro et al. $(21,22)$. Two other studies report increased B lymphocyte values $(25,26)$. Decreased $T$ helper cell numbers were found by Marazziti et al. (24), but this was not confirmed in any other study $(19,21,22,25,26)$. Similar findings were reported for natural killer (NK) cell numbers; only one study reported different cell counts for PD patients (26), whereas others don't confirm the increased NK numbers $(19,21,22,25)$.

Four studies reported human leukocyte antigen (HLA)-DR counts. Two reported no difference $(19,24)$ and two reported increased HLA-DR counts $(25,26)$. The earliest study measuring HLA-DR cells in PD patients found no difference in HLA -DR numbers (24). This study included only ten PD patients and is the smallest study. Schleifer et al. (19) specifically reported that the HLA-DR cells they measured concerned T lymphocytes and found no difference. Rapaport et al. (26) found increased HLA-DR cell numbers as well as a greater number of cells bearing the combination of CD 19 and HLA-DR surface markers. Table 1 gives an overview of the findings described in this section.

Table 1. Enumerative immune findings in panic.

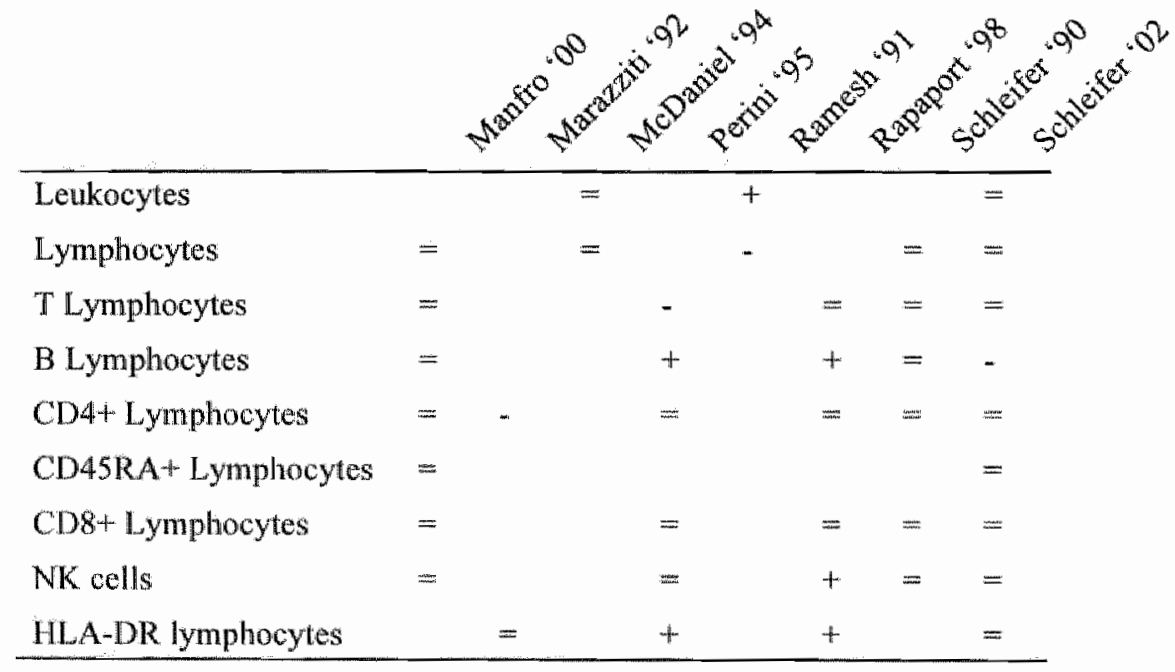

\section{Functional parameters}

Three studies examining mitogen proliferative responses in lymphocytes as a measure of immune functioning have reported no difference between $\mathrm{PD}$ patients and healthy controls (19, 27, 28). However, two other studies reported decreased proliferative responses in respectively ConA and PHA response $(21,29)$. The patient groups in the two studies reporting negative findings consisted of only $11 \mathrm{PD}$ patients. Schleifer et al. (21) reported lower proliferative responses in PD patients to PWM as well, but no comment was given whether this was a 
significant decrease. In another study of this group, a decreased proliferative response to PHA was found, but statistical significance was not reached (19).

Natural killer cell activity was found to be normal $(19,29)$ or increased $(20)$. A striking difference between these studies is that the mean scores on the Hamilton Depression Rating Scale (HDRS) were quite high in the study of McDaniel et al. (18.1), whereas in the study of Schleifer et al. these values were clearly lower (7.6) although still significantly increased compared to normal controls. Table 2 shows an overview of the results of the studies discussed in this section.

Table 2. Functional immune parameters in panic disorder.

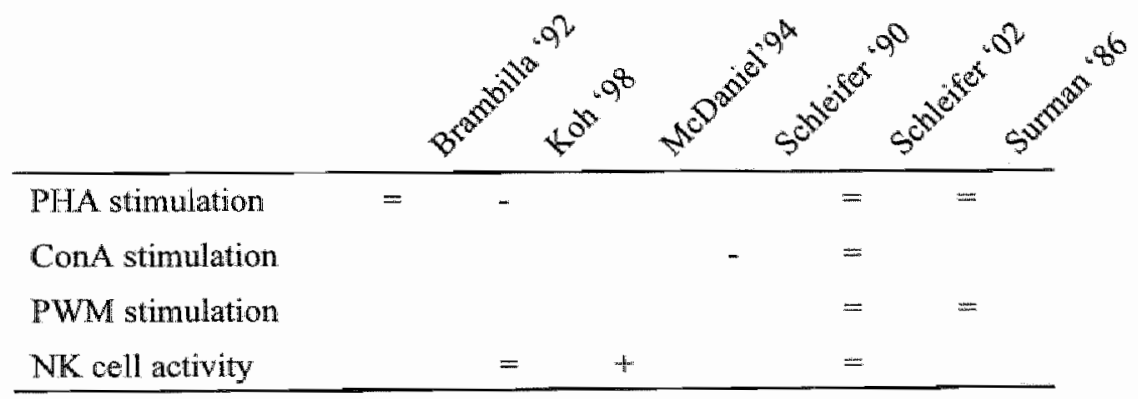

\section{Cytokines}

Two studies have measured IL- $\mathbb{\beta}$ in PD patients and found different results. However, different assays were used. Brambilla et al. (30) used the immunoradiometric assay (IRMA) and found increased $I L-1 \beta$ values, whereas Rapaport et al. (18) used an enzyme-linked immunosorbent assay (ELISA) and found no difference. Furthermore, the study of Rapaport et al. included only female subjects.

Three studies report IL-2 values, of which two report no differences $(18,31)$ and one study reported decreased IL-2 levels in PD patients compared to control persons (29). Both Koh et al. and Weizman et al. measured IL-2 levels following in vitro stimulation with PHA. All three studies measuring $\mathrm{IL}-2$ receptor reported no difference between $\mathrm{PD}$ patients and healthy controls $(18,22,26)$. These results are summarized in table 3 .

Table 3. Cytokine measurements in PD

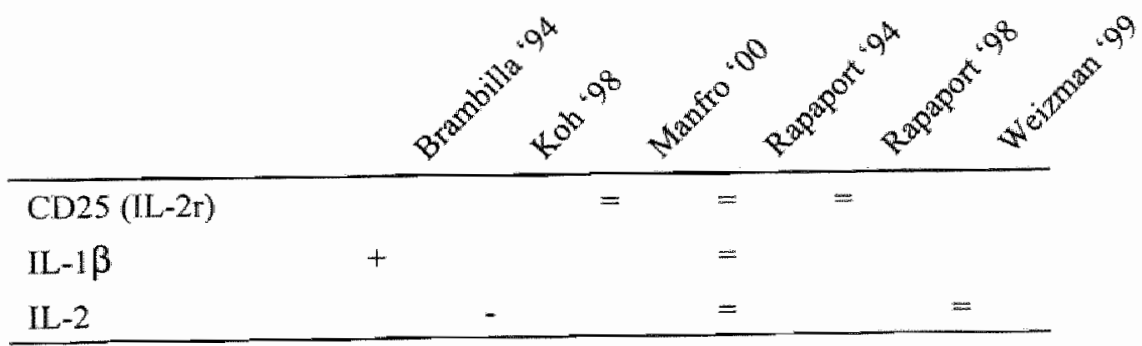




\section{Discussion}

The current review shows that the majority of studies show no clear differences on most of the immune parameters between PD patients and healthy volunteers. Only two parameters show clear increases in PD patients compared to healthy volunteers: B lymphocyte counts and HLADR cells were increased in PD patients compared to control subjects. We will shortly discuss all outcomes of this overview and focus on those parameters that did differ between those groups.

Most studies reported no differences in total lymphocyte count, T-lymphocyte count and Tlymphocyte subset counts. However, one remarkable finding was done by Marazziti et al. (24). Despite the fact that they had the smallest group of PD patients $(n=10)$, they described marked decreases in their CD4 counts. However, Marazziti et al. (1992) evaluated lymphocyte percentages, whereas the others evaluated the absolute numbers of T-lymphocyte, which could explain this aberrant finding. Overall, we can conclude that there are no robust changes in cell numbers in the branch of T-lymphocytic cells in PD patients.

Proliferative responses of T-lymphocytes following stimulation with ConA and PHA were reported to be decreased $(21,29)$ or unchanged $(19,27,28)$. The patient groups in the two studies reporting negative findings were very small consisting of only 11 PD patients, which has to be taken into account. Overall, the T-lymphocytic response to mitogen stimulation seems to be normal. Nevertheless, two studies have found increased HLA-DR cells $(25,26)$. An increased level of HLA-DR cells is suggestive of a general imbalance of immunocompetent cells. These markers are situated on activated $\mathrm{T}$ cells and in that way give direct information about in vivo $T$ cell activity. However, these markers are situated on $B$ cells as well. As increased $T$ cell activation has not been found in PD $(19,21,27-29)$, it seems that an increase in HLA-DR cells would rather be an indication of increased $B$ cell numbers.

The B lymphocytic branch does indeed show some alterations in PD patients. In fact, the two studies that found increased HLA-DR cell numbers $(25,26)$ found strong indications that these increased levels were related to $B$ cells. Rapaport et al. found cells bearing the combination of HLA-DR and CD19 to be increased, which indicates that the increased HLA-DR concentration can be explained by the relative increase in B cells. Perini et al. did not find an increase in cells bearing the CD3-DR surface marker, which is indicative for activated $T$ cells, and also found increased B cell numbers. Remarkably, in depression significantly increased numbers of HLADR cells and $B$ cells have been found as well (32), confirming the similarities between these affective disorders. Moreover, increased immunoglobulin A (IgA) levels have been found in $\mathrm{PD}$ (23). However, the meaning of this change in immune values is hard to interpreted as $\operatorname{Ig} A$ is most importantly involved in the immunological defence on the surface of mucous nembranes. IgE levels were not significantly increased in PD (23), which might be expected considering the relationship between asthma, allergies and PD. Furthermore, IgM and IgG levels were not significantly increased as well (23).

Although the number of $B$ cells in some studies was found to be changed, in vitro $B$ cell activity has not been found to be increased as measured with PWM stimulation $(19,21,28)$. A low lymphocyte proliferative response to mitogens is a well-known feature in autoimmune diseases (33). Higher B lymphocytic levels reflect increased immune activation. Upregulation of immune activity can be expected to coincide with increased B cell activity. However, in vivo hyperactivity of immune cells can lead to a temporary functional exhaustion, which counteracts 
an increased proliferative response to in vitro stimulation (33). In other words, it is conceivable that initially the B cells were hyperactive, leading to exhaustion of these cells, which prevents a stronger proliferative response to PWM stimulation. The actual response of these hyperactive exhausted cells can be equal to a normal $B$ cell response.

NK cell counts don't show differences between PD patients and control subjects $(19,21,22$, 25,26 ). One study found increased NK cell activity in PD patients compared to healthy controls (20). Probably, this can be subscribed to the depressive symptoms that were present in these patients. The mean scores on the HDRS in the study of McDaniel et al. reached 18.1, whereas in the study of Schleifer et al. these values were clearly lower (7.6). In depressed patients increased NK cell activity has consistently been described (34). Although the PD patients in the study of McDaniel et al. were not clinically depressed, it is possible that the biological mechanisms related to the depressive symptomatology influenced the NK cell activity.

Few studies have been performed studying cytokine levels in PD patients. Studies measuring tumor necrosis factor (35), IL-1 $\alpha$ (18), and IL-3 (31) levels in PD found no differences between PD patients and healthy matched controls. Only for IL-1 $\beta$ and IL-2, studies have been replicated. IL-1 $\beta$ levels have found te be increased (30) or decreased (18). However, we need to realise that, at the time these studies were performed, assays to measure IL-1 were not really reliable. The T-lymphocyte system is the major source of $\mathrm{IL}-1 \beta$ and, again, there are no clear increases in that system. Based on that one wouldn't expect increased IL-1 $\beta$ levels either. However, the finding of increased IL-1 $\beta$ levels is potentially interesting as this cytokine is known to stimulate $B$ cell proliferation, which would be consistent with the finding of increased B cell counts.

IL-2 levels were found to be normal $(18,31)$ or decreased (29). The study that reported decreased IL-2 levels in PD did not report any information about depressive symptoms. Although patients suffering from clinical depression were excluded, it is possible that the severity of depressive symptoms influenced the immunological outcomes, as is possibly also the case in the study of McDaniel et al. (20). IL-2 is known to augment locus coeruleus (LC) activity. However, at present, there is no evidence that the increased $L C$ activity seen in PD can be explained by increased IL-2 levels. Furthermore, another action of IL-2 is to induce NK cell proliferation. The finding that NK cell levels are not increased in PD, together with the finding that NK cell activity is normal, is consistent with the finding that IL-2 levels in PD can be considered normal as well. The interleukin-2 receptor (IL-2r) is a marker for T-cell activation. No differences were found in IL-2r numbers $(18,22,26)$. This, again, shows that there are no clear differences in the cell mediated immune activity in PD.

\section{Conclusions and suggestions for future research}

At this moment there is no firm evidence of robust immune changes in PD. This is the most clear in the T-lymphocytic branch. With regard to the B lymphocytic branch, there are some indications that $\mathrm{B}$ cell numbers are increased, although the proliferative response of these cells is not increased. Possibly this can be subscribed to functional exhaustion of these cells. Although, the implication of this finding remains unclear, it might be of importance in affective pathology as the same has been found in depressed patients. A restriction of the studies is that all of the studies compared the basal values of the immunological parameters. The core feature of PD are the PAs, which can be described as short periods of intense discomfort that happen 
suddenly and unexpectedly. Although PD patients tend to be tense in general, they experience the most intense fear during a PA. Possibly, immune changes are more pronounced directly following a PA and don't persist. The immune alterations described in depression are more persistent and extensive, which may reflect the course of this disorder. Therefore, an important aspect that should be addressed in future studies addressing immunological studies in PD, is the degree of depressive symptomatology. Differences in immunological variables exist between studies in PD patients with different degrees of depressive symptomatology. Moreover, patients with PD and comorbid depression show different immunological profiles than depressed patients, which could point to a interaction between biological systems related to the pathology, leading to a shift in immune profiles. Some of the discrepancies in pychoimmunological findings that exist between depression and PD can possibly be explained by differences in hypothalamic-pituitary-adrenal (HPA) axis activity. In depression increased HPA-axis hormone levels have consistently been found (36-38). Immune cells posses glucocorticoid receptors on which cortisol can exert its influences and the other way around, proinflammatory cytokines can stimulate HPA-axis activity (39-42). Interactions between these systems result in coupled changes in both. In other words, differences in immunological parameters can be caused by differences in other, connected, systems such as the HPA-axis.

Most studies used single time point evaluation. This might not be sufficient to draw definite conclusions on immune functioning. The interpersonal variability is substantial and circadian rhythms also exist in the immune system (43). Furthermore, most studies consist of small groups of patients.

Overall, there seems to be an increased B cell number in PD patients, but evidence of disturbances in other immune parameters lacks. Larger studies need to be performed using multiple measurements of different immune subsets. Preferably, these studies involve measurements following a PA and take depressive symptomatology into consideration. 


\section{References}

1. Calabrese JR, Kling MA, Gold PW. Alterations in immunocompetence during stress, bereavement, and depression: focus on neuroendocrine regulation. Am J Psychiatry 1987;144:1123-1134.

2. Sternberg EM, Chrousos GP, Wilder RL et al. The stress response and the regulation of inflammatory disease. Ann Intern Med 1992;117:854-866.

3. Faravelli $C$, Marinoni M, Spiti $R$ et al. Abnormal brain hemodynamic responses during passive orthostatic challenge in panic disorder. Am J Psychiatry 1997;154:378-383.

4. Steptoe A, Willemsen G, Owen $N$ et al. Acute mental stress elicits delayed increases in circulating inflammatory cytokine levels. Clin Sci (Lond) 2001;101:185-192.

5. Gerra $G$, Monti $D$, Panerai AE et al. Long-term immune-endocrine effects of bereavement: relationships with anxiety levels and mood. Psychiatry Res 2003;121:145-158.

6. Zorrilla EP, Luborsky L, McKay JR et al. The relationship of depression and stressors to immunological assays: a meta-analytic review. Brain Behav Immun 2001;15:199-226.

7. Kennedy S, Kiecolt-Glaser JK, Glaser R. Immunologicall consequences of acute and chronic stressors: mediating role of interpersonal relationships. Br J Med Psychol 1988;61 ( Pt 1):77-85.

8. Lacey $\mathrm{K}$, Zaharia MD, Griffiths $\mathrm{J}$ et al. A prospective study of neuroendocrine and immune alterations associated with the stress of an oral academic examination among graduate students. Psychoneuroendocrinollogy 2000;25:339-356.

9. Stein MB, Tancer ME, Uhde TW. Major depression in patients with panic disorder: factors associated with course and recurrence. J Affect Disord 1990;19:287-296.

10. Asnis GM, Wetzler $S_{n}$ Sanderson WC et al. Functional interrelationship of serotonin and norepinephrine: cortisol response to MCPP and DMI in patients with panic disorder, patients with depression, and normal control subjects. Psychiatry Res 1992;43:65-76.

11. Andreoli A, Keller SE, Taban $\mathrm{C}$ et al. Immune function in major depressive disorder: relation to panic disorder comorbidity. Biol Psychiatry 1990;27:95A.

12. Schmidt-Traub S, Bamler KJ. The psychoimmunological association of panic disorder and allergic reaction. Br J Clin Psychol 1997;36 ( Pt 1):51-62.

13. Carr RE. Panic disorder and asthma. J Asthma 1999;36:143-152.

14. Nascimento I, Nardi AE, Valenca AM et al. Psychiatric disorders in asthmatic outpatients. Psychiatry Res 2002;110:73-80.

15. Kennedy BL, Morris RL, Schwab JJ. Allergy in panic disorder patients: a preliminary report(1). Gen Hosp Psychiatry 2002;24:265-268.

16. Hurwitz EL, Morgenstern H. Cross-sectional associations of asthma, hay fever, and other allergies with major depression and low-back pain among adults aged $20-39$ years in the United States. Am J Epidemiol 1999; 150:1107-1]16.

17. American Psychiatric Association (APA). Diagnostic and statistical mamual of mental disorders. Washington, DC, 1994.

18. Rapaport MH, Stein MB. Serum eytokine and soluble interleukin-2 receptors in patients with panic disorder. Anxiety 1994;1:22-25.

19. Schleifer SJ, Keller SE, Bartlett JA. Panic disorder and immunity: Few effects on circulating lymphocytes, mitogen response, and NK cell activity. Brain Behav Immun 2002; 16:698-705.

20. McDaniel JS, Risby ED, Stipetic M et al. Natural killer cell activity in patients with panic disorder. Anxiety $1994: 1: 192-195$.

21. Schleifer SJ, Keller SE, Scott BJ et al. Lymphocyte function in panic disorder. Biol Psychiatry 1990;27:66 A.

22. Manfro GG, Pollack MH, Otto MW et al. Cell-surface expression of L-selectin (CD62L) by blood lymphocytes: correlates with affective parameters and severity of panic disorder. Depress Anxiety $2000 ; 11: 3\lfloor-37$.

23. Ramesh C, Yeragani VK, Balon R et al. A comparative study of immune status in panic disorder patients and controls. Acta Psychiatr Scand 1991;84:396-397.

24. Marazziti D, Ambrogi F, Vanacore R et al. Immune cell imbalance in major depressive and panic disorders. Neuropsychobiology 1992;26:23-26.

25. Perini GI, Zara M. Carraro $\mathrm{C}$ et al. Psychoimmunoendocrine aspects of panic disorder. Human Psychopharm 1995;10:461-465. 
26. Rapaport MH. Circulating lymphocyte phenotypic surface markers in anxiety disorder patients and nomal valunteers. Biol Psychiatry 1998;43:458-463.

27. Brambilla $F$, Bellodi $L$, Perna $G$ et al. Psychoimmunoendocrine aspects of paric disorder. Neuropsychobiology $1992 ; 26: 12-22$.

28. Surman OS, Williams I, Sheehan DV et al. Immunological response to stress in agoraphobia and panic attacks. Biol Psychiatry 1986;21:768-774.

29. KOh KB, Lee BK. Reduced lymphocyte proliferation and interleukin-2 production in anxiety disorders. Psychosom Med 1998;60:479-483.

30. Brambilla F, Bellodi L, Perna $G$ et al. Plasma interleukin-1 beta concentrations in panic disorder. Psychiatry Res 1994:54:135-142.

31. Weizman $R$, Laor $N_{*}$ Wiener $Z$ et al. Cytokine production in panic disorder patients. Clin Neuropharmacol 1999;22:107-109.

32. Maes M, Stevens WI, DeClerck LS et al. A significantly increased number and percentage of B cells in depressed subjects: results of flow cytometric measurements. J Affect Disord 1992;24:127-134.

33. Fagiolo E, Abenante L. Lymphocyte activation and cytokine production in autoimmune hemolytic anaemia (AIHA). A.utoimmunity 1996;24:147-156.

34. Herbert TB, Cohen S. Depression and immunity: a meta-analytic review. Psychol Bull 1993; 113:472486.

35. Brambilla $\mathbb{F}$, Bellodi L, Perna $G$. Plasma levels of tumor necrosis factor-alpha in patients with panic disorder: effect of alprazolam therapy. Psychiatry Res 1999;89:21-27.

36. Holsboer F. The corticosteroid receptor hypothesis of depression. Neuropsychopharmacology $2000 ; 23: 477-501$.

37. Stokes PE. The potential role of excessive cortisol induced by HPA hyperfunction in the pathogenesis of depression. Eur Neuropsychopharmacol 1995;5 Suppl:77-82.

38. Maes M, Meltzer HY, Stevens W et al. Multiple reciprocal relationships between in vivo cellular immunity and hypothalamic-pituitary-adrenal axis in depression. Psychol Med 1994:24:167-177.

39. Blalock JE, Harbour-McMenamin D, Smith EM. Peptide hormones shared by the neuroendocrine and immunologic systems. J Immunol 1985;135:8585-861s.

40. Besedovsky H, del Rey A, Sorkin E et al. Immunoregulatory feedback between interleukin-1 and glucocorticoid hormones. Sicience 1986;233:652-654.

41. Maes M, Scharpe S, Meltzer HY et al. Relationships between interleukin-6 activity, acute phase proteins, and function of the hypothalamic-pituitary-adrenal axis in sewere depression. Psychiatry Res 1993;49:11-27.

42. Maier SF, Watkins LR. Cytokines for psychologists: implications of bidirectional immune-to- brain communication for understanding behavior, mood, and cognition. Psychol Rev 1998;105:83-107.

43. Born J, Lange $\mathrm{T}$, Hansen $\mathrm{K}$ et al. Effects of sleep and circadian rhythm on human circulating immune cells. J Immunol 1997;158:4454-4464. 


\title{
CHAPTER 8
}

\section{Effects of experimental panic on neuroimmunological functioning}

\begin{abstract}
Psychoimmunological research in Panic Disorder (PD) so far has focussed on single time point evaluation in resting conditions. No robust evidence was found for changes in immune functioning using this method. However, $\mathrm{PD}$ is characterised by the occurrence of unexpected panic attacks. The current research locusses on acute alterations in certain aspects of immune functioning following $35 \% \mathrm{CO}_{2}$ inhalation induced panic. Eighteen PD patients were included, together with eighteen carefully matched healthy control subjects. All subjects underwent both a placebo and a $35 \% \mathrm{CO}_{2}$ inhalation on separate days. Blood samples for the determination of cytokines and acute phase proteins were taken before and after the inhalation. In addition to serum determination, whole blood samples were cultured and stimulated with mitogen for assessment of the functional capacity of the immune system.

The $35 \% \mathrm{CO}_{2}$ inhalation induced significantly higher anxiety levels in PD patients as compared to the controls, but there were no differences in immune parameters. Not in basal condition nor after experimental panic induction.

In social phobia similar results have been found, whereas in other affective disorders such as depression and posttraumatic stress disorder, immune changes are evident. The nature and the direction of these changes are not consistent. However, they seem to be positively associated. with changes in HPA-axis function. Therefore, the bidirectional communication pathway between the immune system and the HPA-axis might play a role in some affective disorders, but this system does not seem to be involved in the etiology of PD.
\end{abstract}




\section{Introduction}

Panic Disorder (PD) is a common anxiety disorder with a prevalence of $2-5 \%$ in the general population (1). PD shares a chronic and debilitating course with other affective disorders, especially depression. Approximately two-thirds of PD patients suffer from at least one major depressive episode during their lifetime (2). It may also be noted that similar pharmacotherapeutic interventions are effective in both disorders (3). In fact, there seem to be good reasons to believe that PD and depression do share some underlying biological mechanisms (4).

For depression, several studies have described distinctive immunological findings in the past two decades. Evidence of a positive relationship between the intensity of depressive affect and immune system functioning has been put forward (5). On one hand strong indications of immune activation have been found as appears from increases in enumerative immune outcomes, levels of acute phase reactants and in the production of cytokines. On the other hand, less effective functioning of the cellular arm of both the acquired and the innate immune system, which is indicative of immunosuppression, has been demonstrated at the same time (57).

In spite of the reported clinical and epidemiological links between depression and PD, no robust changes in immune parameters have been found in PD patients. This applies to both enumerative measurements (8-11) as well as to functional measurements (11-13). It should be noted that most studies described above, measured immune parameters in panic using a single evaluation at some given time point during the course of the disorder. However, although panic disorder shows a chronic course, the essential feature of this condition is the acute, unpredictable phenomenon of a panic attack. Panic attacks represent moments of intense fear and can be considered as stressors (14). It is currently unknown whether acute alterations occur in the immune system as a consequence of the panic attack itself. This would be plausible, considering the significant effects that other forms of acute stress have on the immune system. In the recent years, experimental psychiatry developed different paradigms that allow to provoke panic in an experimental setting (15). The current study used $35 \% \mathrm{CO}_{2}$ inhalation to elicit panic in order to investigate possible immunological changes associated to the event of a panic attack. The $35 \% \mathrm{CO}_{2}$ inhalation has proven to be a specific $(16,17)$, valid $(18)$, reliable (19) and safe (20) way to produce experimental panic which, in addition, has proven to be sensitive to pharmaceutical intervention $(21-23)$. The aim of the present study was to examine certain aspects of immune functioning in PD, both in resting condition and after the event of experimental panic. To our knowledge, the current study is the first to measure basal serum cytokine and haptoglobin levels and, in addition, albumin levels and in vitro cytokine production following mitogen stimulation before and after a panicogenic challenge.

\section{Methods}

Subjects

Subjects were recruited by advertisements in local newspapers and mouth-to-mouth information. Eighteen PD patients ( 10 men, 8 women; mean age 37 years \pm 12 ) were enrolled in the study. Diagnosis of PD was based on the DSM-IV criteria supported by the Mini 
International Neuropsychiatric Interview (MINI) (Sheehan et al., 1994), and confirmed by an experienced psychiatrist (KS). Two female subjects dropped out of the study following the first test day for reasons not related to the study. Of these two patients and their matched controls, only variables that were used for baseline comparisons, were included. On average, patients had suffered from PD for 10 years, with a mean of 3 panic attacks per week. In order to gain insight in the severity of the panic symptomatology, the Panic and Agoraphobia Scale (PAS) (24) was used (mean score: $27 \pm 10$ ). None of the patients had a concurrent axis I disorder and all had been free of psychotropic medication for at least three weeks before entering the study. The control group was carefully matched for gender, age and smoking habits and consisted of 10 men and 8 women (mean age $36 \pm 14$ years). In both groups, 7 subjects smoked, with a mean of 8.4 cigarettes per day in the patient group and 8.7 in the control group. Heavy smokers, defined as more than 15 cigarettes per day, were excluded as it has been suggested that it is likely that regular smoking causes disturbances in immune responsiveness (25). Participation was postponed when subjects got ill, caught a cold, or had an infection or allergic reaction in the two weeks before the test day.

All subjects filled out a complete medical history inventory and underwent a standard physical examination. The MINI and the Family History Research Diagnostic Criteria (FHRDC) interview were taken off to exclude any psychiatric diagnosis in the subjects (except for PD in the patient group) or their first degree relatives.

All women were tested in the follicular phase of their menstrual cycle, since immune responses to stress have found to be suppressed in the luteal phase (26). The local medical ethics committee approved the study and written informed consent was obtained from all participants before participation, after the procedure had been fully explained.

\section{Procedure}

The study was performed according to a fixed-order double-blind design, with the placebo inhalation always on the first test day. Physiological and psychological symptoms induced by the inhalation were assessed using the Visual Analogue Scale of Anxiety (VAAS) and the Panic Symptom List (PSL).

The participants arrived at the laboratory at 13,00. Upon arrival an intravenous catheter was inserted in the forearm. After half an hour of habituation blood samples for serum preparation were taken using $\mathrm{BD}$ Vacutainer blood collection tubes (BD, Alphen aan den Rijn, The Netherlands) for the determination of resting immune parameters. These included interleukin-1 receptor antagonist (IL-1RA), soluble IL-6 receptor (sIL-6R), sIL-2R, tumor necrosis factor- $\alpha$ $(\mathrm{TNF}-\alpha),[\mathrm{L}-8$ and the positive acute phase protein (APP) haptoglobin. Immediately before the experimental procedure blood samples for whole blood stimulation and albumin determination were taken and subjects filled out the VAAS and the PSL. At 14.00 the inhalation was performed. The active inhalation consisted of $35 \% \mathrm{CO}_{2}$ and $65 \% \mathrm{O}_{2}$, the placebo inhalation consisted of $80 \% \mathrm{~N}_{2}$ and $20 \% \mathrm{O}_{2}$. All subjects had to inhale at least $80 \%$ of their vital capacity to consider the inhalation valid. The inhalation procedure has been described in detail before (16). Following the inhalation, the questionnaires were filled out again to measure the behavioural effects of the challenge. Subjects had to take in mind the worst moment following the inhalation. An increase in at least 4 physical symptoms of the PSL together with an increase of at least 25 units at the VAAS were used as criteria for an experimental PA (27). Besides baseline samples, blood was sampled 30 and 90 minutes following the inhalation. For serum 
preparation, blood was allowed to clot at room temperature for $30 \mathrm{~min}$. before centrifugation. Blood was centrifuged at $1000 \mathrm{~g}$ for 10 minutes at $4^{\circ} \mathrm{C}$. Serum for cytokine determinations and culture supernatant was stored at $-20^{\circ} \mathrm{C}$. Serum for $\mathrm{APP}$ determinations was stored at $-80^{\circ} \mathrm{C}$ until analysis.

For the whole blood stimulation, heparinized whole blood was diluted four times with RPMI1640 culture medium (Gibco Life Technologies, Belgiam). Two cultures serwed as controls, and two cultures were stimulated with $5 \mu \mathrm{g} / \mathrm{ml}$ lipopolysaccharides (E.coli 026:B6, Sigma-Aldrich, Zwijndrecht, The Netherlands) and $1 \mu \mathrm{g} / \mathrm{ml}$ phytohaemagglutin (PHA-HAl6, Abbott Diagnostics, Hoofddorp, The Netherlands). Cultures were incubated at $37^{\circ} \mathrm{C}$ in an atmosphere containing $5 \% \mathrm{CO}_{2}$. After 48 hours, cultures supernatant was collected and stored at $-20^{\circ} \mathrm{C}$ untill analysis.

Cytokines were determined using commercially available enzyme linked immunosorbent assays (ELISAs). Reagents for IL-6, IL-8, IL-10, IL-1RA and interferon- $\gamma$ (IFN- $\gamma$ ) wrere purchased from BD-Biosciences (Erembodegem, Belgium); those for TNF- $\alpha$, slL-6R and sIL-2R were obtained from DiaMed-Eurogen (Turnhout, Belgium). Determinations were performed in a single assay run by the same operator. Detection limits were: $1 \mathrm{pg} / \mathrm{ml}$ (IL-6, IL-8 and TNF- $\alpha$ ), $1.5 \mathrm{pg} / \mathrm{ml}$ (IL-10), $10 \mathrm{pg} / \mathrm{ml}$ (IL-1RA), $0.2 \mathrm{ng} / \mathrm{ml}$ (sIL-6R), $50 \mathrm{U} / \mathrm{ml}$ (sIL-2R), $2.5 \mathrm{pg} / \mathrm{ml}$ (IFN$\gamma)$.

Serum haptoglobin was measured by fixed-time immunonephelometry on a BN II analyser (Dade Behring, Marburg, Germany) (28). The haptoglobin assay was calibrated against the international CRM 470 reference material (29).

Serum protein electrophoresis and quantification for albumine determination was performed with the capillary zone electrophoresis technique on a Paragon CZE 2000 (Beckman Instruments). The intra assay CV value was $0.8 \%$

\section{Statistical analyses}

Statistical analyses were performed using General Linear Models (GLM) for repeated measurements (SPSS 10 for Windows) with "time' and "day" as within subjects factor (both 2 levels) and 'group' (patient or control) as between subjects factor. Greenhouse-Geisser correction was used when appropriate. Between group comparisons were performed using the students t-test for independent samples when distributions were normally divided as assessed with one-sample Kolmogorov-Smirnov goodness of fit test, or the Mann-Whitney U test in case of non-Gaussian distribution.

\section{Results}

The $35 \% \mathrm{CO}_{2}$ inhalation induced an increase in anxiety and physical symptoms in both the patient group and the control group as measured on respectively the VAAS and the PSL. Delta VAAS scones were significantly higher in the patient group $\left(t_{30}=-3.48 ; \mathrm{p}=0.002\right)$ compared to thie controls, as was the number of PAs $\left(\chi^{2}=10.2 ; \mathrm{p}=0.001\right)$.

Serum cytokine levels measured at baseline showed no differences between the patient group and the control group. Haptoglobin levels did not show differences between patients and controls either. Since different phenotypes can influence haptoglobin levels, a second analysis was performed using the phenotypes as co-variate. Phenotype did not significantly influence 
haptoglobin levels in the current sample (univariate analysis of variance: $F_{1}: 0.033 ; p=0.86$ ). Mean values and statistics are presented in table 1 .

Table 1. Cytokine levels in PD patients and normal controls. Values represent mean values \pm SD.

\begin{tabular}{|c|c|c|c|c|}
\hline & PD & Controls & $t$ & $p$ \\
\hline TNF- $\alpha(p g / m I)$ & $5.9 \pm 1.3$ & $5.6 \pm 1.4$ & -0.73 & 0.47 \\
\hline $\mathrm{IL}-6(\mathrm{pg} / \mathrm{ml})$ & $3.0 \pm 1.3$ & $5.7 \pm 7.0$ & $-1.01(z)$ & 0.33 \\
\hline $\mathrm{IL}-8(\mathrm{pg} / \mathrm{ml})$ & $15.8 \pm 5.0$ & $16.5 \pm 4.5$ & 0.4 & 0.69 \\
\hline $1 \mathrm{~L}-10(\mathrm{pg} / \mathrm{mI})$ & $6.9 \pm 5.7$ & $7.7 \pm 8.5$ & $-0.31(z)$ & 0.76 \\
\hline IL-IRA (pg/ml) & $10.2 \pm 6.9$ & $14.9 \pm 11.0$ & 1.54 & 0.14 \\
\hline sIL-2R (U/ml) & $385.3 \pm 128.0$ & $396.6 \pm 156.9$ & 0.24 & 0.82 \\
\hline sIL-6R (ng/ml) & $95.9 \pm 21.5$ & $93.5 \pm 20.4$ & -0.34 & 0.74 \\
\hline Hp $(\mathrm{g} / \mathrm{L})$ & $1.2 \pm 0.4$ & $1.1 \pm 0.5$ & -0.77 & 0.45 \\
\hline
\end{tabular}

Cytokine production in stimulated whole blood appeared to be comparable for PD patients and their matched controls both before and after the challenge. GLM for repeated measurements revealed no significant difference for any of the cytokines. Due to technical problems, a number of blood cultures was lost, leaving the samples of 13 controls and 10 patients for analysis. Albumin levels showed no difference between patients and controls either. Mean values and statistics are presented in table 2 .

Table 2. Immune response measures in Panic Disorder patients and healthy matched controls. IFN- $\gamma$ and IL -6 are expressed in $\mathrm{ng} / \mathrm{ml}$. Other cytokines are expressed in $\mathrm{pg} / \mathrm{ml}$, albumin in $\mathrm{g} / \mathrm{L}$.

\begin{tabular}{|c|c|c|c|c|c|c|c|c|c|c|}
\hline & \multicolumn{4}{|c|}{ Placebo } & \multicolumn{4}{|c|}{$35 \% \mathrm{CO}_{2}$} & \multirow{3}{*}{$F$} & \multirow{3}{*}{$p$} \\
\hline & \multicolumn{2}{|c|}{$\mathrm{PD}$} & \multicolumn{2}{|c|}{ Control } & \multicolumn{2}{|c|}{ PD } & \multicolumn{2}{|c|}{ Control } & & \\
\hline & pre & post & pre & post & pre & post & pre & post & & \\
\hline TNF- $\alpha$ & 4519 & 4677 & 5344 & 5268 & 4848 & 4594 & 6010 & 5335 & 0.05 & 0.83 \\
\hline IFN- $\gamma$ & 87 & 85.6 & 80.2 & 66.5 & 80.1 & 75.3 & 69.7 & 59.7 & 0.58 & 0.46 \\
\hline IL-6 & 34.9 & 34 & 41.3 & 42 & 37.7 & 36.2 & 46.7 & 40.7 & 3.25 & 0.09 \\
\hline $\mathbb{L}-1 \beta$ & 5171 & 5185 & 5851 & 5858 & 5970 & 6276 & 6431 & 6274 & 1.34 & 0.27 \\
\hline IL-10 & 1544 & 1642 & 1945 & 1891 & 1802 & 1846 & 1989 & 1929 & 239 & 0.14 \\
\hline alb. & 44.1 & 44.1 & 44.3 & 43.7 & 43.6 & 43.4 & 44.1 & 43.1 & 0.59 & 0.45 \\
\hline
\end{tabular}




\section{Discussion}

The present study applied $35 \% \mathrm{CO}_{2}$ inhalation in order to induce panic in otherwise healthy, unmedicated panic disorder patients. As expected, the challenge resulted in significantly higher anxiety levels in panic disorder patients as compared to their healthy matched controls.

At baseline, sIL-2R, TNF- $\alpha$, IL-6, sIL-6R, IL-8, IL-10, IL-1 RA, and haptoglobin levels were determined. All of these consistently showed no difference between the PD group and their matched controls.

Only few studies have studied cytokine levels and directly related parameters in PD patients before. In accordance with the current results, former studies investigating sIL-2R levels found no difference between PD patients and control subjects $(8,30)$. The IL-2 receptor is a marker for T-cell activation as these receptors are shed from activated $\mathrm{T}$-cells. The present results therefore indicate that there is no T cell activation in PD patients. In addition, IL-10 levels, an anti-inflammatory cytokine secreted by $\mathrm{T}$-helper $(\mathrm{Th}) 2$ cells, showed no difference between PD patients and controls either.

One study (31) investigated TNF- $\alpha$ levels in PD and found no differences between PD patients and controls either. TNF- $\alpha$ is one of the major monocytic pro-inflammatory cytokines, and is as such indicative for the activity of the monocytic arm of the immune system (32). Soluble cytokine receptors or cytokine receptor antagonists can also be markers for immune activation. For instance, IL-1RA is secreted by monocytes and macrophages after initial activation. As such it is an indicator of immune activation, but its final function is to restrict the actions of $\mathbb{L}-1$. The same principle accounts for most of the soluble cytokine receptors which prevent cytokines from binding to their target cells. However, IL-6R enhances the biological activity of circulating IL-6, as the complex formed by these molecules can bind to a membrane molecule that mediates IL-6 signalling (33). In the current study, TNF- $\alpha$ levels, as well as IL-8, IL-1RA, IL-6 and SIL6R levels were normal. In other words, no evidence for monocytic activation in PD patients was found. Furthermore, normal haptoglobin levels were found. Increased haptoglobin values are indicative of activation of the humoral arm of the innate immune system.

As mentioned in the introduction, most neuroimmunological studies in PD measured immune parameters using a single evaluation at some given time point during the course of the disorder. In addition to immunological values under resting conditions, the current study aimed to investigate whether acute alterations occur in the immune system as a consequence of a panic attack. Possible direct effects of experimental panic induction on cytokine production were examined in stimulated whole blood. TNF- $\alpha$, IFN- $\gamma, I L-6$, IL-1b and IL- 10 levels were measured in mitogen stimulated whole blood both before and after the inhalation. No evidence was found for changes in immune functioning in PD or in control subjects. In other words, neither $35 \% \mathrm{CO}_{2}$ inhalation in itself nor experimentally induced panic seems to have an effect on cytokine production. In addition, serum levels of the negative acute phase protein (APP) albumin showed similar outcomes. Cytokines, in particular IL-1, IL-6, and TNF- $\alpha$, mediate the acute phase reaction (34). The lack of a decrease in albumin levels following panic is compatible with the lack of increase in monocytic cytokine levels. Furthermore, IFN- $\gamma$ and IL10 are both markers for acquired immune system activity. IFN- $\gamma$ is secreted by Thl cells and stimulates in this way cell-mediated immunity. IL-10 is characterised by its role in humoral immunity. One of the actions of $\mathrm{LL}-10$ as an anti-inflammatory cytokine is to inhibit Th-1 proinflammatory cytokine secretion. The balance between pro-inflammatory and anti-inflammatory 
cytokines is important for normal immune functioning. To our knowledge, the current study is the first to assess anti-inflammatory cytokine levels in PD.

$35 \% \mathrm{CO}_{2}$ induced panic did not affect immune functioning. In addition, the normal levels of APPs, pro-inflammatory and anti-inflammatory cytokines are suggestive of nomal immune functioning in PD in basal conditions.

In sharp contrast to the apparently normal immune function in PD demonstrated in the present study, systemic immune alterations have been found in other affective disorders. However, the nature and the direction of the immune changes seems to lack consistency. In depressed patients, increased leukocyte numbers and cytokine levels, together with a decreased proliferative response of both T lymphocyts and NK cells has been reported (5-7). In posttraumatic stress disorder (PTSD) on the other hand, decreased white blood cell counts and increased NK cell activity were found (35). In Social Phobia (SP) parameters of immune functioning parallelled the values of control subjects (36). This latter finding seems to be consistent with the current findings in PD patients. Yet another analogy between PD and SP seems important with regard to the parallel in immune findings. In neither PD nor SP there is consistent evidence ofHPA-axis dysregulation (37-41). In contrast, increased HPA-axis activity has been found in major depression(42), whereas PTSD is characterised by decreased HPA-axis activity (43).

Numerous reports have described bidirectional interactions between the HPA-axis and the immune system (44-46). Certain cytokines exert potent enhancing effects on the HPA-axis by directly stimulating CRH release (47). In fact, IL-6 for example, stimulates HPA-axis activity at concentrations known to occur in human plasma $(48,49)$. In depression, increases in IL-1 $\beta$ have shown to directly stimulate, to a certain extend, HPA-axis activity (50). Cortisol, on the other hand, reduces immune activity by binding to glucocorticoid receptors in immunocompetent cells, thereby inhibiting pro-inflammatory cytokine expression (51).

In conclusion, the current study finds no evidence for immune activation in PD, neither in basal condition nor after experimental panic induction. Correspondingly, similar results have been found in SP. The involvement of a bidirectional communication between the immune system and the HPA-axis in affective disorders has been hypothesised. Indeed, in other affective disorders this mechanism seems to be present. In depression, indicators of both immune and HPA-axis activity are increased. The opposite seems to occur in PTSD where decreased HPAaxis activity is related to decreased immune functioning. Compatible with the hypothesis, HPAaxis activity in PD and SP seems to be unaffected. Possibly, the induction of changes in cellular immunity, as seen in PTSD and depression, may be a prerequisite for disturbed HPA-axis functioning. Therefore, interactions between the HPA-axis and the immune system might be of influence in some, but not all affective disorders. 


\section{References}

1. Faravelli $\mathrm{C}$, Paioni A: Panic disorder: clinical course, morbidity and comorbidity, in Anxiety disorders. An introduction to clinical management and research, wol 1. Edited by Griez EJL, Faravelli $\mathrm{C}, \mathrm{Nutt} D$, Zohar J. Chichester, John Wiley \& Sons, Itd., 2001, pp 53-79

2. Stein MB, Tancer ME, Uhde TW: Major depression in patients with panic disorder: factors associated with course and recurrence. J Affect Disord 1990; 19(4):287-296

3. Gorman JM, Coplan JD: Comorbidity of depression and panic disorder. J Clin Psychiatry 1996; 57 Suppl 10:34-41; discussion $42-43$

4. Strohle A, Holsboer F: Stress responsive neurohormones in depression and anxiety. Pharmacopsychiatry $2003 ; 36$ Suppl 3:S207-214

5. Herbert TB, Cohen $\mathrm{S}$ : Depression and immunity: a meta-analytic review. Psychol Bull 1993; $113(3): 472-486$

6. Maes $M$ : Evidence for an immune response in major depression: a review and hypothesis. Prog Neuropsychopharmacol Biol Psychiatry 1995; 19(1):11-38

7. Zorrilla EP, Luborsky L, McKay JR, Rosenthal R, Houldin A, Tax A, MoCorkle R, Seligman DA, Sclumidt $K$ : The relationship of depression and stressors to immunological assays: a meta-analytic review. Brain Behav Immun 2001; 15(3):199-226

8. Mantro GG, Pollack MH, Otto MW, Worthington JJ, Rosenbaum JF, Scott EL, Kradin RL: Cell-surface expression of L-selectin (CD62L) by blood lymphocytes: correlates with affective parameters and severity of panic disorder. Depress Anxiety 2000; 11(1):31-37

9. Rapaport MH: Circulating lymphocyte phenotypic surface markers in anxiety disorder patients and normal volunteers. Biol Psychiatry 1998; 43(6):458-463

10. Schleifer SI, Keller SE, Scott BJ, Vechione J: Lymphocyte function in panic disorder. Biol Psychiatry $1990 ; 27: 66 \mathrm{~A}$

11. Schleifer SI, Keller SE, Bartlett JA: Panic disorder and immunity: Few effects on circulating lymphocytes, mitogen response, and NK cell activity. Brain Behav Immun 2002; 16(6):698-705

12. Surman OS, Williams J, Sheehan DV, Strom TB, Jones KJ, Coleman J: Inmunological response to stress in agoraphobia and panic attacks. Biol Psychiatry 1986; 21(8-9):768-774

13. Brambilla F, Bellodi L, Perna G, Battaglia M, Sciuto G, Diaferia G, Petraglia F, Panerai A, Sacerdote P: Psychoimmunoendocrine aspects of panic disorder. Neuropsychobiology $1992 ; 26(1-2): 12-22$

14. McNally RJ, Lukach BM: Are panic attacks traumatic stressors? Am J Psychiatry 1992; 149(6):824-826

15. Griez E, Schruers K: Experimental pathophysiology of panic. J Psychosom Res 1998; 45(6):493-503

16. Griez E, de Loof C, Pols $\mathrm{H}$, Zandbergen J, Lousberg $\mathrm{H}$ : Specific sensitivity of patients with panic attacks to carbon dioxide inhalation. Psychiatry Res 1990; 31(2):193-199

17. Perna $\mathrm{C}$, Barbini B, Cochi $\mathrm{S}$, Bertani A, Gasperini $\mathrm{M}: 35 \% \mathrm{CO} 2$ challenge in panic and mood disorders. J Affect Disord 1995; 33(3):189-194

18. Griez EJ, Lousberg H, van den Hout MA, van der Molen GM: CO2 vulnerability in panic disorder. Psychiatry Res 1987; 20(2):87-95

19. Verburg K, Pols $\mathrm{H}$, de Leeuw $\mathrm{M}$, Griez $\mathrm{E}$ : Reliability of the $35 \%$ carbon dioxide panic prowocation challenge. Psychiatry Res 1998; 78(3):207-214

20. Perma G, Cocchi S, Allevi L, Bussi R, Bellodi L: A long-term prospective evaluation of first-degree relatives of panic patients who underwent the $35 \% \mathrm{CO} 2$ challenge. Biol Psychiatry $1999 ; 45(3): 365-367$

21. Perna G, Cocchi S, Bertani A, Arancio C, Bellodi L: Pharmacologic effect of toloxatone on reactivity to the $35 \%$ carbon dioxide challenge: a single-blind, random, placebo-controlled study. J Clin Psychophamacol 1994; $14(6): 414418$

22. Pols $\mathrm{H}$, Zandbergen J, de Loof $\mathrm{C}$, Griez $\mathrm{E}$ : Attenuation of carbon dioxide-induced panic after clonazepam treatment. Acta Psychiatr Scand 1991; 84(6):585-586

23. Gorman JM, Browne ST, Papp LA, Martinez J, Welkowitz L, Coplan JD, Goetz RR, Kent J, Klein DF: Effect of antipanic treatment on response to carbon dioxide. Biol Psychiatry 1997; 42(11):982-991

24. Bandelow B, Hajak G, Holzrichter S, Kunert HJ, Ruther E: Assessing the efficacy of treatments for panic disorder and agoraphobia. I. Methodological problems. Int Clin Psychopharmacol 1995; 10(2):8393 
25. Fuxe K, Andersson K, Enetoth $P$, Harfstrand A, Agnati LF: Neuroendocrine actions of nicotine and of exposure to cigarette smoke: medical implications. Psychoneuroendocrinology $1989_{,}, 14(1-2): 19,41$

26. Pehlivanogh B, Balkanci ZD, Ridvanagaoglu AY, Durnazlar N, Ozturk G, Erbas D, Okir H: Impact of stress, gender and menstrual cycle on immune system: possible role of nitric oxide. Aroh Playsiol Biochem 2001; 109(4):383-387

27. Verburg K, Perna G, Griez EJL: A case study of the $35 \% \mathrm{CO} 2$ challenge, in Anxiety disorders. An introduction to clinical management and research, vol 1. Edited by Griez EN, Faravelli $C_{4} N u t t D$, Zohar J. Chichester, John Wiley \& Sons, Itd., 2001, pp 341-357

28. Fink PC, Romer M, Haeckel $R$, Fateh-Moghadam A, Delanghe J, Gressner AM, Dubs RW: Measurement of proteins with the Behring Nephelometer. A multicentre evaluation. J Clin Chem Clin Biochem 1989; 27(4):261-276

29. Dati $F$, Schumann $G$, Thomas L, Aguzzi F, Baudner $S$, Biemvenu J, Blaabjerg $O$, Blirup-Jensen $S$, Carlstrom A, Petersen PH, Johnson AM, Milford-Ward A, Ritchie RF, Svendsen PJ, Whicher J: Consensus of a group of professional societies and diagnostic companies on guidelines for interim reference ranges for 14 proteins in serum based on the standiardization against the IFCC/BCR/CAP Reference Material (CRM 470). International Federation of Clinical Chemistry. Community Bureau of Reference of the Commission of the European Communities. College of American Pathologists. Eur I Clin Chem Clin Biochem 1996; 34(6):517-520

30. Rapaport MH, Stein MB: Serum cytokine and soluble interleukin-2 receptors in patients with panic disorder. Anxiety 1994; 1(1):22-25

31. Brambilla F, Bellodi $L_{3}$ Perna G: Plasma levels of tumor necrosis factor-alpha in patients with panic disorder: effect of alprazolam therapy. Psychiatry Res 1999; 89(1):2 1-27

32. Abraham E: Effects of stress on cytokine production. Methods Achiev Exp Pathol 1991; 14:45-62

33. Peters M, Muller AM, Rose-John S: Interleukin-6 and soluble interleukin-6 receptor: direct stimulation of gpl30 and hematopoiesis. Blood 1998; 92(10):3495-3504

34. Kronfol Z, Remick DG: Cytokines and the brain: implications for clinical psychiatry. Am J Psychiatry $2000 ; 157(5): 683-694$

35. Ironson G, Wynings C, Schneiderman N, Baum A, Rodriguez M, Greenwood D, Benight C, Antoni M, LaPerriere A, Huang HS, Klimas N, Fletcher MA: Posttraumatic stress symptoms, intrusive thoughts, loss, and immune function after Hurricane Andrew. Psychosom Med 1997; 59(2):128-141

36. Rapaport MH, Stein MB: Serum interleukin-2 and soluble interleukin-2 receptor levels in generalized social phobia. Anxiety 1994; 1(2):50-53

37. Uhde TW, Tancer ME, Gelernter CS, Vittone BJ: Normal uninary free cortisol and postdexamethasone cortisol in social phobia: comparison to normal volunteers. J Affect Disord 1994; 30(3):155-161

38. Martel FL, Hayward C, Lyons DM, Sanbon K, Varady S, Schatzberg AF: Salivary cortisol levels in socially phobic adolescent girls. Depress Anxjety 1999; 10(1) $25-27$

39. Uhde TW, Joffe RT, Jimerson DC, Post RM: Normal urinary free cortisol and plasma MHPG in panic disorder: clinical and theoretical implications. Biol Psychiatry 1988; 23(6):575-585

40. var Duinen MA, Schruers KR, Maes M. Griez EJ: Salivary cortisol in panic: are males more vulnerable? Neuroendocrinology Letters 2004; $25(5): 285-289$

41. Bandelow $B$, Sengos $G$, Wedekind $D$, Huether $G$, Pilz $J$, Broocks A, Hajak G, Ruther E: Urinary excretion of cortisol, norepinephrine, testosterone, and melatonin in panic disorder. Pharmacopsychiatry 1997; 30(4):113-117

42. Checkley S: The neuroendocrinology of depression and chronic stress. Br Med Bull 1996; 52(3):597617

43. Yehuda R: Current status of cortisol findings in post-traumatic stress disonder. Psychiatr Clin North Am $2002 ; 25(2): 341-368$, vii

44. Besedovsky HO, del Rey A, Klusman I, Furukawa H, Monge Arditi G, Kabiersch A: Cytokines as modulators of the hypothalamus-pituitary-adrenal axis. J Steroid Biochem Mol Biol 1991; 40(4-6):613618

45. Elenkov $1 J$, Wilder RL, Chrousos GP, Vizi ES: The sympathetic nerwe-an integrative interface between two supersystems: the brain and the inmune system. Pharmacol Rev 2000; 52(4):595-638

46. Mater SF, Watkins LR: Cytokines for psychologists: implications of bidirectional immune-to- brain communication for understanding behavior, mood, and cognition. Psychol Rev 1998; 105(1):83-107 
47. Dunn AJ: Cytokine activation of the HPA axis. Ann N Y Acad Sci 2000; 917:608-617

48. Tsigos $C_{n}$ Papanicolaou DA, Defensor R, Mitsiadis CS, Kyrou I, Chrousos GP: Dose effects of recombinant human interleukin-6 on pituitary hormone secretion and energy expenditure. Neuroendocrinology $1997 ; 66(1): 54-62$

49. Steensberg A, Fischer CP, Keller C, Moller K, Pedersen BK: IL-6 enhances plasma IL- $\|$ ra, IL-10, and cortisol in humans. Am J Physiol Endocrinol Metab 2003; 285(2):E433-437

50. Maes $M_{2}$ Besmans $\mathrm{E}$, Meltzer HY, Scharpe $\$$, Suy $\mathrm{E}$. Interleukin-1 beta: a putative mediator of HPA axis hyperactivity in major depression? Am J Psychiatry 1993; 150(8):1189-1193

51. Kovalovsky D, Refojo D, Holsboer F, Arzt E: Molecular mechanisms and Th1/Th2 pathways in corticosteroid regulation of cytokine production. I Neuroimmunol 2000; 109(1):23-29 


\section{CHAPTER 9}

General discussion 
Since the initial work of Hans Selye in 1936 (Selye, 1936), literally thousands of studies have been dedicated to 'stress', and the importance of the role the HPA-axis fulfills in this has become strongly acknowledged. Stress, a quite fashionable and widely adopted construct today, was originally defined by Selye as a non-specific response to noxious stimuli, characteristically resulting in increased ACTH secretion, indicative of activation of the HPA-axis. As we stated, the HPA-axis is known to play a vital role in adaptation to homeostatic challenge. Its main function is to redirect bodily energy resources, resulting in a scala of actions (Ganong, 1995). Both fear and stress are defined as adaptive responses that involve HPA-axis activation. However, as was stated in the introduction, although the equation of panic with fear seems obvious, until now it remained unclear whether the "stress-axis" was activated during panic. Accordingly, one of the later published works of Hans Selye was entitled: "The stress of life". The current thesis partly aimed to investigate whether "The stress of panic" is the same stress as described in "The stress of life", or that it is a different entity, probably better referred to as "distress".

The immune system, a second stress-responsive system which is closely interconnected with the HPA-axis, shows stress-specific adaptations, depending on the nature of the stressor, its intensity and duration, and the perceived control over the stressor (Kronfol \& Remick, 2000). Acute stressors are associated with an upregulation of parameters of natural immunity of which increases in natural killer cell numbers and neutrophils were most pronounced, but also cytokines as interleukin-6 (IL-6) and interferon- $\gamma$ (IFN- $\gamma$ ) were increased. At the same time, certain functions of specific immunity were downregulated, reflected by decreased mitogenstimulated proliferative responses (Segerstrom \& Miller, 2004). Panic attacks would fit in the category of acute stressors. Accordingly, comparable immune changes are expected to be found following panic. However, to our knowledge, this issue has not yet been addressed before in an experimental design.

In general, the studies in the current thesis were performed to gain more insight in the activity of the two above described stress-responsive systems in panic. The outcomes of the different studies are discussed below.

In the first four chapters, the HPA-axis response to $35 \% \mathrm{CO}_{2}$ inhalation in both PD patients and healthy volunteers is addressed. At first sight, the outcomes of the different studies might seem contradictory. In chapter one it was found that healthy volunteers show no increase in salivary cortisol values following $35 \% \mathrm{CO}_{2}$ inhalation, whereas in chapter three, in a comparable group, an increase was found in both salivary and serum cortisol as well as an increase in ACTH levels. This apparent discrepancy in HPA-axis activation can be explained by methodological differences. Most importantly, in the second study, an additional baseline sample was taken directly before the inhalation, to assess the direct effect of the challenge. Although it was assumed that at that point cortisol levels might be increased as a consequence of anticipatory anxiety awaiting an unfamiliar, possibly fear-inducing stimulus, cortisol concentration was lower directly before the inhalation than half an hour earlier. Apparently, in this half hour when the subjects sat quietly, cortisol levels were not affected by anticipatory anxiety. In fact, cortisol levels decreased, which indicates that the normal circadian pattern of cortisol secretion was not disturbed. The Jower baseline value that was now used in statistical analysis led to the detection of the rise in cortisol values following the inhalation. Furthermore, the protocol was more strictly standardised in the second study, so that all subjects started at the same hour. Although 
in the first study all participants were tested in the early afternoon, the activity of the axis still declines during these hours. In other words, differences in the hour of commencement will increase variability in cortisol values, which hampers detection of subtle differences.

Summarising, $35 \% \mathrm{CO}_{2}$ inhalation increases $\mathrm{HPA}$-axis activity in healthy volunteers. However, although the increases in cortisol and ACTH were statistically significant, the magnitude of the cortisol increase was not impressive, underlining that the reaction to this challenge is not very strong in healthy volunteers. The neuroendocrine response rather reflects the natural response to homeostatic disturbance.

However, a different response might be expected when PD patients are studied. Since PD patients show an increased vulnerability to the effects of $\mathrm{CO}_{2}$ most often resulting in panic, the question whether panic is an extreme form of fear can be adressed in this group. In chapter two and four, $\mathrm{HPA}$-axis response to $35 \% \mathrm{CO}_{2}$ inhalation was compared between PD patients and healthy control subjects. The specificity of the challenge was confirmed in both studies, since the patient group reported significantly higher levels of fear after the $\mathrm{CO}_{2}$ inhalation. Surprisingly however, the neuroendocrinological response in PD patients did not differ from the response in the control subjects.

As discussed above, healthy volunteers showed a minimal neuroendocrine response which probably reflected an adaptive response to the changed homeostasis. There is a sharp contrast between PD patients and healthy controls in the subjective response, while there is no difference in the neuroendocrine response. Since HPA-axis activation is characteristic of normal fear, this implies that panic is not extreme fear or stress. One explanatory concept proposed by Donald Klein states that panic is a specific type of response, linked to an oversensitive, inborn, internal alarm system (Klein, 1993). The specific threat for which this alarm system should warn is suffocation, a potentially life threatening event. Lack of hypothalamic-pituitary-adrenal (HPA)axis response has been claimed to be a characteristic feature of panic. In fact, maintaining a low level of energy expenditure would be adaptive in case of suffocation, sparing $\mathrm{O}_{2}$ consumption and reducing the further build up of $\mathrm{CO}_{2}$ and asphyxiation.

The initial event that elicits a PA is still a matter of debate. However, the uniqueness of panic is that a seemingly spontaneous internal event triggers a very strong emotional response.

In specific phobia fear is clearly elicited by a circumscribed external stressor. We originally hypothesized that confrontation with the feared stimulus would be accompanied by HPA-axis activation in contrast to panic. This hypothesis was put to the test in chapter five. Spider phobic subjects and control subjects were exposed to spiders in a standardised paradigm. Salivary cortisol was used as an index of HPA-axis activity. Phobic exposure induced high levels of fear, yet, surprisingly, no cortisol response. This dissociation has been referred to as 'desynchrony of fear' (Curtis, Nesse, Buxton, \& Lippman, 1978).

Cortisol release in response to spider exposure, can be considered maladaptive, since it no longer provides improved survival, and therefore the potential benefits do not counterbalance the costs of the energy expenditure. It can be hypothesised that this supposedly genetically coded feature extinguished in modern man.

Continuing on evolutionary evolved adaptive systems, it has been suggested that the classic defensive response, the fight flight response, originally evolved from the phylogenetically much older immune system (Maier \& Watkins, 1998). This would explain the close physiological link between these two stress-responsive systems. If panic is considered an acute stress-response resulting in HPA-axis activation, altered immune functioning might be expected as well. 
Chapter six provides a review of neuroimmunological findings in panic. Overall, no alterations are reported for most immune parameters. However, the current thesis focusses on the direct effects of panic on stress-responsive systems, and until now, immune parameters in PD have only been studied in basal conditions. As described in chapter seven, we studied immune responsivity following a $35 \% \mathrm{CO}_{2}$ challenge to address the issue of the influence of the corefeature of PD on certain aspects of immune functioning. No changes were found in any of the immune variables measured. It can be argued that this could be the result from a type 2 error, since our power was limited related to the small number of participants. On the other hand, chances on type 1 errors increased by the large amount of determinations. Since none of the immune variables tended to be affected, this strengthens our findings that panic does not affect immune responsivity.

In conclusion, the current work supports the notion that panic can not be equated with fear and stress. In other words, there is no stress of panic. In agreement with this, no change was found in responsivity of the immune system as measured with the determination of cytokine levels following whole blood stimulation. Intense bidirectional communication between the HPA-axis and the immune system suggests that dysfunction in one of these stress-responsive systems wil] affect the other. Both systems are not activated by the event of a PA, strengthening our statement that panic does not equal stress.

Phobic fear does not appear to be stressful either, since the HPA-axis is not activated during confrontation with the phobic stimulus. Desynchrony could be proposed both in panic and spider phobia, since the high level of experienced distress is not accompanied by the neuroendocrinological response that is characteristic of a fear-response.

\section{Future research}

\section{Real-life panic}

'Further research is needed' always is a bit of a clincher. However, this hackneyed phrase also applies here. In the current thesis, panic was elicited by experimental means. Although we stress that the $35 \% \mathrm{CO}_{2}$ model is very specific and induces symptoms that closely mimic real-life panic, it remains a model of which we assume it approaches reality. The use of this model has been very valuable in investigating the HPA-axis response in panic. We found no increases in HPA hormones other than directly related to the $\mathrm{CO}_{2}$ inhalation. However, the next siep would be to verify this in real-life. It will be difficult and time-consuming to perform such a study, especially when true unexpected attacks are considered and patients are not brought into a surrounding that facilitates the occurrence of attacks. Since PAs are also experienced during sleep, studies performed in patients that are asleep might offer a promising possibility to avoid influences of anticipatory anxiety.

\section{Phobia}

Whereas in the studies with PD patients panic was evoked using experimental means, specific phobia offered the advantage that the phobic response is evoked by a interspecific threat. This enables us to evoke true phobic fear in the laboratory under standardised circumstances. In chapter five it was stated that interspecific threats have become less pertinent for humans. 
Putatively, in modern man, there would be an ongoing process of progressive extinction of those phylogenetically ancient fears. The disappearance of the HPA component could be a forerunner of this process. This would imply that in phobias with an ontogenetical content the HPA-axis is activated in response to phobic stimuli, since this is a relevant threat for modern man. This could be relatively easily tested in a standardised design. The only demerit would be that phobias with an ontogenetically relevant content are not frequent.

\section{Psychoneuroendocrinology}

In chapter three and four, we acknowledged that measuring cortisol values might not be conclusive. Disnuption of the axis at higher levels could prevent initial activation of the axis to be expressed in higher glucocorticoid levels. Therefore, in the studies presented in the current thesis, both cortisol and ACTH were used as indicators of the activity of the axis. Corticotropin Releasing Hormone (CRH) and Arginine-Vasopressine (AVP) are secreted by the hypothalamus and thus form the first step of the cascade. To answer the question whether panic is an extreme form of fear, hormones at all levels of the HPA-axis should be measured. In fact, CRH and AVP levels were determined as well (unpublished data), and in agreement with the ACTH and cortisol values, no differences were found between PD patients and healthy controls. This strengthens our conclusion that panic does not equal a classic fear-response.

However, there are indications that increased secretion of Atrial Natriuretic Hormone (ANH), during panic exerts an inhibiting effect on cortisol and ACTH release. ANH is the physical antagonist of AVP. In healtiny subjects it was shown that infusion of ANH suppressed CRH induced ACTH secretion (Kellner, Wiedemann, \& Holsboer, 1992). Kellner et al. (1998) found a more pronounced $\mathrm{ANH}$ increase in $\mathrm{PD}$ patients as compared to healthy controls following lactate-induced panic. Moreover, ANH levels were significantly decreased in the patient group at baseline. It is still unclear which role ANH plays in panic, but the above described findings imply that further research is indicated. Currently, preparations for a replication study on ANH release during panic are underway in our laboratory. If this response is also present following $35 \% \mathrm{CO}_{2}$ induced panic, it seems plausible that ANH plays a the role in the etiology of panic. 


\section{References}

Curtis, G. C., Nesse, R., Buxton, M., \& Lippman, D. (1978). Anxiety and plasma cortisol at the crest of the circadian cyclerreappraisal of a classical hypothesis. Psychosom Med, 40(5), 368-378.

Ganong; W. F. (1995). The adrenal medulla \& adrenal cortex. In C. Langan (Ed.), Rewew of medical physiology (17 ed., pp. 327-3511). Norwalk, Conneticut: Appleton \& Lange.

Kellner, M., Knaudt, K, Jahn, H., Holsboer, F., \& Wiedemann, K. (1998). Atrial natriuretic hormone in lactateinduced panic attacks: mode of release and endocrine and pathophysiological consequences. $J P$ sychiatr Res, $32(1), 37-48$.

Kellner, M., Wiedemann, K., \& Holsboer, F. (1992). Atrial natriuretic factor inhibits the CRH-stimulated secretion of ACTH and contisol in man. Life Sci, 50(24), 1835-1842.

Klein, D. F. (1993). False suffocation alarms, spontaneous panics, and related conditions. An integrative hypothesis. Arch Gen Psychiatry, 50(4), 306-317.

Kronfol, Z, \& Remick, D. G. (2000). Cytokines and the brain: implications for clinical psychiatry. $A m J$ Psychiatry, 157(5), 683-694.

Maier, S. F., \& Watkins, L. R. (1998). Cytokines for psychologists: implications of bidirectional immune-tobrain communication for understanding behavior, mood, and cognition. Psychol Rev, 105(1), 83-107.

Segerstrom, S. C., \& Miller, G. E. (2004). Psychological stress and the human immune system: a meta-analytic study of 30 years of inquiry. Psychol Bull, 130(4), 601-630.

Selye, H. (1936). A syndrome produced by diverse noxious agents. Nature, 32, 138. 
Summary 
Panic Disorder (PD) is an anxiety disorder, characterised by sudden spells of acute fear or discomfort, referred to as panic attacks (PAs). Considering the symptoms and cognitions of a $\mathrm{PA}$, the resemblance with a normal fear response or classic stress response might seem obvious. However, considering the neuroendocrinological and neuroimmunological aspects the comparison with fear might be less straightforward. The current thesis focusses on these aspects.

Chapter one provides a general introduction into the different subjects of the thesis.

From a symptomatological point of view, panic can be compared to fear. This would implicate that certain characteristic features of an acute fear response might also be implemented in panic. Characteristic for fear is the hypothalamic-pituitary-adrenal (HPA-) axis response. Studies in panic measuring HPA-axis activity have shown inconsistent results. Basal HPA-axis functioning, the HPA-axis response following real-life PAs, and the HPA-axis response following laboratory induced panic are discussed. A scala of experimental models exist that have been developed to study panic. However, most of these models lack specificity. Lactate infusion, cholecystokinin-4 infusion and particularly carbon dioxide $\left(\mathrm{CO}_{2}\right)$ inhalation seem to be the most promising methods. These models can be applied to study the underlying mechanisms of panic. HPA-axis hormone levels can be assessed to gain insight into the issue of the relationship between panic and fear. Not only HPA-axis activity can be measured to serve this purpose, also other stress response systems are known to show altered activity in periods of stress. In fact, evidence exists of intense reciprocal communication between the HPA-axis and the immune system. In psychiatric research, studies in psychoneuroimmunology have been performed mainly in major depression. Findings in PD are scarce and scanty, and only apply to the basal conditions.

The following four chapters describe a series of related experimental studies in which the HPAaxis response following panic induction is monitored.

Chapter two focusses on the occurrence of a cortisol response following the $35 \% \mathrm{CO}_{2}$ challenge in healthy volunteers. Former studies have shown that, in general, healthy volunteers do not react with high levels of anxiety as measured on the Visual Analogue Scale of Anxiety (VAAS). Also, the physical symptoms that are evoked in these subjects do not seem to be very stressful. From this, it might be expected that the $35 \% \mathrm{CO}_{2}$ inhalation will not increase cortisol release. However, literature is not consistent in this matter. Methodological differences seem to account for most of the inconsistencies. In accordance with our hypothesis, we found no cortisol increase following $35 \% \mathrm{CO}_{2}$ inhalation. However, the methods used in this study were somewhat crude. Therefore, it warrants replication in a methodologically stronger study.

In chapter three, the sample with healthy subjects is extended with a group of matched PD patients. The $35 \% \mathrm{CO}_{2}$ challenge is especially relevant for $\mathrm{PD}$ patients. In this chapter, the issue of panic being equal to fear, is addressed in this population. Most PD patients experienced an experimental PA, whereas only one healthy subject did. In other words, the patient group was significantly more affected than the controls, especially with regard to the anxiety levels. However, the cortisol response of the patients equalled the controls' response. Therefore, these results seem to support the hypothesis that fear and panic are different entities that probably rely on different brain circuits.

Chapter four provides a second study on the neuroendocrinological response to $35 \% \mathrm{CO}_{2}$ inhalation in healthy volunteers. Compared to the first study, some methodological improwements were implemented. Furthermore, disturbances at higher levels of the HPA-axis 
might prevent initial activation from being expressed in cortisol release, which might erroneously lead to the conclusion that the HPA-axis is not activated. We therefore also included ACTH measurements.

In contrast with our former study in healthy volunteers (chapter 2), there was a significant increase in cortisol values accompanied by a proportional ACTH response. Although this might seem unexpected, this difference can be subscribed to the methodological improvements. This suggests that $35 \% \mathrm{CO}_{2}$ inhalation is accompanied by cortisol release even in modestly reacting healthy subjects. Even though this increase is statistically significant, from a clinical point of view, the magnitude is quite modest. In other words, in healthy subjects $35 \% \mathrm{CO}_{2}$ inhalation induces modest feelings of anxiety with a corresponding small increase in ACTH and cortisol levels.

In chapter five the neuroendocrinological response of $\mathrm{PD}$ patients and healthy subjects is compared, also using the improved design. The modest increase in ACTH and cortisol levels that we described in healthy subjects before, was now found in the PD patients as well. Despite the significant difference in anxiety levels, there was no difference in the neuroendocrinological responses between the two groups, which is in agreement with our former results in PD patients. Even though $35 \% \mathrm{CO}_{2}$ inhalation apparently does induce some HPA-axis activation, it does not induce a classic stress response, which is characterised by a strong HPA-axis response. If panic would be an extreme form of normal fear, robust increases in cortisol and ACTH levels should be expected in the patient group. It is proposed that this could either be the result of subsensitisation, or that panic is a separate entity, distinguished by its lack of HPA-axis activity. The apparent "spontaneousness' is a characteristic feature of panic. Initially, there seems to be no assignable external trigger, which suggests that internal disturbances trigger a PA. Hypothetically, this could explain the absence of the HPA response: how could one flee from or fight an internal stressor? From this, it can be expected that in other anxiety disorders, where fear is elicited by external stressors such as specific phobias, confrontation with the feared stimulus is accompanied by HPA-axis activation.

This hypothesis is put to the test in chapter six. Sixteen spider phobic subjects and a matched control group were exposed to different conditions involving spiders in a standardised paradigm. Saliva was sampled for cortisol determination as an index of HPA-axis activity.

Subjective fear was significantly increased in the phobics as compared to the controls. However, their cortisol levels remained unaffected. This phenomenon has been described as 'desynchrony of fear". Putatively, ancient fears that no longer provide survival benefits, such as fear for spiders, are subjected to an ongoing process of progressive extinction of which the disappearance of the HPA component may be a forerunner. Another possibility would be that these phobias, like PD, represent a separate entity with specific pathophysiological properties. In chapter seven and eight, the focus shifts to another stress responsive system that is strongly connected to the neuroendocrinological system: the immune system.

Chapter seven provides a review of the literature on immunological variables in PD. Only a limited number of studies has been performed on this topic with various methodological designs, small patient groups and several variables. The majority of these studies showed no clear differences in immune levels between PD patients and controls. Only two parameters, Blymphocyte counts and HLA-DR cells, showed increased levels in the patients group as compared with the controls. Probably, the increase in HLA-DR cells is directly related to the increase in B-cells, since this marker is expressed on B-cells. The implication of this finding is unclear, although it is potentially important since the same has been found in major 
depression. The increase in B-cell numbers was not reported to be accompanied by increased proliferative responses in response to mitogen stimulation, which might be expected in view of the signs of increased immune activation. Possibly, this is the result of functional exhaustion of the B-cells.

All of the studies that were included in the review compared basal values of the immune variables. However, PD is characterised by sudden spells of acute fear or discomfort limited in time. It is conceivable that immune changes are more pronounced directly following a PA and do not persist. In the next chapter, this subject is addressed.

In chapter eight the $35 \% \mathrm{CO}_{2}$ challenge is applied to study the direct effect of panic on the functional capacity of the immune system. Eighteen panic disorder patients and eighteen controls were included. Blood samples were taken at fixed time intervals before and after the challenge. Determinations of acute phase proteins were performed in serum, and cytokines were determined both in serum samples and following mitogen stimulation. The results showed no sign of panic-induced, altered immune functioning. This is in line with findings in social phobia (SP) in which no changes in immune functioning were found either. On the other hand, in other affective disorders such as major depression and post-traumatic stress disorder (PTSD), signs of immune disturbances have been found. In major depression, ongoing inflammatory processes are present, whereas in PTSD decreased immune functioning is found. It is suggested that these changes might be related to changes in HPA-axis functioning. In depression and PTSD, respectively increased and decreased HPA-axis functioning have indeed been found. In accordance, in PD and SP, both HPA-axis and immune functioning seem to be normal. Disturbances in the neuroendocrinological system related to disturbances in the immune system might therefore play a role in some, but not all affective disorders.

Chapter nine provides a general discussion that integrates the results of the different chapters. Neither panic nor phobic fear equal normal fear or stress, as evidenced by a lack of HPA-axis activity. It has been hypothesised that in both these disorders, cortisol release and the resulting mobilisation of energy resources would be maladaptive. In case of spider phobia, cortisol release would be maladaptive, since it no longer promotes survival. Therefore, the potential benefits do not counterbalance the costs of energy expenditure. Panic would normally be induced in case of suffocation. Maintaining a low level of energy expenditure in that specific situation, would be adaptive. A similar response would occur in the immune system. The close physiological link between the two stress-responsive systems can be explained by the theory that the classic defensive response emerged from the immune system.

Furthermore, some suggestions for future research are proposed. Results obtained with laboratory models should preferably be verified in real-life situations. PAs during sleep might offer a promising natural model in this respect since influences of environmental factors can be avoided.

With regard to phobias, it was suggested that HPA-axis activity extinguished in phobias with phylogenetically ancient contents. This implies that phobias with an ontogenetically based content are accompanied by HPA-axis activation, which could relatively easily be examined. Neuroendocrinological research in panic still offers new challenges. It has been found that following lactate infusion in PD patients and controls, atrial natriuretic hormone (ANH) levels increased more in the patient group. ANH exerts an inhibiting effect on cortisol and ACTH release and therefore can account for the lack of HPA-axis activity that we found. A simillar study is currently underway in our laboratory using the $35 \% \mathrm{CO}_{2}$ challenge. 
Samenvatting 
De Paniekstoornis (Eng.: Panic Disorder: PD) is een angststoornis die gekenmerkt wordt door plotselinge aanvallen van acute vrees ${ }^{1}$ of ongemak, die paniekaanvallen (PAs) genoemd worden. Gezien de symptomen en de cognities van een PA, lijkt de vergelijking met een normale vrees respons of klassieke stress respons voor de hand liggend. Echter, als we kijken naar de neuroendocrinologische en neuroimmunologische aspecten is de vergelijking met vrees minder evident. Het huidige proefschrift richt zich op deze aspecten.

Hoofdstuk eén is een algemene introductie op de verschillende onderwerpen in het proefschrift. Vanuit een symptomatologisch perspectief gezien, kan paniek vergeleken worden met vrees. Een gelijkenis zou impliceren dat bepaalde karakteristieke eigenschappen van een acute vrees respons ook aanwezig zijn bij paniek. Kenmerkend voor vrees is de hypothalamus-hypofysebijnier as respons (Eng. hypothalamic-pituitary-adrenal axis; HPA-axis). Onderzoek naar het fenomeen paniek waarin HPA-as activiteit werd gemeten leverde inconsistente resultaten op. Basale HPA-as functie, de HPA-as respons op natururlijke PAs en de HPA-as respons volgend op experimenteel geïnduceerde paniek worden bediscussieerd. Er bestaat een scala aan experimentele modellen dat gebruikt wordt om paniek te bestuderen. Echter, de meeste van deze modellen zijn weinig specifiek. Lactaat infusie, cholecystokinine-4 infusie en in het bijzonder koolstofdioxide $\left(\mathrm{CO}_{2}\right)$ inhalatie lijken de meest veelbelovende modellen. Deze modellen kunnen gebruikt worden om de onderliggende mechanismen van paniek te bestuderen. HPA-as hormoon niveaus kunnen worden bepaald om inzicht te verkrijgen in de relatie tussen paniek en vrees. Niet alleen HPA-as activiteit kan gemeten worden in dit opzicht, ook van andere stress-responsieve systemen is bekend dat hun activiteit verandert ten tijde van stress. Het is zelfs zo dat er bewijs bestaat van intensieve wederkerige communicatie tussen de HPA-as en het immuun systeem. In het psychiatrische onderzoeksveld zijn neuroimmunologische studies hoofdzakelijk uitgevoerd bij depressie. Bevindingen in het veld van PD zijn schaars en hebben alleen betrekking op de basale toestand van deze aandoening en niet op de kern: de paniekaanvallen.

De volgende vier hoofdstukken beschrijven een serie gerelateerde experimentele studies waarbij de HPA-as respons op paniek-inductie gevolgd wordt.

Hoofdstuk twee richt zich op het vóórkomen van een cortisol respons volgend op de $35 \% \mathrm{CO}_{2}$ challenge bij gezonde vrijwilligers. Voorgaande studies hebben aangetoond dat, over het algemeen, gezonde vrijwilligers niet met hoge mate van angst reageren zoals gemeten op de Visual Analogue Scale of Anxiety (VAAS). Eveneens lijken de lichamelijke symptomen die bij deze proefpersonen worden opgewekt niet erg stressvol te zijn. Om deze reden mag verwacht worden dat de $35 \%, \mathrm{CO}_{2}$ inhalatie de cortisol afgifte niet zal doen toenemen. Echter, de literatuur is hier niet consistent over. Methodologische verschillen lijken de meeste inconsistenties te kunnen verklaren. In overeenstemming met onze hypothese, vonden we geen toename in cortisol niveaus na $35 \% \mathrm{CO}_{2}$ inhalatie. Echter, de methoden die in deze studie gebruikt werden, bleken achteraf onvoldoende verfijnd. Om deze reden zou deze studie gerepliceerd moeten worden in een methodologisch sterker onderzoek.

\footnotetext{
'Aangezien getracht wordt een onderscheid te maken tussen "fear" en 'anxiety' is er bij deze vertaling voor gekozen het Engelse "fear" te vertalen met het misschien iets minder gebruikelijke 'vrees'. Zie ook de algenene inleiding van dit proefschrift woor een toelichting op het onderscheid in betekenis van deze begrippen.
} 
In hoofdstuk drie wordt de groep gezonde proefpersonen uitgebreid met een groep gematchte $\mathrm{PD}$ patiènten. De $35 \% \mathrm{CO}_{2}$ challenge is immers vooral relevant voor $\mathrm{PD}$ patiénten. In dit hoofdstuk wordt het vraagstuk of paniek gelijk is aan vrees, behandeld in deze populatie. De meeste PD patiënten ervoeren een experimentele PA, terwijl dat sleclits bij én gezonde vrijwilliger het geval was. Met andere woorden, de patiënten groep was significant gevoeliger dan de controles, vooral wat betreft de angst niveaus. Echter, de cortisol respons van da patiënten verschilde niet van die van de controles. Derhalve lijken deze resultaten de hypothese dat vrees en paniek verschillende entiteiten zijn, die waarschijnijk geassocieerd zijn met verschillende netwerken in de hersenen, te ondersteunen.

Hoofdstuk vier omvat een tweede studie over de neuroendocrinologische respons op $35 \% \mathrm{CO}_{2}$ inhalatie bij gezonde vrijwilligers. In vergelijking met de eerste studie zijn ei echter enkele methodologische verbeteringen aangebracht. Daarnaast is het zo dat verstoringen op de hogere niveaus van de HPA-as ervoor kumen zorgen dat initiële activatie niet tot uitdrukking komt in. cortisol afgifte. Dit zou onterecht tot de conclusie kunnen leiden dat de HPA-as niet geactiveerd wordt. Om die reden hebben wij ook ACTH bepalingen gedaan.

In tegenstelling tot onze vorige studie bij gezonde vrijwilligers (hoofdstuk 2), was er wel een significante toename in cortisol waarden gepaard aan een evenredige ACTH respons. Dit mag op het eerste gezicht onverwacht lijken, maar het verschil kan toegeschreven worden aan de methodologische verbeteringen. Dit suggereert dat $35 \% \mathrm{CO}_{2}$ inhalatie gepaard gaat met cortisol secretie bij matig reagerende gezonde vrijwilligers. Alhoewel statistisch significant, is de toename vanuit klinisch perspectief beperkt. Met andere woorden, $35 \% \mathrm{CO}_{2}$ inhalatie induceert bij gezonde vrijwilligers beperkt gevoelens van angst, samengaand met een bescheiden toename in ACTH en cortisol niveaus.

In hoofdstuk vijf wordt de neuroendocrinologische respons van PD patiènten en gezonde vrijwilligers vergeleken waarbij eveneens het verbeterde design wordt toegepast. De bescheiden toename in ACTH en cortisol niveaus die we eerder beschreven bij gezonde vrijwilligers, werd nu ook bij PD patiënten gevonden. Ondanks het significante verschil in angst niveaus, was er geen verschil tussen de groepen wat betreft de neuroendocrinologische responsen. Dit is in overeenstemming met onze vorige resultaten bij PD patienten. Alhoewel $35 \% \mathrm{CO}_{2}$ inhalatie schijnbaar enige mate van HPA-as activatie veroorzaakt, induceert bet geen klassieke stress respons, die juist gekarakteriseerd wordt door sterke HPA-as activatie. Wanneer paniek een extreme vorm van normale vrees zou zijn, zou er een sterke toename in cortisol en ACTH niveaus verwacht worden in de patiënten groep. Een dergelijke toename treedt echter niet op. Dit zou een gevolg kunnen zijn van subsensitisatie, maar mogelijk is paniek een aparte entiteit, die zich juist onderscheid door de afwezigheid van HPA-as activatie.

Het schijnbaar spontane optreden is een kenmerkende eigenschap van paniek. Er lijkt geen aanwijsbare externe trigger te zijn, wat suggereent dat inwendige verstoringen een $P A$ veroorzaken. Dit zou hypothetisch de afwezigheid van de "fight-flight" respons met HPA-as activatie kumnen verklaren: hoe zou men kunnen vluchten voor, of vechten tegen een inwendige stressor? Derhalve kan verwacht worden dat bij andere angststoornissen waar de angst opgewekt wordt door externe stressoren, zoals bij specifieke fobieern, confitontatie met de gevreesde stimulus wel gepaard gaat met HPA-as activatie.

Deze hypothese wordt getest in hoofdstuk zes. Zestien spin fobici en een gematchte controle groep werden in een gestandaardiseerd paradigma blootgesteld aan verschillende condities waarbij spinnen betrokken waren. Speeksel werd verzameld voor cortisol bepalingen om een 
index van HPA-as activiteit te verkrijgen. De fobici hadden significant hogere niveaus van vrees dan de controles. Echter, het cortisol niveau van beide groepen bleefonveranderd. Dit fenomeen is eerder beschreven als 'desynchrony of fear'. Vermoedelijk zijn deze 'oude' angsten, die de kans op overleving niet langer vergroten, onderhevig aan een doorlopend proces van progressieve extinctie, waarvan het verdwijnen van de HPA-as component een voorloper zou kunnen zijn. Een andere mogelijkheid is dat deze fobieën, net zoals PD, een aparte eenheid vormen met specifieke pathofysiologische eigenschappen.

In hoofdstuk zeven en acht ligt de nadruk op een ander stress-responsief systeem dat sterk verbonden is met het neuroendocrinologische systeem: het immun systeem.

Hoofdstuk zeven verschaft een overzicht van de literatuur over de rol van immunologische variabelen bij PD. Slechts een beperkt aantal studies zijn verschenen over dit onderwerp, met verschillende methodologische designs, kleine patiënten groepen en verscheidene variabelen. De meerderheid van deze studies toonde geen duidelijk verschil aan in niveaus van immuun variabelen tussen $\mathrm{PD}$ patiënten en controles. Slechts twee parameters; B-lymfocyt tellingen en HLA-DR cellen, waren verhoogd in de patiënten groep ten opzichte van de controles. Mogelijk is de toename in H.LA-DR cellen direct gerelateerd aan de toename in B-cellen, aangezien deze marker tot expressie wordt gebracht op B-cellen. De implicatie van deze bevinding is onduidelijk, alhoewel het potentieel belangrijk is gezien het feit dat dezelfde bevinding is gedaan bij depressie. De toename in B-cel aantallen ging niet gepaard met een toename van de proliferatie capaciteit in respons op mitogeen stimulatie, hetgeen wel verwacht zou kunnen worden in het kader van de gevonden tekenen van verhoogde immuun activatie. Mogelijk is dit het resultaat van functionele uitputting van de B-cellen.

Alle onderzoeken die in het literatuuroverzicht opgenomen waren, vergeleken basale waarden van de immuun variabelen. PD wordt echter gekenmerkt door plotselinge aanvallen van acute vrees of ongemak die beperkt zijn in tijd. Het is aannemelijk dat veranderingen in het immuun systeen duidelijker aanwezig zijn direct na een PA en vervolgens weer verdwijnen. In het volgende hoofstuk zal aandacht besteed worden aan dit onderwerp.

In hoofdstuk acht wordt de $35 \% \mathrm{CO}_{2}$ challenge toegepast om het directe effect van paniek op de functionele capaciteit van het immuun systeem te onderzoeken. Achttien paniekstoornis patiénten en achttien controle personen werden geïncludeerd. Op vastgestelde tijdsinterval.len voor en na de challenge werden bloed samples genomen. De bepalingen van acute fase eiwitten werden in serum gedaan, en cytokine niveaus werden gemeten zowel volgend op mitogeen stimulatie als in serum monsters. De resultaten lieten geen tekenen zien van paniekgeinduceerde veranderdingen in immuun functioneren. Dit is in overeenstemming met bevindingen bij sociale fobie (SP) waarbij ook geen veranderingen in immuun functioneren werden gevonden. Daarentegen, bij andere affectieve stoornissen, zoals depressie en posttraumatische stress stoornis (PTSD), zijn wel verstoringen in het immuun systeem aangetoond. Bij ernstige depressie is er sprake van aanhoudende ontstekingsprocessen, terwijl bij PTSD juist verminderd immuun functioneren is gevonden. Er is gesuggereerd dat deze veranderingen gerelateerd zouden zijn aan veranderingen in het HPA-as functioneren. Bij depressie en PTSD zijn inderdaad respectievelijk verhoogd en verlaagd HPA-as functioneren gevonden. De verstoringen van het endocriene en het immunologische systeem lijken met andere woorden parallel te lopen. In overeenstemming hiermee lijken bij PD en SP zowel het HPA-as als het immuun functioneren normaal. Verstoringen in het neuroendocrinologische systeem, gerelateerd aan verstoringen in het immuun systeem zouden daarom een rol kunnen spelen bij sommige, maar niet alle affectieve stoornissen. 
Hoofdstuk negen onvat een algemene discussie die de resultaten van de verschillende hoofdstukken integreert. Noch paniek, noch fobische vrees is gelijk aan "normale" vrees of stress, wat blijkt uit het uitblijven van verhoogde HPA-as activiteit. Verondersteld wordt dat bij deze twee stoornissen cortisol afgifte en de daarop volgende mobilisatie van energie voorraden, juist ongewenst zou zijn. In het geval van de spin fobie zou het ongewenst zijn omdat het de overlevingskansen niet vergroot. Hierdoor zou het mogelijke voordeel niet opwegen tegen de verspilling van energie. Paniek zou normaal gesproken ontstaan in het geval van verstikking. In die specifieke situatie zou een laag energie verbruik het gunstigst zijn. Een zelfde respons zou plaatsvinden binnen het immuun systeem. De hechte fysiologische link tussen de twee stress-responsieve systemen kan verklaard worden door de theorie dat de klassieke defensieve endocriene respons ontstaan is vanuit het immuun systeem.

Verder worden nog enkele voorstellen gedaan voor vervolgonderzoek. Resultaten die verkregen zijn met laboratorium modellen zouden bij voorkeur geverifieerd moeten worden in situaties uit het dagelijks leven. PAs tijdens de slaap vormen in dit opzicht een veelbelovend natuurlijk model aangezien de invloed van omgevingsfactoren vermeden kan worden. Wat betreft fobieën is gesuggereerd dat HPA-as activiteit verdwenen is bij fobieën met een fylogenetisch 'oude' inhoud. Dit impliceert dat fobieën met een ontogenetisch gebaseerde inhoud wel gepaard gaan met HPA-as activatie, hetgeen relatief gemakkelijk onderzocht zou kunnen worden.

Neuroendocrinologisch onderzoek bij paniek biedt nog steeds nieuwe uitdagingen. Volgend op lactaat infusie werd gevonden dat bij PD patiënten niveaus van 'atrial natriuretic hormone' (ANH) sterker stegen dan bij controle personen. ANH heeft een remmende invloed op de cortisol en ACTH afgifte en zou daardoor verantwoordelijk kunnen zijn voor het uitblijven van een HPA-as respons, zoals in ons onderzoek. Een vergelijkbare studie wordt momenteel opgezet in ons laboratorium waarbij gebruik zal worden gemaakt van de $35 \% \mathrm{CO}_{2}$ challenge. 


\section{Dankwoord}


Het dankwoord staat achteraan in een proefschrift, maar is vaak juist het eerste wat gelezen wordt. Wellicht is de plaatsing van het dankwoord dan ook geen toeval, maar is het juist een manier om ervoor te zorgen dat men eerst door het proefschrift zal bladeren om vervolgens bij het dankwoord uit te komen. Onderweg ontdekt men in een vogelvlucht het resultaat van vier jaar werk. Onderzoek waar met toewijding aan is gewerkt en zeker niet alleen door de promovendus. Een dankwoord staat hier aldus volledig op zijn plaats.

Allereerst zou ik alle mensen willen bedanken die tijd wilden vrijmaken voor deelname aan een van de onderzoeken die in dit proefschrift beschreven staan. Dat geldit zowel voor de 'controle personen' (en meer dan eens waren dit vrienden, of collega's die mij gelukkig konden vergeven voor alles wat ik ze aandeed), maar met name geldt dit voor de mensen met een paniekstoornis of een spinnenfobie. In beide gevallen stemden deze mensen vrijwillig toe om geconfronteerd te worden met datgene waar ze juist zo ontzettend bang voor waren, wat ze normal gesproken juist probeerden te vermijden of voorkomen. Al spreken we bij deze mensen van een angststoornis, dat was juist enorm dapper en ik ben ervan overtuigd dat het feit dat ze dat aandurfden hun ook zal helpen om zich overeind te houden tijdens behandeling.

Een AIO zijn betekend een leer-traject doorlopen. Bij iedere stap die je zet kom je erachter dat de weg die je nog te gaan hebt een stuk langer is dan je dacht. Gelukkig word je op deze weg begeleid en in mijn geval heeft dat er zeker voor gezorgd dat de reis een stuk aangenamer was. Professor Griez, ik zou met $\mathrm{u}$ willen beginnen. Een van uw favoriete uitspraken is denk ik wel: "Keep it simple" en dit is van toepassing op meerdere terreinen. Kijk eerst naar de ruwe data en maak simpele grafiekjes voordat je 'met je computer gaat schudden en kijkt of er iets uitvalt'. Ook wat het schrijven betreft hanteert u deze stelregel. Maak dingen niet nodeloos ingewikkeld, maar houd de lezer bij de les. Ik heb veel van u mogen leren en ben als onderzoeker gegroeid onder uw leiding. Daarbij is, wat mij betreft, onze onderlinge relatie ook steeds prettiger geworden. Ik vermoed dat dit te maken heeft met mijn verhuizing naar 'de onderzoeksgang", waardoor er buiten de 'officiële afspraken' ook ruimte is voor wat meer luchtiger gesprekken. Ik ben blij dat ik de komende tijd ook met u mag blijven samenwerken, want ik ben nog lang niet uitgegroeid. (...)

Beste Koen, met veel plezier heb ik de afgelopen jaren met je samengewerkt. Om eerlijk te zijn had ik, toen ik hier begon, nog nooit van een paniekstoornis gehoord. Bewust heb jij ervoor gezorgd dat ik mijn werkplek kreeg op het Academisch Angst Centrum (AAC) en stimuleerde jij mij om bijvoorbeeld naar de patiënten-besprekingen te komen. Hier heb ik heel erg veel van geleerd en buiten dat, vond ik dit enorm interessant. Op deze manier kreeg de beschrijving 'a group of sixteen PD patients' een gezicht en een eigen verhaal. Dank hiervoor. Ik hoop dat we op de dagen dat Vijverdal in een broeikas verandert nog vaak een ijsje zullen gaan halen!

Op deze plaats hoort ook een dankwoord aan professor Maes, die ik als mijn tweede promotor zie. Beste Michael, ik kan me nog herinneren dat tijdens mijn studie eens een artikel van uw hand besproken werd. Uiteraard betrof dit een onderzoek in het veld van psychoneuroimmunologie. Ik kan u zeggen dat ik onder de indruk was van dit artikel, en me afvroeg hoe iemand deze theorieën toch kon bedenken. Ik heb het dan ook een eer gevonden om met u samen te werken. Uw kennis van de neuroimmunologie reikt toch nog altijd veel verder dan die van mij, en ook wat betreft uw statische kennis zou ik nog een boel van u kunnen leren, maar ik wil u bedanken voor die kennis die $u$ aan mij heeft overgedragen. 
Dan een dankwoord voor de mensen die mij in praktische zin geholpen hebben. Deze ondersteuning is voor mij onmisbaar geweest. Inge en Nicolette, als research-verpleegkundigen hadden jullie al ruim ervaring met onderzoek op het AAC en konden jullie mij goed op weg helpen. Inge, door jouw aanwezigheid was het verblijf voor de proefpersonen in het lab een stuk aangenamer en door jouw enorm grote 'kennissenkring' binnen Vijverdal konden er altijd op korte termijn nog een paar controle-personen gevonden worden. Nicolette, ik kon altijd volledig vertrouwen op jouw score lijsten. Misschien niet altijd even opwindend werk, maar je deed het toch altijd met de nodige toewijding en nam mij op die manier een heleboel werk uit handen. Beiden bedankt voor jullie inzet! Ook Mark wil ik bedanken voor het zijn aandeel in functie als documentalist.

Dan waren er nog talloze co-assistenten, stagiaires, en collega's die met enige regelmaat mij wilden helpen om al die buisjes met bloed te vullen. I $\mathrm{k}$ ga niet alle namen noemen, want dan loop ik een grote kans toch enkele mensen te passeren... Dus bij deze allen nogmaals heel hartelijk dank. Erika, jij hebt de uitvoering van de studies die in de eerste twee hoofdstukken beschreven staan uitgevoerd en Dieneke jij mag wat dat betreft hoofdstuk zes op je naam zetten. Bedankt voor het goede werk dat jullie geleverd hebben. Daarnaast zijn met name Rob van Diest en José Sulon zeer behulpzaam geweest bij het oplossen van meerdere inhoudelijke en wat Rob betreft meestal statistische kwesties. Thank you for your help! Gunter, ook jij bedankt voor het de vele cytokine bepalingen en het meedenken. Ook Robert Verkerk van de Universiteit van Antwerpen zou ik hierbij willen noemen. Hoeveel tijd u heeft gestoken in het opzetten van een nieuwe methode voor het bepalen van catecholamines is ongelofelijk. Spijtig genoeg kwamen de resultaten te laat om nog onderdeel te kunnen zijn van dit proefschrift, maar deze resultaten zullen samen met de verschillende serotonerge parameters toch nog een mooi artikel op gaan leveren. De volgende mensen hebben niet direct iets te maken met de inhoud van dit proefschrift, but I'd like to thank Yves Mercier and Petro van Bergen from Pierre-Fabre medicaments, France, for the good coorporation during the pharmaceutical trial. Ook Femke, kan ik hierbij bedanken. Jouw inzet bij dit onderzoek: fantastisch!

Lieve Karen, niet alleen heb jij in praktische zin een bijdrage geleverd aan dit onderzoek, je zult ook letterlijk en figuurlijk achter me staan als paranimf. Tijdens onze studie biologische gezondheidskunde konden we altijd al goed met elkaar opschieten, maar het is pas tot vriendschap gekomen toen jij gedurende een half jaar op het AAC werkte. Met de jaren is de band alleen maar sterker geworden en ik ben blij dat ik jou als vriendin heb, want je hebt een gouden hart!

Mijn andere paranimf, Christianne, ken ik al wat langer. In 1996 kwamen we bij elkaar in de allereerste onderwijsgroep terecht, dus volgend jaar kunnen we ons 10-jarig jubileum vieren! Pas geleden werd jou gevraagd wat onze vriendschap kenmerkt. Daar is misschien niet direct een pasklaar antwoord voor. Je schreef ook dat juist het feit dat wij zo van elkaar verschillen deze vriendschap bijzonder maakt. We kunnen in ieder geval heel goed met elkaar praten en zitten gevoelsmatig toch meestal op dezelfde lijn. Er viel ook veel te bepraten de afgelopen jaren en ik ben ook heel erg blij dat jouw leven nu toch in wat rustiger vaarwater is gekomen (afgezien van af en toe nog wat tegenwind...). Nu staat er in mijn leven het nodige te gebeuren en, lieve Christianne, het is goed te weten dat ik bij jou altijd een luisterend oor kan vinden. 
Ik ben van mening dat, om goed werk te kunmen leveren, er een goede verhouding moet zijn tussen werk en ontspanning. Er zijn een heleboel mensen die mij de afgelopen jaren heel goed geholpen hebben bij het ontspannen en zo in feite indirect een bijdrage hebben geleverd aan dit proefschrift. Ik denk dat hierbij alle medewerkers van het AAC een rol hebben gespeeld. Er zijn heel wat vlaaien doorheen gegaan zal ik maar zeggen. Ik merk dat het nu door de fysieke afstand moeilijker is om betrokken te blijven bij de 'sociale activiteiten' op het AAC, maar gelukkig is er altijd nog de lunch waarbij ik weer helemaal bijgepraat kan worden over het reilen en zeilen van het $A A C$. Iedereen heel erg bedankt voor de fijne tijd die ik op het $A A C$ heb gehad! Door mijn 'verhuizing' zijn er weer andere mensen bijgekomen. Lenie en Jolanda, bedankt voor jullie hulp en ook Lea en len bedankt voor de warme ontvangst bij jullie op de gang!

Onder de (ex-)AAC medewerkers is op den duur een klein clubje ontstaan dat regelmatig met elkaar ging eten. Jaimie, Femmie, Karen en Maaike, wat hebben we een boel lol gehad op de avondjes met de AAC-tjes. Ook dikwijls waren er (heftige) discussies over zeer witeenlopende onderwerpen waarbij er toch een aantal (twee?) zeer regelmatig terugkwamen (...). Een groep met hele verschillende persoonlijkheden wat het juist zo boeiend makk. Respect voor elkaars mening met de nodige humor: daar zouden meer mensen een voorbeeld aan mogen nemen! Jaimie, jij bent lange tijd mijn kamergenote geweest. Vanzelf krijg je dan veel mee van wat er in elkaars leven gebeurt. Dat is nu ook wat moeilijker, maar met een beetje moeite moet het toch lukken om op de hoogte te blijven toch? Sinds begin van dit jaar is Lies dan mijn kamergenote. Een heel groot verschil met Jaimie, dus even wennen, maar daarom niet minder leuk. Lies, jij ook veel succes toegewenst met jouw AIO-traject!

Kim, ik zou jou ook graag willen bedanken voor het nakijken van mijn manuscripten als "native American'. Daarbij hielp jij me nog met ontspannen door onze squash-partijtjes, en ook de tripjes naar de Ardennen samen met Jos, Ramon en Mariska, en natuurlijk Harry hielpen hier goed bij.

Mijn ouders wil ik graag bedanken voor de basis die zij mij hebben gegeven. Mede door jullie opvoeding ben ik geworden wie ik ben. Jullie hebben mij mijn eigen keuzen leren maken, zelfvertrouwen en vooral veel liefde gegeven. Hiervoor kan ik jullie niet genoeg bedanken.

En als laatste: Harry. Dit jaar stond in het teken van een aantal grote veranderingen in ons leven. Eindelijk hoef je me niet meer te vragen: "Wanneer gaan we nou trouwen?". Het was een fantastische dag die ons zo mogelijk nog dichter bij elkaar heeft gebracht. En nu ook jouw vraag: "Wanneer krijgen we nou een kindje" beantwoord kan worden, is ons geluk helemaal compleet. Met onze vaste uitspraak: "Gelukkig hebben we elkaar nog" kan ook in de toekomst alles gerelativeerd worden. Een toekomst die ik samen met jou tegemoet ga, kan alleen maar goed zijn. Bedankt voor alles. 


\section{Publications}


Van Duinen, M.A., Schruers, K.R.J., Maes, M., Griez E.G.L, 2005. $\mathrm{CO}_{2}$ challenge results in HPA-activation in healthy volunteers. Journal of Psychopharmacology $19 ; 243-7$.

Van Duinen, M.A., Schruers, K.R.J., Maes, M., Griez E.G.L, 2004. Neuroimmunological parameters in panic disorder. Acta Neuropsychiatrica 16; 1-7. (Invited review)

Van Duinen, M.A., Schruers, K.R.J., Maes, M., Griez E.G.L. Salivary cortisol in panic: are males more vulnerable? Neuroendocrinology Letters 25(5); 285-9.

Van Duinen, M.A., Schruers, K.R.J., Jaegers, E., Maes, M., Griez E.G.L., 2004. Hypothalamic-Pituitary-Adrenal axis function following a $35 \% \mathrm{CO}_{2}$ inhalation in healthy volunteers. Progress in Neuro-Psychopharmacology and Biological Psychiatry 28(2); $279-83$.

Sobczak, S., Honig A., van Duinen, M.A., Riedel, W.J., 2002. Serotonergic dysregulation in bipolar disorders: a literature review of serotonergic challenge studies. Bipolar Disorders 4; $347-56$.

Sobczak, S., Honig A., van Duinen, M.A., Maes, M., Riedel, W.J., 2002. Mood, prolactin and cortisol responses following intravenous L-tryptophan challenge: evidence for serotonergic vulnerability in first-degree relatives of bipolar patients. International Journal of Neuropsychopharmacollogy $5 ; 249-54$.

Van Duinen, M.A., Schruers, K.R.J., Maes, M., Griez E.G.L, 2005. $\mathrm{CO}_{2}$ challenge induced HPA axis activation in panic. Submitted.

Van Duinen, M.A., Schruers, K.R.J., Kenis, G.R.L., Wauters, A., Delanghe J., Griez E.G.L., Maes, M., 2005. Effects of experimental panic on neuroimmunological functioning. Submitted.

Van Duinen, M.A., Schruers, K.R.J., Griez E.G.L, 2005. Desynchrony of fear: phobic exposure is not stressful. Submitted. 


\section{Curriculum vitae}


Marlies van Duinen werd geboren op 12 maart 1978 te Winterswijk. Zij volgde het VWO aan de Christelijke Scholengemeenschap "Dingstede" te Meppel van 1990 tot 1996. Van 1996 tot 2001 studeerde zij Gezondheidswetenschappen aan de Universiteit Maastricht met als afstudeerrichting Biologische Gezondheidskunde. Haar afstudeerproject betrof een studie naar de neuroendocrinologische respons op een tryptofaan challenge bij eerstegraads familieleden. van manisch depressieven. Daarbij werkte zij enige tijd als onderzoeks-assistent binnen de vakgroep Psychiatrie \& Neuropsychologie op een tweetal projecten, te weten "The occurrence of a depression after a CVA" (dr. I. Aben), en "The occurrence of a depression after a myocardinfarct" (dr. J. Strik).

In maart $2001 \mathrm{kwam}$ zij als AlO in dienst bij deze vakgroep, waar zij in de vier jaar daarop volgend haar promotie-onderzoek afrondde met als onderwerp de neuroendocrinologie en neuroimmunologie van de Paniekstoornis. Mede dankzij het verkrijgen van het Kootstra Fellowship 2005 zal Marlies de komende jaren verbonden blijven aan de capaciteitsgroep Psychiatrie \& Neuropsychologie van de Universiteit Maastricht. 